\section{Check for updates}

Cite this: Mater. Adv., 2021 2, 4532

Received 4th March 2021 Accepted 4th May 2021

DOI: 10.1039/d1ma00193k

rsc.li/materials-advances

\title{
Recent advances in the synthesis of smart hydrogels
}

\author{
Partha Sikdar, (D) *a Md. Mazbah Uddin, (D) a Tanvir Mahady Dip, (D) ${ }^{\mathrm{b}}$ \\ Shafiqul Islam, (D) ${ }^{\text {ac }}$ Md. Saiful Hoque, (D) ${ }^{d}$ Avik K. Dhar ${ }^{e}$ and Shuangyan Wu ${ }^{a}$
}

\begin{abstract}
Understanding the surrounding atmosphere and reacting accordingly with a precise action are always fascinating features of a material. Materials that pose such responsiveness are called smart materials. Currently, research studies on smart materials are being accelerated exponentially around the world; this is also true for smart hydrogels. Smart hydrogels with various chemically and structurally responsive moieties exhibit excellent characteristics of reacting under different environmental conditions such as $\mathrm{pH}$, temperature, light, electric field, and magnetic field as well as biological and chemical stimuli. These smart hydrogels are drawing the attention of researchers for a wide range of applications, for instance, in designing biomedical, industrial, agricultural, electrical, healthcare, and hygienic products. This review encompasses the latest developments in the field of smart hydrogel synthesis based on their unique features and different aspects of their responsive behaviors. Additionally, this paper covers some of the recent strategies for tuning special functional properties of smart hydrogels for targeted applications.
\end{abstract}

\section{Introduction}

${ }^{a}$ Department of Textiles, Merchandising and Interiors, University of Georgia, Athens, GA, USA.E-mail: ppprs92@gmail.com,si59291@uga.edu;

Tel: +17065244239

${ }^{b}$ Department of Yarn Engineering, Bangladesh University of Textiles, Dhaka 1208, Bangladesh

${ }^{c}$ Department of Textile Engineering, Dhaka University of Engineering and Technology, Gazipur, 1700, Bangladesh. E-mail: shafiqul.islam.@duet.ac.bd

${ }^{d}$ Department of Human Ecology, University of Alberta, 302 Human Ecology Building, Edmonton, $A B, T 6 G$ 2N1, Canada

${ }^{e}$ Textile Engineering College, Chittagong, Bangladesh

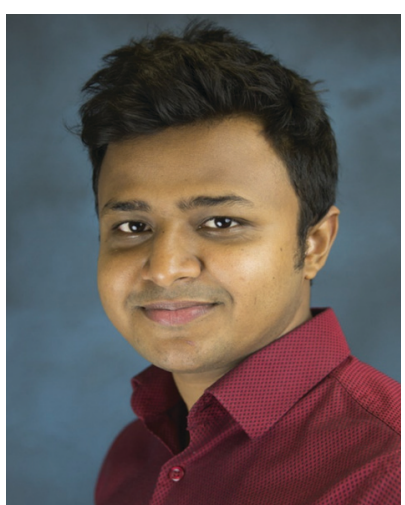

Partha Sikdar
Partha Sikdar is currently a PhD student in the Department of Textiles, Merchandising and Interiors at The University of Georgia (UGA) with his research focusing on Fiber, Polymer and Textile Science. He has been working as a research fellow at the Nonwoven Functional Materials Lab of UGA. He did his master's degree in the same department at UGA. Partha graduated with a Bachelor's degree in Textile Engineering from the University of Chittagong, Bangladesh in 2015. His research focuses on the synthesis of cotton-based nonwovens and composites, stretchable cotton nonwovens, functional biopolymers, and hydrogels.

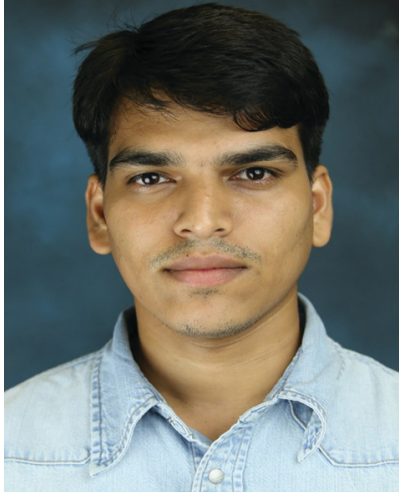

Md. Mazbah Uddin
Md Mazbah Uddin has graduated with a bachelor's degree in Textile Engineering from Bangladesh University of Textiles, Bangladesh. $\mathrm{He}$ is currently pursuing his master's degree at the University of Georgia, USA, in polymer, fiber, \& textile sciences (PFTS). He is a part of the Innovative Materials Research Team and Nanostructured Materials Lab of the University of Georgia. His current research work involves the fabrication of nanogenerators that are able to harness the mechanical energy generated by the human body. He is interested in biomaterials, nanotechnology, smart textiles, and biomedical implants. 
paradigm in the field of polymer-based biomaterials. The biomimetic nature of hydrogels has envisioned widespread applications in biomedical engineering for cell culture, drug delivery, and therapeutics. Hydrogels are water-absorbing polymeric networks and are developed to mimic many of the inherent properties of soft tissue. $^{2,3}$ For instance, the properties of hydrogels can be tuned to mimic the biochemical, mechanical, and rheological properties and stimulus responsiveness of soft tissue. ${ }^{4,5}$ Smart hydrogels can undergo structural and volume phase transitions in response to external stimuli, providing enormous potential for scientific observations and various advanced multidimensional technological applications. ${ }^{6}$ The development of smart hydrogels as functional materials has revolutionized the field of study concerning responsive materials known as stimuli-responsive hydrogels (SRHs). ${ }^{7}$ Generally, SRHs are absorbent to superabsorbent ${ }^{8}$

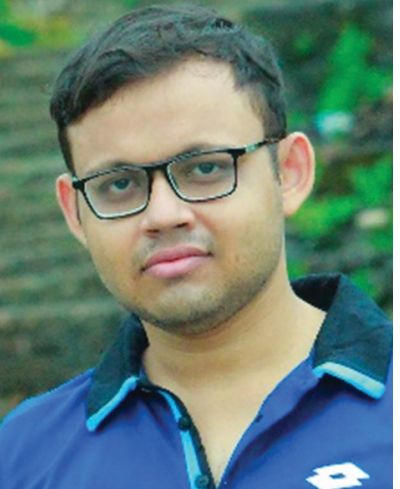

Tanvir Mahady Dip
Tanvir Mahady Dip graduated with a bachelor's degree in Textile Engineering with specialization in Yarn Manufacturing from the Bangladesh University of Textiles. He is working as a lecturer in the Department of Yarn Engineering, Faculty of Textile Engineering, Bangladesh University of Textiles, Bangladesh, with his research focusing on functional polymer coatings, life cycle analysis of textiles, and technical textiles.

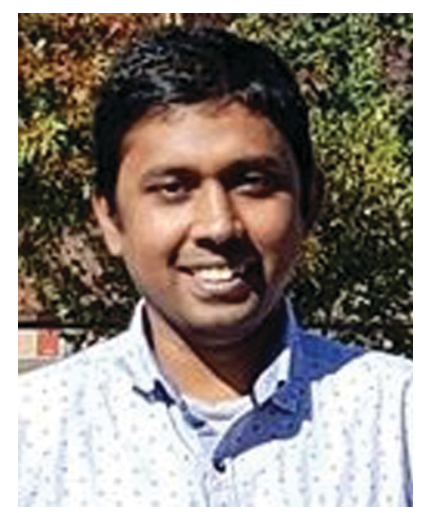

Shafiqul Islam materials that can react to any subtle environmental changes such as $\mathrm{pH},{ }^{9}$ temperature,${ }^{10}$ chemical species, ${ }^{11}$ ionic strength, ${ }^{12}$ electric field, ${ }^{13}$ and biological conditions. ${ }^{14-16}$ Fig. 1 shows a classification of external factors that can instigate smart hydrogels. These wonderful characteristics have the potential to trigger many applications, for example, biomedical (i.e., tissue engineering, drug delivery, and drug release), ${ }^{17}$ personal healthcare and hygienic products, ${ }^{18}$ agriculture (i.e., soil moisturizing, conditioning, nutrient carrier, and erosion control), ${ }^{19}$ wastewater treatment, ${ }^{20}$ sensors and actuators, ${ }^{21,22}$ textiles, ${ }^{23}$ construction, ${ }^{24}$ electrical, ${ }^{25}$ membranes, ${ }^{26}$ and flocculation. ${ }^{27}$ Based on their desired application trigger, hydrogels can be synthesized by physical interactions and chemical reactions. Physical hydrogels can be developed either by the interaction between oppositely charged polyelectrolytes or oppositely charged multivalent ion/surfactants Shafiqul Islam is a PhD student and researcher at the department of TMI of the University of Georgia. He pursued his undergraduate and master's degrees in textile engineering from the Bangladesh University of Textiles. After completing the undergraduate degree, Shafiqul worked in research and developed sections of an export oriented industry. Later he joined at Dhaka University of Engineering and Technology as a faculty member. Currently, he is on study leave and pursuing his PhD degree at UGA. His main research focus is on the design and development of composite materials and production of environmentally friendly, sustainable insulation materials. He is also working on lifecycle assessment (LCA) to check the true sustainability of produced composite materials and comparing them with those of commercially available products. Another desirable property of such composites is that of self-repairing. At present, Shafiqul is investigating the possibility of incorporating the right ingredients to make self-healing composite materials.

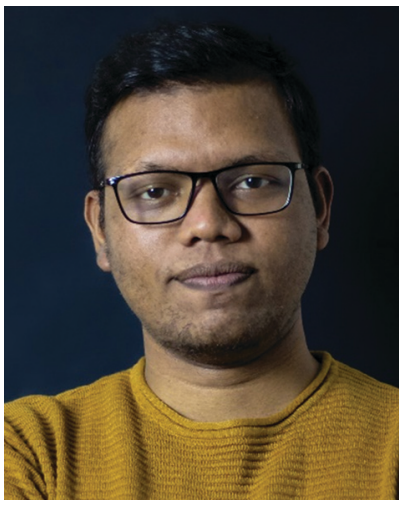

Md. Saiful Hoque
Md. Saiful Hoque, with a solid background in fibers and polymers, textiles, and apparel, is currently pursuing his $P h D$ in Textile and Apparel Science at the University of Alberta, Canada. Mr. Hoque is pursuing his research in protective clothing, which includes the performance of protective clothing, smart textiles for protective clothing, and clothing comfort.

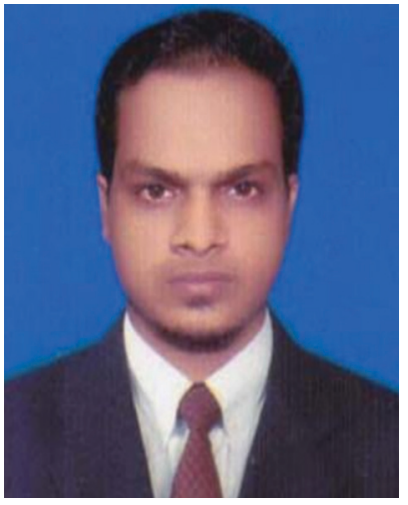

Avik Kumar Dhar graduated with a master's degree in Textile Engineering from the Bangladesh University of Textiles. In 2016, he joined the Department of Textile Engineering, Shyamoli Textile Engineering College, University of Dhaka as a faculty member, with his research currently focusing on functional fibers and polymers, non-woven, protective clothing, and technical textiles.

Avik K. Dhar 


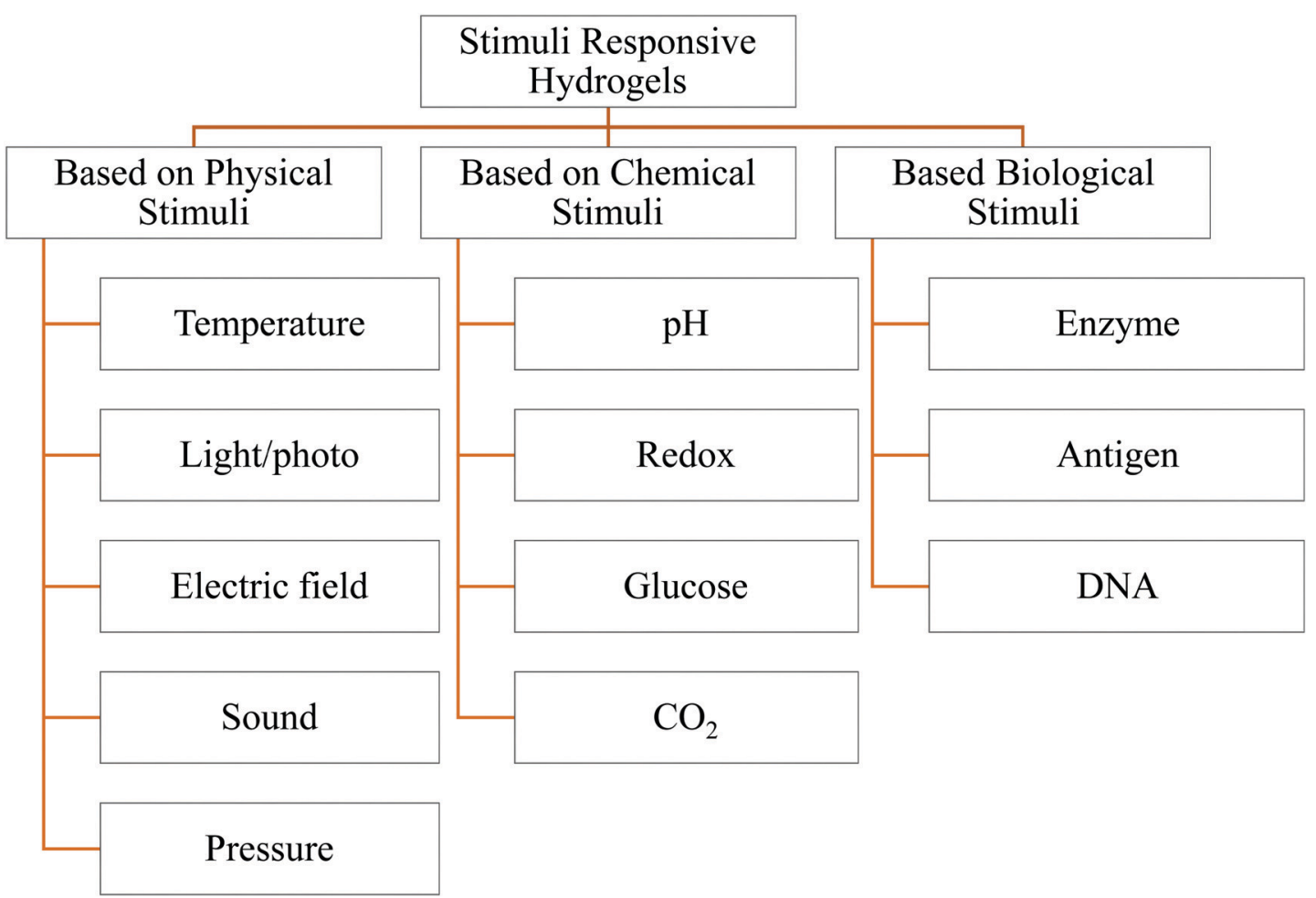

Fig. 1 Major classification of SRHs (based on ref. 48 and 58-61) [reproduced with permission from ref. 58, (C)The Royal Society of Chemistry, 2014].

and polyelectrolytes. ${ }^{28,29}$ In contrast, chemical hydrogels are typically formed through a covalently crosslinked polymeric network. ${ }^{30}$ These smart hydrogels are capable of swelling and shrinkage reversibly in response to changes in external environmental stimuli. $^{7}$ These hydrogels are composed of homo-polymeric, co-polymeric, or multi-polymeric networks that are synthesized from one, two, or multiple polymers, respectively. ${ }^{29,31}$ Consequently, these hydrogels can display many functionalities. Such functional hydrogels can be engineered in multiple desired dimensions. For example, they can be subjected to biomedical applications by modifying their chemical structure, composition, biological functions, biodegradability, and various physicochemical properties such as mechanical and rheological, spectral, $\mathrm{pH}$ stability, release, and loading properties. ${ }^{32-34}$

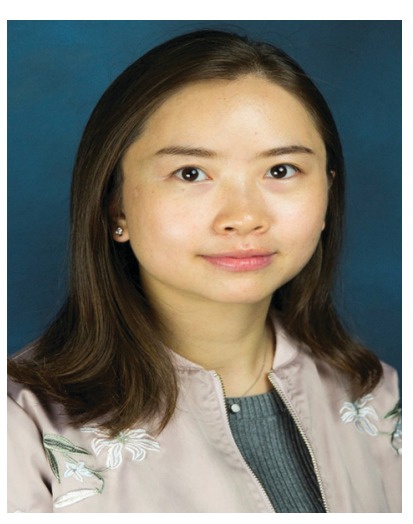

Shuangyan Wu
Shuangyan Wu is a PhD student and $a$ researcher at the department of TMI of the University of Georgia (UGA). She obtained her bachelor's and master's degrees in textile engineering from Jiangnan University, China. Her research focuses on investigating the effect of the incorporation of PUs and nanomaterials such as graphene, fullerenes and carbon nanotubes (CNTs) into fiber reinforced composite structures.
SRHs can be engineered based upon the application of external stimuli that trigger them to show a switchable solgel transition. External stimuli, including temperature, light, magnetic and electrical fields, and ultrasonic waves, are considered as physical triggers, while $\mathrm{pH}$ and redox reactions are considered as chemical triggers. ${ }^{35}$ In addition, biological triggers include enzymes, ${ }^{36-40}$ antigens, ${ }^{14,41}$ and DNA. ${ }^{42-45}$

During the past few decades, a plethora of research studies have been conducted to fabricate hydrogels with stimuli-responsive properties that correspond to regular hydrogel attributes such as swelling, porosity, physical structure, and modulus. ${ }^{4-48}$ Furthermore, the diversified properties and applications of hydrogels have resulted in thousands of research articles focusing on various aspects. In addition, numerous review articles have been found based on hydrogel applications ${ }^{49-52}$ and their types. ${ }^{53-57}$ However, a critical review addressing the techniques to tailor different functional properties and governing mechanisms of responsive behavior is yet to be amassed into a single article. This review article is therefore devoted to designing this. In this review article, we explicitly concentrated on the recent and advanced hydrogel synthesis technologies, together with process design implications, and optimized conditions of the preparation process.

\section{Typical polymerization techniques for hydrogel synthesis}

Hydrogels are three-dimensional polymeric networks that can absorb and contain water due to the presence of hydrophilic groups in the constituent polymeric networks. The term 
"network" implies the presence of crosslinks within hydrogels which provide pure elastic to viscoelastic properties. Hydrophilic monomers are typically used to prepare hydrogels, but hydrophobic monomers are also included to tune the physical, mechanical, and chemical properties towards specific applications. Both synthetic and natural polymeric networks can be regarded as hydrogels. Typically, synthetic polymers are hydrophobic and more chemically stronger than natural polymers. They provide a slow degradation rate and a mechanically robust structure when incorporated with natural polymers. ${ }^{62-64}$

The most practical approach to producing SRHs is to combine monomers that exhibit different behaviors in response to various environmental stimuli. Any technique that is appropriate for synthesizing a cross-linked polymeric network can be applied to produce hydrogels. Free radical polymerization techniques are commonly applied to natural and/or synthetic hydrophilic monomers with multifunctional cross-linkers to produce hydrogels. ${ }^{31}$ The choice of the polymerization process/technique influences the properties of the resultant hydrogels greatly. ${ }^{65}$ Hydrogels can be synthesized either through a one-step process in the form of simultaneous polymerization and crosslinking of multifunctional monomers or by a stepwise process of producing polymers with reactive groups that can crosslink themselves or can react with appropriate crosslinkers. ${ }^{31,66,67}$

Composite hydrogels are developed by combining two or more types of organic, inorganic, and polymeric materials in combination to bring about the best synergistic effect of those materials for specific applications. For example, achieving desired mechanical strength and conforming to a particular shape could be achieved by incorporating hydrophobic polymer segments in the presence of crosslinkers. ${ }^{67,68}$

\subsection{Chain growth polymerization}

Chain growth polymerization with a free radical mechanism is popular to synthesize chemically crosslinked hydrogels. The polymerization process involves three steps: initiation, propagation, and termination. Mostly hydrophilic $-\mathrm{C}=\mathrm{C}-$ containing monomers participate in free radical polymerization. ${ }^{69}$ Various free radical polymerization techniques for hydrogel synthesis are described below.

Bulk polymerization (Fig. 2a) is widely applied to produce hydrogels because of its simple mechanism. This technique involves the polymerization of liquid monomers and monomersoluble initiators with a small number of crosslinkers. The polymerization process is typically initiated using ultraviolet light, radiation, and/or chemical catalysts. ${ }^{72}$ Shin et al. synthesized $\mathrm{pH}$-responsive bulk polymerized hydrogels from sodium functionalized acrylic acid (NaAAc) and hydroxyethyl methacrylate (HEMA). At first, AAc was neutralized by $\mathrm{NaOH}$ to get NaAAc. Afterward, the initiator (i.e. $\alpha, \alpha^{\prime}$-azobisisobutyronitrile: AIBN) and crosslinker ( $N, N^{\prime}$-methylenebisacrylamide: MBAAm) along with HEMA were added to the reaction mixture. The polymerization was continued on a Petri dish for 30 minutes at $75{ }^{\circ} \mathrm{C}$ in an oven. The unreacted reaction ingredients were discarded by repeatedly washing with deionized (DI) water. $^{73}$ Bulk polymerization has a higher polymerization rate and inefficient heat control, and the viscosity of the reaction increases very rapidly. Therefore, it is crucial to control the conversion rate to tune the hydrogel properties. The resultant hydrogels exhibit a glassy and transparent polymer matrix, which swells and becomes flexible upon immersion into water. ${ }^{31}$ With the increase in reaction temperature and the initial concentration of the initiator, the rate of polymerization and conversion increases. By controlling temperature and the (a)

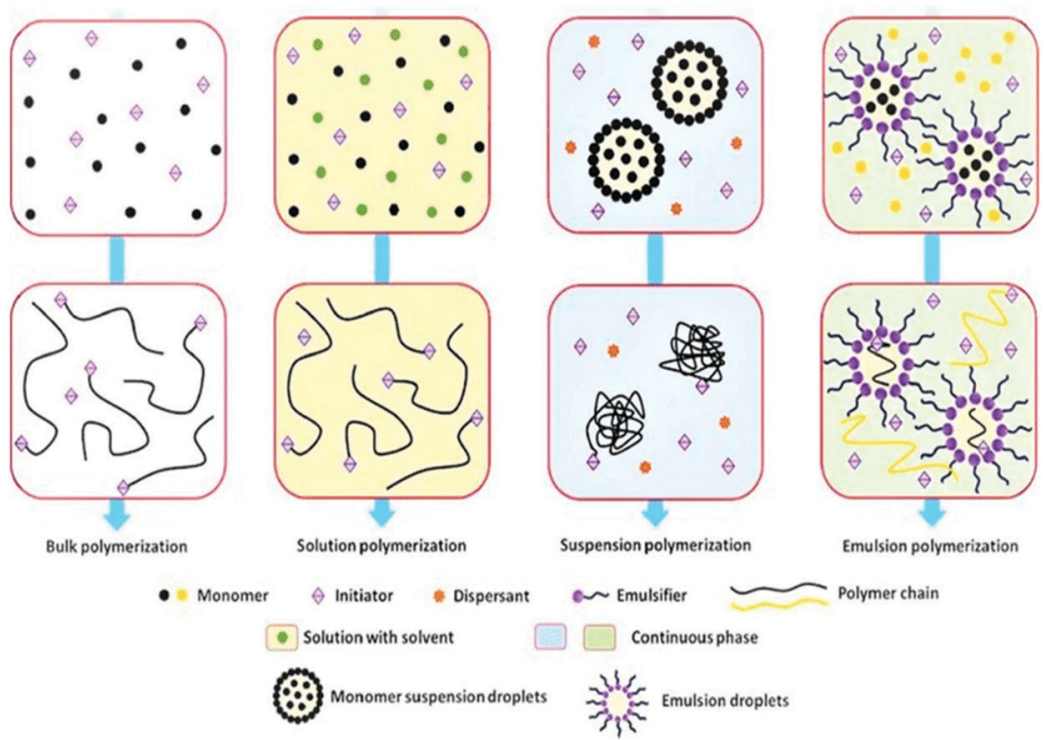

(e)
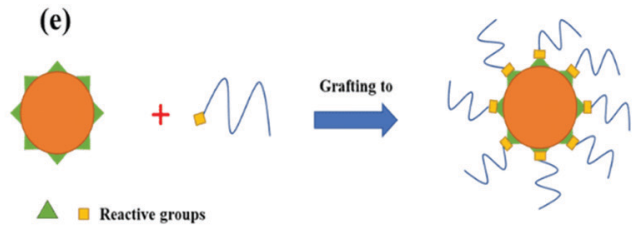

$\triangle$ Reactive groups
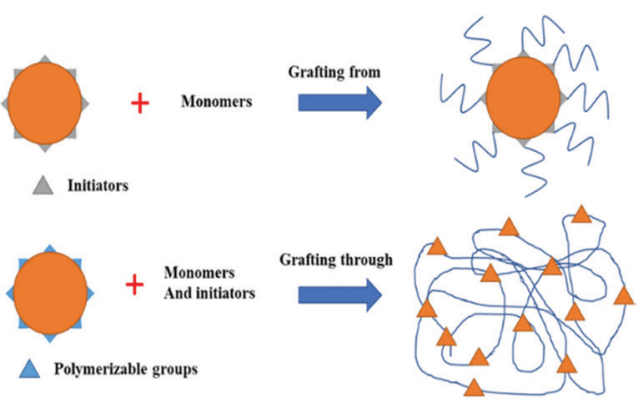

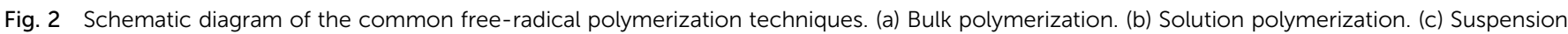

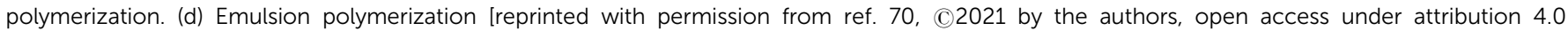

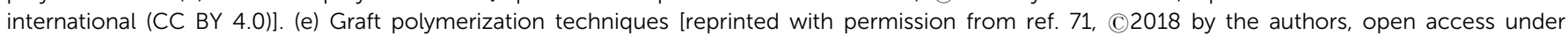
attribution 4.0 international (CC BY 4.0)]. 
concentration of the initiator, it is possible to control the conversion rate of bulk polymerization. ${ }^{74}$ Besides, terminating the reaction at low conversion could be another approach, but in large-scale processes it is considered as uneconomical. Hence, other polymerization techniques such as solution, suspension, and emulsion polymerization are widely adopted for hydrogel synthesis. ${ }^{75}$

2.1.1. Solution polymerization. In solution polymerization, ionic or neutral monomers with a solvent (e.g., benzyl alcohol, water, ethanol, or water-ethanol mixtures) and multifunctional cross-linkers undergo polymerization by ultraviolet (UV) or redox initiation to form hydrogels. The hydrogel is separated, and the residual monomers, cross-linkers, initiators, and other impurities are extracted by washing with distilled water (Fig. 2b). ${ }^{76}$ Solution polymerization is well-known for ease of synthesis and low-cost processing with better heat transfer control during polymerization. Since polymerization occurs in the aqueous medium, it is safe and harmless. ${ }^{72,77}$ Solution polymerization is greatly used for synthesizing cellulose-based superabsorbent hydrogels. The polymerization rate is high, and the reaction can be conducted at room temperature. Since the solution has low viscosity, stirring of the reaction mixture becomes easier; therefore, better heat transfer and dissipation are achieved in solution polymerization than in bulk polymerization. ${ }^{77,78}$ Generally, bulk and solution polymerization processes are homogenous with the potential to become heterogeneous when the formed polymer is insoluble in the monomer and solvent in the respective processes. ${ }^{78}$

2.1.2. Suspension polymerization (including inverse-suspension polymerization). Suspension polymerization (Fig. 2c) involves generally insoluble monomers and initiators with a low hydrophilic-lipophilic balance suspending agent in aqueous solution. They are constantly agitated to create droplets of monomers (0.1-5 $\mathrm{mm}$ in diameter). As polymerization proceeds, the polymer hydrogel beads are formed, which can be filtered to separate from the reaction mixture. ${ }^{57}$ Herein, individual monomers undergo small-scale bulk polymerization. Since water is the usual medium, it functions as an excellent heat transfer medium. However, a protective colloidal agent [e.g., carboxymethyl cellulose (CMC) or methylcellulose (MC) and polyvinyl alcohol (PVA)] is often used to obstruct the coalescence of the droplets. ${ }^{78}$ Inverse suspension polymerization is also widely used for hydrogel synthesis. ${ }^{79}$

2.1.3. Emulsion polymerization (including micellar polymerization). Synthesis of hydrogels can also be done by emulsion polymerization. A typical emulsion polymerization process involves a water-soluble initiator, a surfactant, crosslinkers, and real but small water-soluble monomers (i.e. slightly water-soluble or completely hydrophobic monomers).$^{80,81}$ In inverse emulsion polymerization, a hydrophilic monomer from an organic liquid is used. ${ }^{76}$ Fig. 2 d shows a typical emulsion polymerization technique. It produces polymer particles much smaller than those from suspension polymerization $(0.1-3 \mu \mathrm{m})$. The suspension and emulsion polymerization processes can be easily controlled and heat transfer can be performed effectively over bulk polymerization. ${ }^{78}$ In contrast to suspension polymerization, emulsion polymerization uses a water insoluble initiator.

2.1.4. Graft polymerization mechanism. Poor mechanical properties of a bulk polymerized hydrogel can be induced when using a grafting technique, especially when grafted onto more robust support frames. Usually, free radical sites are generated on the surface of the support where monomers can be directly polymerized to form stronger covalent bonds with the support structure. For example, grafting vinyl monomers onto polysaccharides is common. ${ }^{31}$ Besides, grafted PAAc from hybridized chitosan (CHT) with cellulose via thiourea formaldehyde resin produces $\mathrm{pH}$-responsive hydrogels which are mechanically more robust than grafted AAc from CHT hydrogels. ${ }^{82}$ Fig. 2e demonstrates a different grafting approach to synthesize hydrogels.

\subsection{Step-growth polymerization}

Step-growth polymerization utilizes distinct functional groups containing monomers to synthesize hydrogels. These complementary functional groups react and form covalent bonds to propagate a one-step polymerization process. ${ }^{69}$ Tibbitt et al. studied the mechanical properties of photodegradable hydrogels synthesized via chain and step-growth polymerization processes (Fig. 3). It was demonstrated that mechanical integrity, tensile toughness, ductility, and shear strain to yield of step-growth hydrogels were better than those of chain growth hydrogels because of network homogeneity and cooperativity. However, the rate of erosion due to light exposure was less for chain-growth hydrogels due to higher network connectivity in chain-grown hydrogels. ${ }^{83}$ With the understanding of hydrogel networking, desirable properties of hydrogels can be achieved.

\section{Crosslinking methods of hydrogel fabrication}

Since hydrogels contain hydrophilic segments, cross-linking is essential to avoid the dissolution of hydrophilic polymer segments in the aqueous medium. Without substantial cross-links, the solutions of hydrophilic polymers behave as Newtonian fluids.

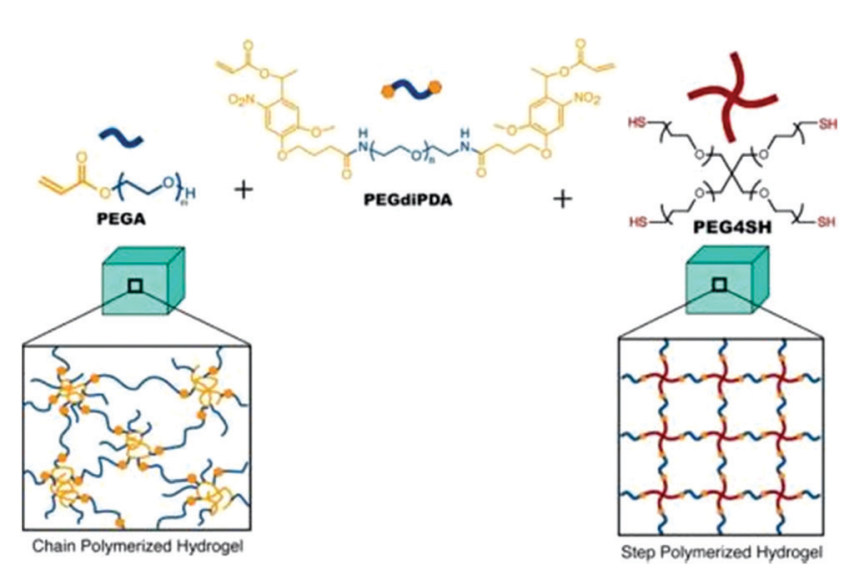

Fig. 3 Photo-degradable hydrogel based-on chain and step polymerization of a photolabile monomer (PEGdiDPA). (a) Chain polymerization of PEGdiPDA and PEGA via free radical mechanism (e.g. heterogeneous network structure). (b) Step-polymerization of PEGdiDPA with PEG4SH via Michael-addition polymerization [reprinted with permission from ref. 83, (C)American Chemical Society, 2013]. *PEGA (monoarylated poly(ethylene glycol)); poly(ethylene glycol) di-photodegradable acrylate (PEGdiPDA); four-arm poly(ethylene glycol) functionalized with thiol end groups (PEG4SH). 
(a)

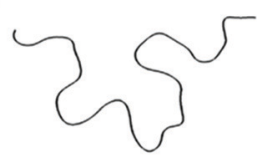

Polymer

(b)

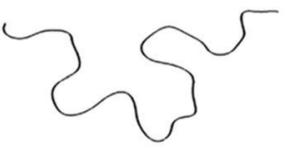

Polymer
Polymerization

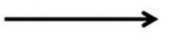

Fig. 4 Schematic illustration of hydrogel fabrication. (a) Physical crosslinking. (b) Chemical Crosslinking [reprinted with permission from ref. 77, (C)Springer Nature, 2018].

On the other hand, elastic to visco-elastic behavior is achieved by increasing the number of cross-links. ${ }^{66}$ The degree of crosslinking is correlated with overall hydrogel properties and characteristics. ${ }^{59,60}$

Typically, hydrogels are classified into two categories and their 3D networks can be formed in numerous ways, as shown in Fig. $5 .{ }^{84}$ The first category is known as physically crosslinked hydrogels that form networks in polymers via physical interactions, such as ionic interactions between polycations/multivalent cations and polyanions, or hydrophobic interactions in polymer chains, and so on (Fig. 4a). The other category is called chemically crosslinked hydrogels that form networks in polymers via chemical interactions (i.e. covalent bonds). Herein, crosslinking can be instigated by heating, or ultraviolet radiation, and/or by chemical crosslinking achieved by different reactions, such as Michaelis-Arbuzov reaction, nucleophilic reaction, and Michael's reaction, to name a few (Fig. 4b). ${ }^{85,86}$ Theoretically, different applications of hydrogels are possible through the optimization of their properties which is controlled by the degree of crosslinking..$^{87,88}$

\section{Synthesis of stimulus-responsive hydrogels (SRHs)}

\subsection{Synthesis of thermo-responsive hydrogels (TRHs)}

Hydrogels responsive to temperature are considered as one of the smartest types of hydrogels that can change their shapes and formation in response to temperature changes. ${ }^{89}$ They are

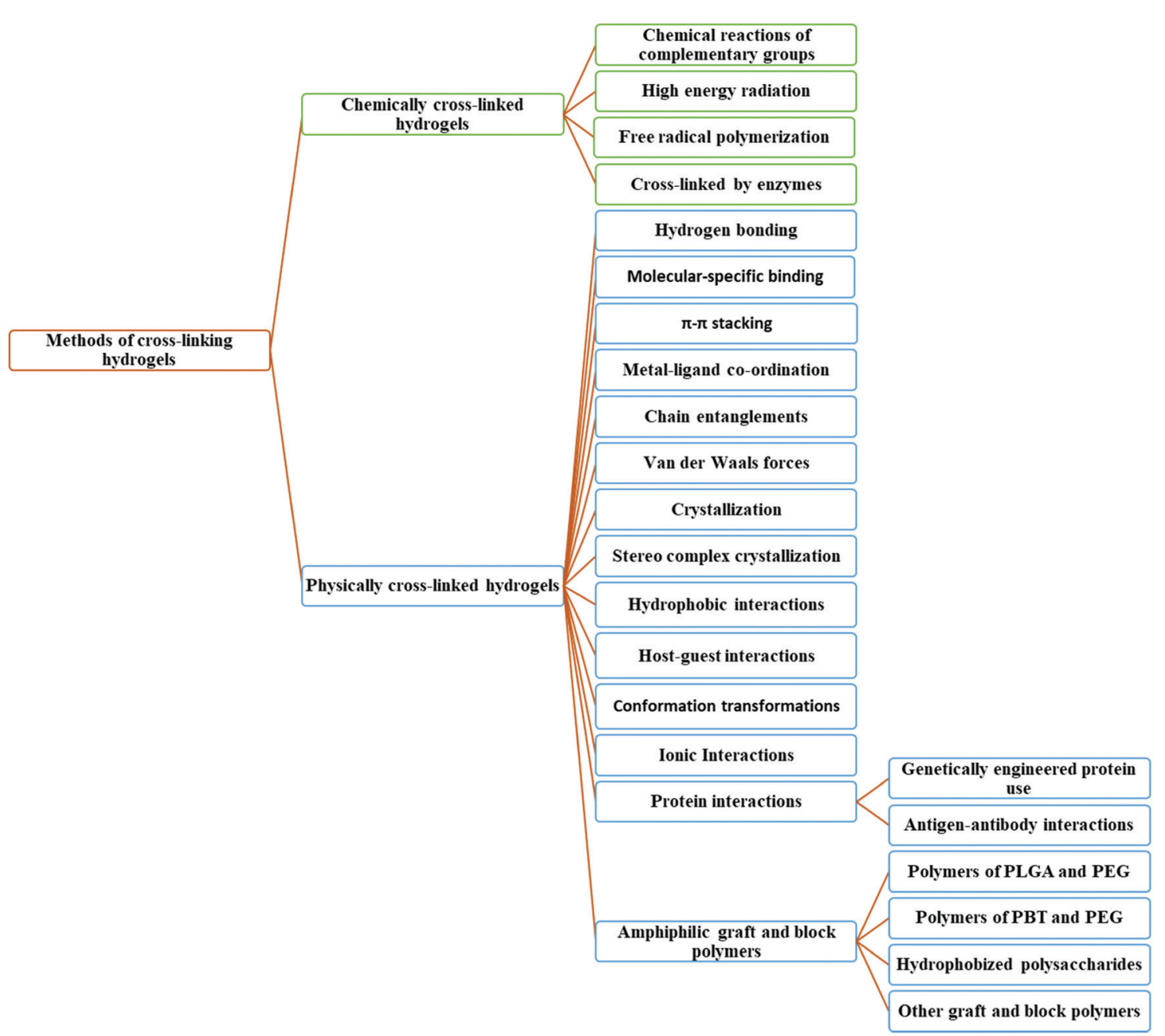

Fig. 5 Methods of cross-linking hydrogels (based on ref. 63). *Polylactic-co-glycolic acid (PLGA); polybutylene terephthalate (PBT). 
Table 1 Conditions and parameters of PNIPAAm synthesis

\begin{tabular}{|c|c|c|c|c|c|c|}
\hline Synthesis method & $\begin{array}{l}\text { Synthesis } \\
\text { temperature }\end{array}$ & Fluid & Crosslinkers & Reagents & Effect on PNIPAAm properties & Ref. \\
\hline $\begin{array}{l}\text { Free radical } \\
\text { polymerization }\end{array}$ & $22{ }^{\circ} \mathrm{C}$ & DI water & MBAAm & $\begin{array}{l}\text { APS and } \\
\text { TEMED }\end{array}$ & $\begin{array}{l}\text { Increased sensitivity to temperature triggered controllable } \\
\text { drug release and improved mechanical properties }\end{array}$ & 98 \\
\hline $\begin{array}{l}\text { Surfactant-free emulsion } \\
\text { polymerization }\end{array}$ & $70^{\circ} \mathrm{C}$ & DI water & MBAAm & KPS & $\begin{array}{l}\text { Improved crosslinks, charge distribution impact and } \\
\text { temperature-responsive deswelling behavior }\end{array}$ & 99 \\
\hline Free radical polymerization & $\begin{array}{l}10,15,20, \\
\text { or } 25 \pm 0.2{ }^{\circ} \mathrm{C}\end{array}$ & DI water & MBAAm & $\begin{array}{l}\text { APS and } \\
\text { TEMED }\end{array}$ & $\begin{array}{l}\text { The transition towards a turbid substrate became more gradual } \\
\text { (at } 33.5-34.5^{\circ} \mathrm{C} \text { ) which consequently had an influence on the } \\
\text { light scattering behavior in response to temperature }\end{array}$ & 100 \\
\hline $\begin{array}{l}\text { Free-radical precipitation } \\
\text { copolymerization }\end{array}$ & $70{ }^{\circ} \mathrm{C}$ & DI water & MBAAm & SDS, APS & $\begin{array}{l}\text { The particle size can be influenced by controlling the } \\
\text { concentration of the free radical initiator, which is a crucial } \\
\text { factor for drug delivery }\end{array}$ & 101 \\
\hline $\begin{array}{l}\text { Sedimentation } \\
\text { polymerization }\end{array}$ & $80^{\circ} \mathrm{C}$ & $\begin{array}{l}\text { Silicone } \\
\text { oil }\end{array}$ & MBAAm & $\begin{array}{l}\text { KPS, } \\
\text { TEMED }\end{array}$ & $\begin{array}{l}\text { The swelling rate of the resulting hydrogel beads was directly } \\
\text { influenced by the morphology (especially porosity in the } \\
\text { structure) of the gel delivered by the applied polymerization }\end{array}$ & 102 \\
\hline
\end{tabular}

Abbreviations: ammonium persulfate (APS); $N, N, N^{\prime}, N^{\prime}$-tetramethyl ethylenediamine (TEMED); potassium persulfate (KPS); sodium dodecyl sulfate (SDS); and $N, N^{\prime}$-methylenebisacrylamide (MBAAm).

mainly characterized by the presence of hydrophobic groups, such as methyl, ethyl, and propyl groups. ${ }^{90}$ Usually, TRHs can be divided into positively thermo-sensitive, negatively thermosensitive, and thermally reversible gels. ${ }^{91}$ Positively thermosensitive hydrogels swell at high temperatures and shrink at low temperatures, for instance, interpenetrating polymeric networks (IPNs) based on poly(acrylamide-co-butyl methacrylate) [P(NIPAAm-co-BMA)] and PAAc. ${ }^{92}$ Conversely, negatively thermosensitive hydrogels swell with decreasing temperature and vice versa. TRHs can be synthesized from both natural polymers (e.g., chitosan, cellulose, and gelatin) and synthetic polymers (e.g. poly( $N$-isopropylacrylamide) (PNIPAAm) and polyfluorene 127) ${ }^{93}$ Here, the choice of a monomer is important because the behavior of a hydrogel is largely regulated by the type of monomer and crosslinker used for the synthesis. The most common monomer, NIPAAm, is widely used to design drug release systems. Research reveals that the presence of both hydrophilic amide groups and hydrophobic isopropyl groups in side chains allows PNIPAAm to show temperature-controlled phase transition behavior in aqueous solution at a lower critical solution temperature (LCST) of around $32{ }^{\circ} \mathrm{C} .{ }^{94-96}$ PNIPAAm is one of the most intensely studied hydrogels, especially in biomedical applications, because its volume phase transition temperature (VPTT) at LCST is close to human body temperature and due to its fast on-off switching. ${ }^{89,97}$ Some typical parameters and ingredients considered in the synthesis of PNIPAAm are shown in Table 1.

Another source of novel thermo-responsive hydrogels can be in the form of renewable resource-based hydrogels. It is possible to synthesize them using bacterial cellulose (BC) and castor oil, in combination with NIPAAm. ${ }^{103}$ Most of the thermo-responsive polymers undergo phase transitions with the change of temperature. ${ }^{104}$ The critical solution temperature is responsible for controlling the solubility of such hydrogels. ${ }^{47,105}$ The synthesis of thermo-responsive hydrogels from polymers using temperature changes as a trigger is shown in Fig. 6.

Some cellulose-based functionalized MCs with the protein laminin can be used to develop a bioactive scaffold for neural tissue engineering. ${ }^{106}$ Similarly, composite thermo-sensitive hydrogels synthesized from CHT/CMC, CHT/collagen, and CHT/PEG can be alternatives to invasive surgeries. ${ }^{107-109}$ They can also be used

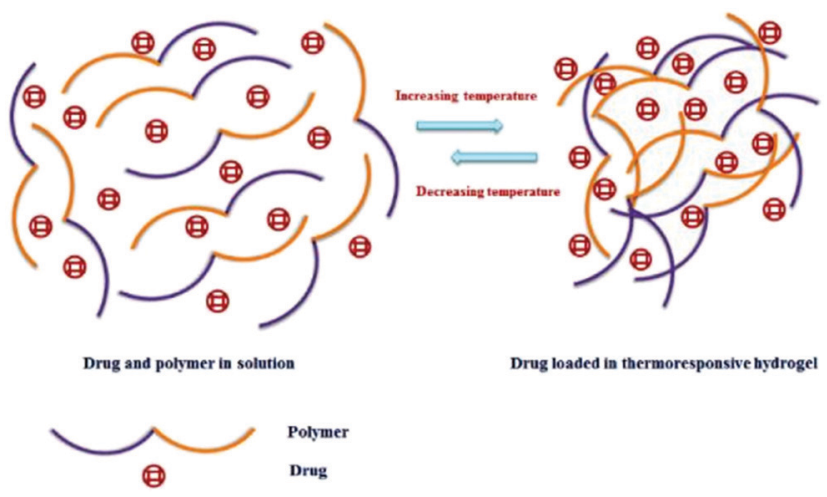

Fig. 6 Formation of TRHs using temperature as a trigger [reprinted with permission from ref. 93, (C)2018 by the authors, open access under attribution 4.0 international (CC BY 4.0)].

as potential targeted drug carriers that are injected into the body as a liquid and form a gel if the body temperature rises above their LCST. ${ }^{84}$

TRHs have become an optimum material for advanced bioprinting applications because of their easy tunability from the sol-gel state by changing temperature (rapid gelation), printability with good shape fidelity, high resolution, ${ }^{110}$ cell compatibility ${ }^{111,112}$ with the ability to mimic the micro-environment, natural shape, and vascularization. ${ }^{113,114}$ TRHs that are used for bioprinting can be synthesized from gelatin and its derivatives, MC, agarose, collagen, pluronic and its derivatives, $\mathrm{PEG} /$ polyethylene oxide (PEO) based block polymers, and poly(N-PNIPAAm) and its derivatives. ${ }^{115}$ Josergio et al. developed a composite PAAm hydrogel containing silica nanoparticles (NPs) with an enhancement in the thermal diffusivity of PAAm hydrogel nanocomposites. ${ }^{116} \mathrm{Chu}$ et al. summarized the most used techniques to fabricate and engineer different thermo-responsive smart hydrogel materials in different forms of functional compounds (shown in Fig. 7). ${ }^{117}$

\subsection{Synthesis of light-responsive hydrogels (LRHs)}

Hydrogels responsive to light show reversible deformations from a flowable state to a non-flowable state when exposed to light 


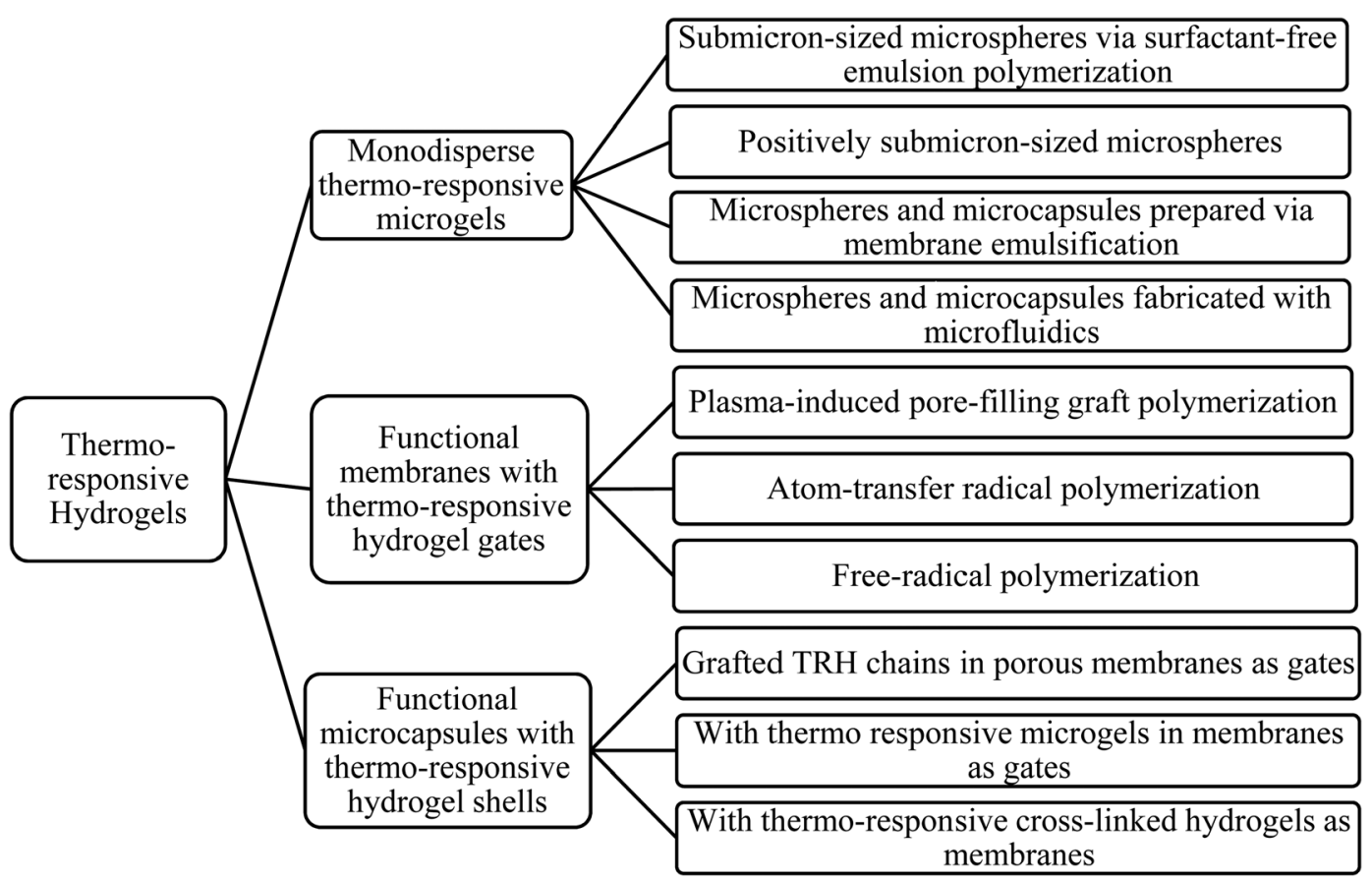

Fig. 7 Synthesis and engineering techniques for different thermo-responsive smart hydrogels (based on ref. 117).

sources such as UV light, visible light, and near IR light. ${ }^{54,118}$ LRHs are generally classified into two categories: one contains photolabile moieties (e.g. azobenzene and o-nitro benzyl) and the other contains near IR absorbing nanostructures such as nanorods, nano-shells, and carbon nanotubes embedded in thermo-responsive hydrogels. ${ }^{119}$ Such hydrogels are functionalized as light-sensitive through photochromism by incorporating photochromic molecules into the hydrogel matrix. This can be performed by chemical coupling or mechanical processes and controlled by the right selection of chromophores, wavelength, light intensity, and chromophore-polymer interactions. ${ }^{120}$ These hydrogels can undergo sol-gel phase transitions due to the cleavage of photo-responsive moieties linked to the hydrogel networks, contraction-expansion of volume occurring due to photothermal heating of NPs incorporated within TRHs, ${ }^{121}$ and/or chemical modifications (as demonstrated in Fig. 8). ${ }^{122}$

Ter Schiphorst et al. developed a light-responsive hydrogel by incorporating chromophore (photochrome) spiropyrans via copolymerization with NIPAAm and AAc. This hydrogel contracts and swells due to the photoisomerization of the photochrome. ${ }^{123}$ In another study, the incorporation of metallic NPs such as Au, $\mathrm{Pt}, \mathrm{Ag}$, and $\mathrm{Cu}$ was reported to synthesize light-sensitive hydrogels due to their superior light adsorbing and/or scattering capability than molecular chromophores. ${ }^{124}$ The light responsiveness of hydrogels based on trans-cis photoisomerization and thereby sol-gel and gel-sol transitions were reported by Zhao and Fraser Stoddart. The photoinduced cis-trans isomerization of azobenzene found applications in many hydrogel systems. The host-guest ${ }^{119}$ chemistry of some materials such as cyclodextrins (CDs) and their derivatives was also used in the synthesis of light-responsive hydrogels. ${ }^{125}$ Another study suggests that the composite hydrogels of PNIPAAm synthesized with the nanofillers of glycidyl methacrylate (GMA) functionalized graphene oxide (GO) exhibited light responsiveness due to the infrared light sensitivity of GO. ${ }^{126}$ A light-responsive hydrogel of polymeric NPs (light-sensitive) embedded in a thermo-responsive and mechanically stable double networked hydrogel was recently developed. ${ }^{121}$ Hydrogels based on photo-responsive agents (e.g., polydopamine $)^{127}$ and semi-conductive polymers ${ }^{128}$ were also synthesized and studied to fabricate light-responsive hydrogels.

\subsection{Synthesis of electrically conductive hydrogels (ECHs)}

Hydrogels responsive to electrical stimuli are typically polymeric blends or co-networks of electroactive polymers and highly hydrated hydrogels. The electroactive constituent contributes to electrical conductivity and on-off electrical and optical switching, whereas the hydrated constituent endows the swelling ability, biocompatibility, and small molecular diffusion. ${ }^{129}$ When a water-swollen crosslinked polyelectrolyte gel (i.e. electroconductive hydrogels) is sandwiched between two electrodes and subject to a DC voltage, a potential gradient is generated, and based on the charges on the hydrogel it contracts anisotropically, thereby discharging the water content. ${ }^{13,48,130}$ Hydrogels containing ionic moieties exhibit such a contraction mechanism, whereas hydrogels with charge neutrality show zero contraction. The presence of polyanions makes hydrogels contract extensively near the anode and swell to a lesser extent near the cathode. On the contrary, hydrogels with polycations show an opposite contractionswelling mechanism, meaning that they contract extensively near the cathode and show little swelling near the anode. Moreover, the contraction rate increases with the applied electric field. ${ }^{130-132}$

The use of free radical polymerization and the chemical crosslinking approach was reported for the fabrication of 


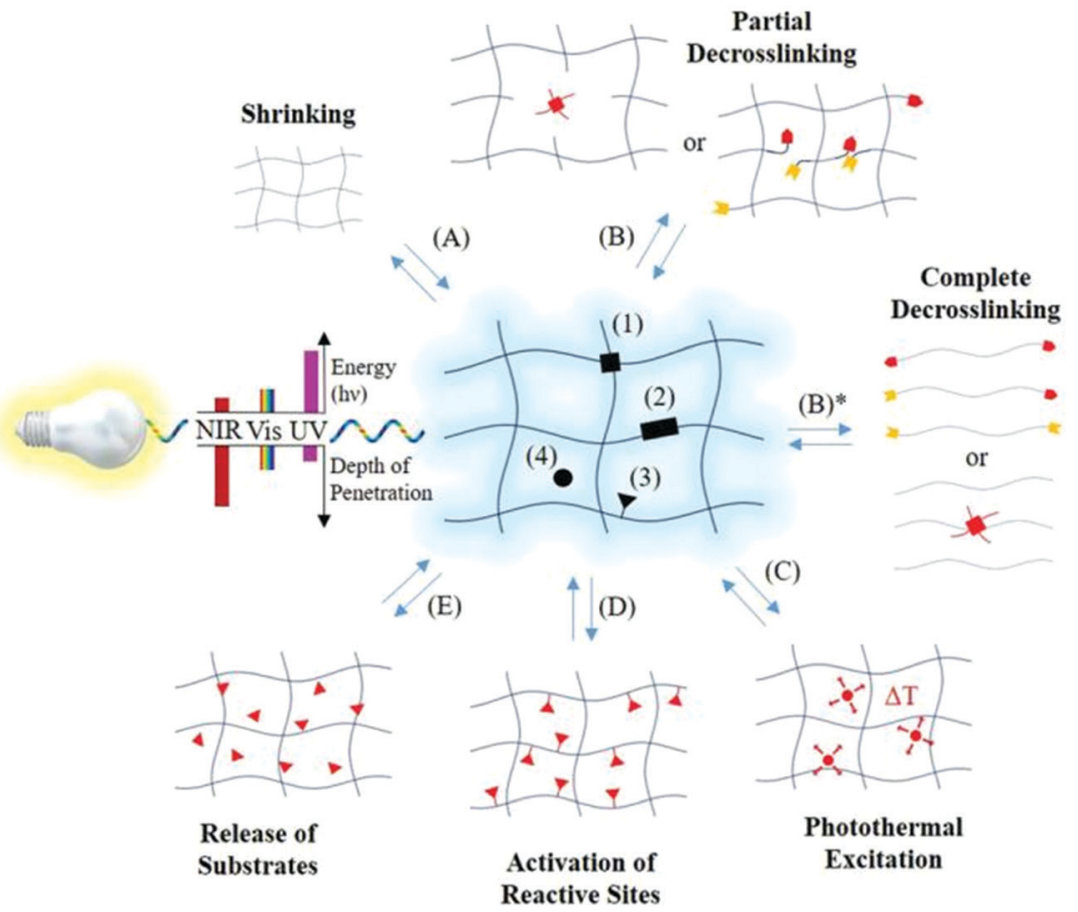

Fig. 8 Molecular architecture and responses of a photo-responsive hydrogel (center). The photo-responsive entities (black geometries) may be present at (1) crosslinking points, (2) polymer or supramolecular backbone, (3) side chains, or (4) aqueous medium of dissolved hydrogels. Based on the placement and photo-responsive moieties, photoresponses may include (A) shrinkage and (B) partial de-crosslinking (results in water uptake and thus increasing hydrogel volume). Nevertheless, increasing photoinduced crosslinking leads to hydrogel shrinkage and full de-crosslinking leads to degradation to liquefication of hydrogels $(B)^{*}$. Besides these, there can be $(C)$ photothermal excitation due to the increase in temperature locally, (D) reactive site activation or deactivation, and (E) release or capture of substrates [reprinted with permission from ref. 122, (C) John Wiley and Sons, 2019].

electric field responsive hydrogels, for example, poly(2-(acrylamido)-2-methylpropanesulfonic acid) (PAMPS) hydrogels. ${ }^{130,133}$

ECHs are synthesized by the incorporation of conductive materials (Fig. 9) such as metallic NPs (e.g. Au NPs), conductive polymers (e.g., polypyrrole (PPy), polyaniline (PANI), and poly3,4-ethylene dioxythiophene: PEDOT, etc.), and carbon-based materials (e.g., graphene and carbon nanotubes) as fillers into the hydrophilic hydrogel matrix. ${ }^{13,134}$

The application of ECHs in soft electronics is drawing attention due to their enhanced conductivity, stretchability, and flexibility. ${ }^{135,136}$ These properties are favorable for flexible strain sensors and highly applicable in soft robotics, human-machine interfaces, and micromachines. ${ }^{131}$ Biosensors and bioelectronicsbased conductive hydrogels for the detection of pathogens, ${ }^{137}$ glucose concentration, ${ }^{138}$ and viruses, ${ }^{139}$ delivering drugs,,${ }^{140}$ and environmental monitoring ${ }^{140}$ are being developed rapidly. ${ }^{141}$

\subsection{Synthesis of magnetically responsive hydrogels (MRHs)}

Usually, magnetic responsive behavior can be imparted by incorporating magnetic NPs (MNPs) as a dispersion in a crosslinked polymeric matrix rendering responsive behavior against magnetic stimuli. ${ }^{142}$ With the change of magnetic state, the mechanical, thermal, and acoustic behaviors are also affected simultaneously as the magnetic part behaves as a composite along with the hydrogel matrix. ${ }^{143}$ Due to the inclusion of magnetic NPs, the hydrogel application expands through many areas. Moreover, the optimum effect can be achieved by ensuring the homogeneous distribution of magnetic NPs to create a hybridized hydrogel composite. ${ }^{144,145}$ Therefore, in the case of magnetic NPs embedded into hydrogels, it is necessary to control the distribution of NPs within the hydrogel network which can be manipulated by creating a magnetic field outside. Furthermore, the properties of such a hydrogel can also be affected by factors like the concentration and size of both the hydrogel and magnetic particles. These magnetic gel types can be synthesized by incorporating NPs that are responsive to a magnetic field into a cross-linked hydrogel network. Mainly, three major synthesis processes are followed to develop a magnetic nanoparticle hybridized hydrogel: the blending method, the encapsulation or co-precipitation method, and the grafting approach (Fig. 10). ${ }^{133,146-149}$

By comparing hydrogels with randomly distributed MNPs with those incorporating homogeneously distributed MNPs, it is found that the distribution arrangement greatly influences the magnetothermal behavior of hydrogels. Hence, magnetothermal properties can be regulated by controlling the arrangement of MNPs inside the hydrogel via the regulation of the magnetic field. ${ }^{151-154}$ To improve the collective magnetic properties of MNPs as well as their monodispersity and homogeneity, they can be assembled into a one-dimensional structure (Fig. 11). ${ }^{144,158}$

Besides, when MNPs are exposed to an alternating electromagnetic field, the magnetization flip dissipates thermal energy to the surroundings and causes magnetic hyperthermia. ${ }^{155,156,162}$ This phenomenon has been largely used in chemotherapy to kill malignant cells. ${ }^{159,160,163,164}$ There are four major methods for 


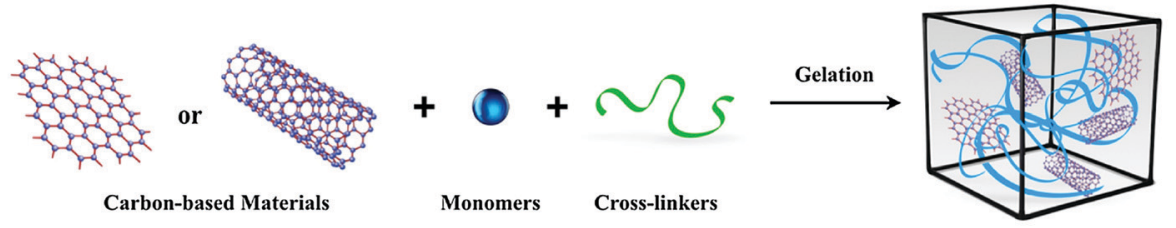

(a)

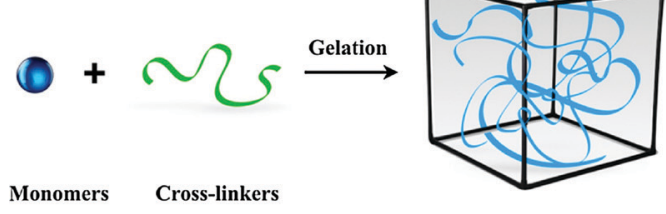

Polymerization

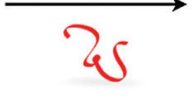

Monomers of Conductive Polymers

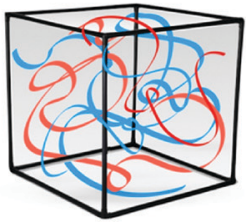

(b)
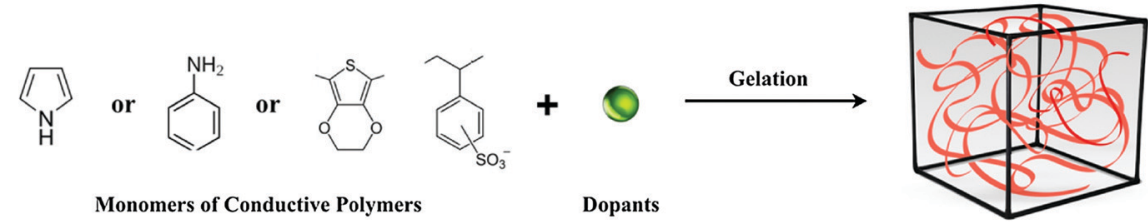

(c)
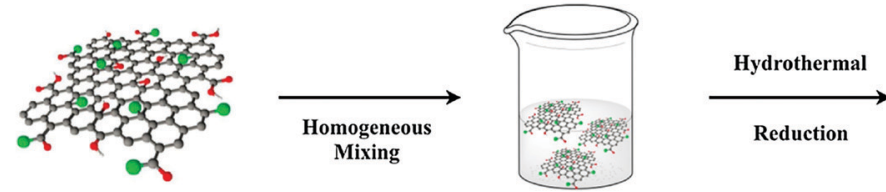

Graphene Oxide

Graphene Oxide Suspension

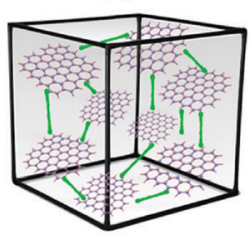

(d)

Fig. 9 Four main approaches were used to obtain ECAs. (a) Hydrogel formation from a conductive filler suspension. (b) Polymerization within a preformed hydrogel matrix. (c) Crosslinking conductive polymers by dopant molecules. (d) Self-assembly of a graphene hydrogel via supramolecular interactions [reprinted with permission from ref. 134, (C) Elsevier, 2019].

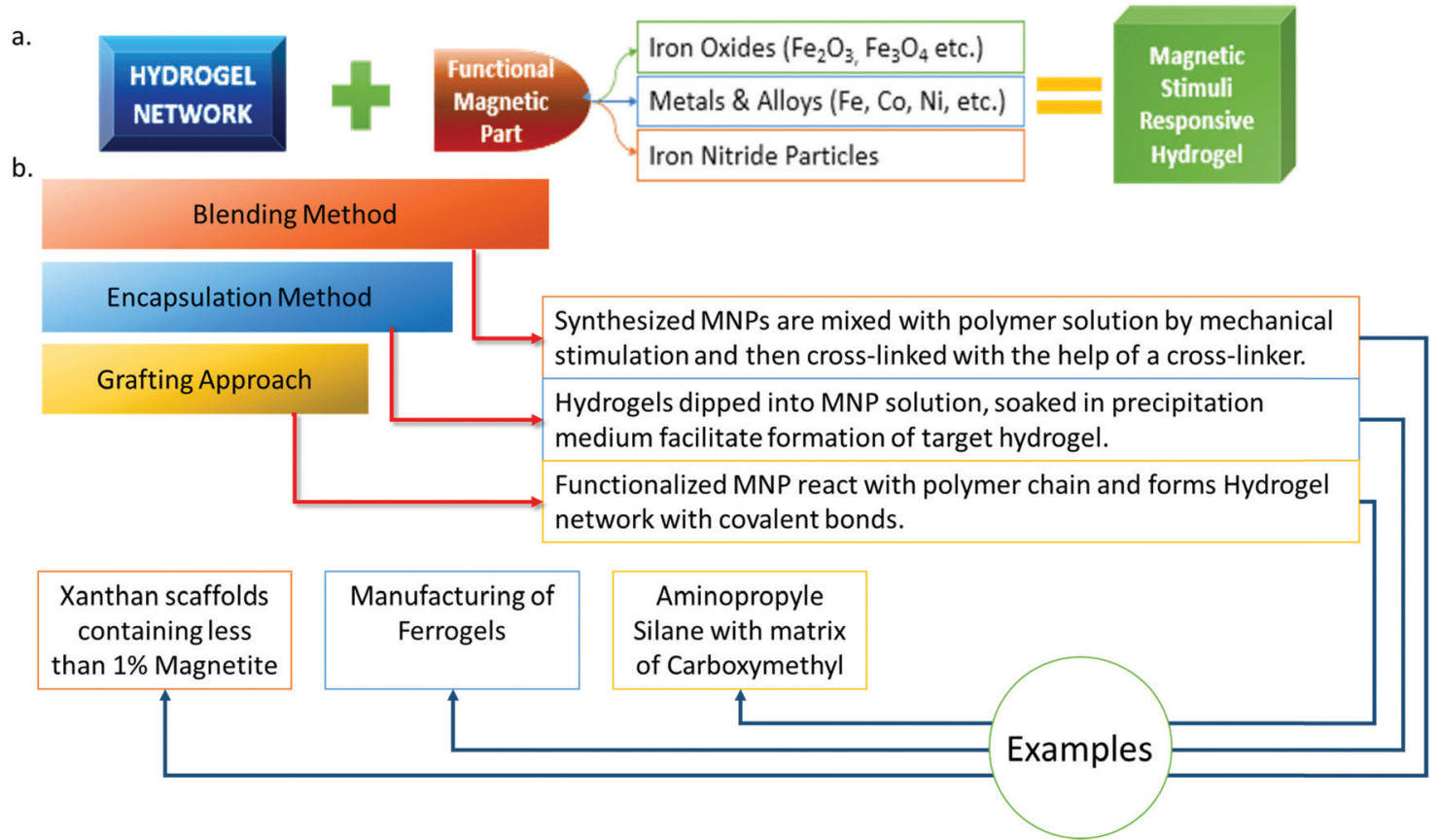

Fig. 10 (a) Principle of magnetically responsive hydrogel synthesis (based on ref. 143). (b) Major synthesis principles of MNP hydrogels with examples (based on ref. 142, 143 and 150-157). 


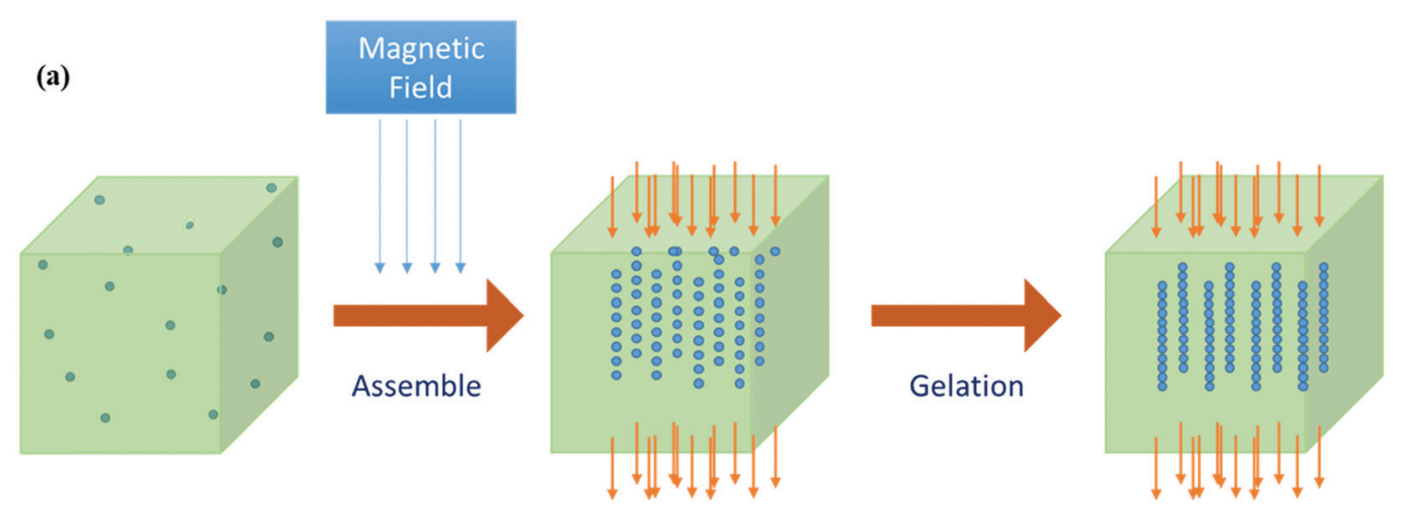

- = Magnetic Nanoparticles

(b)
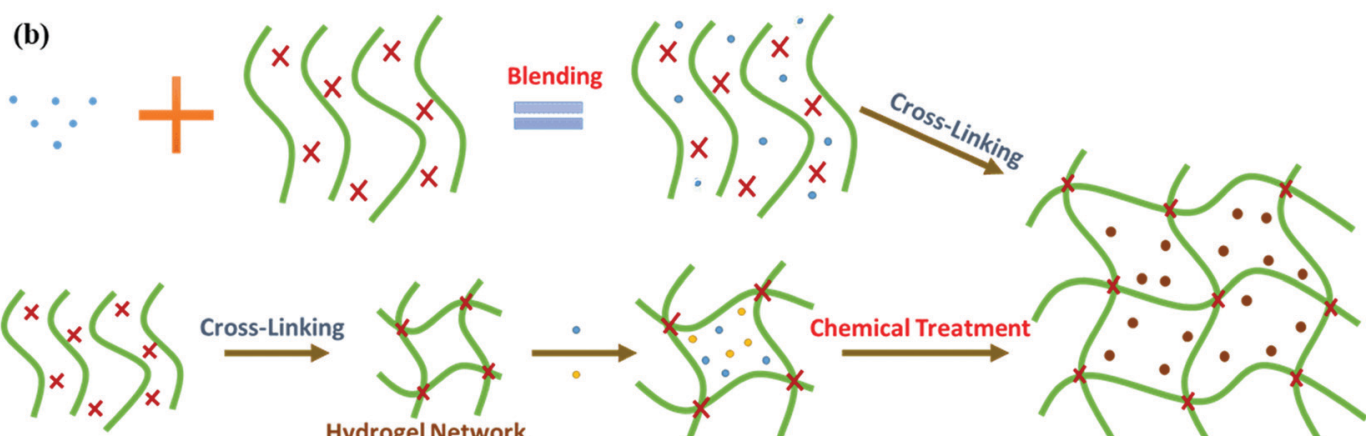

Hydrogel Network
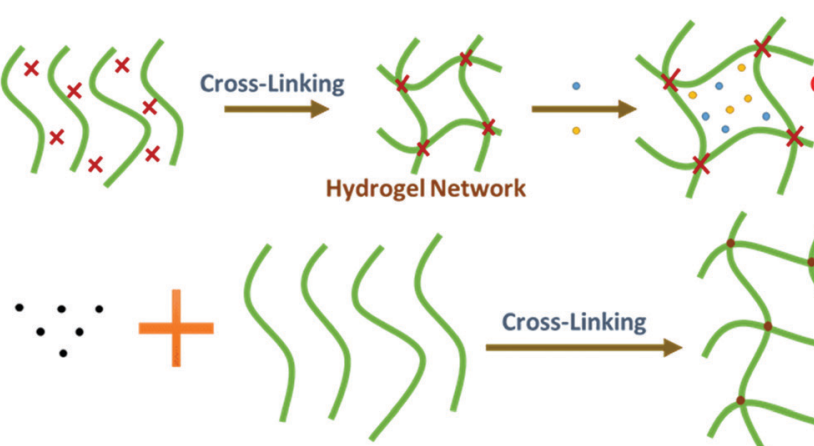

- = Magnetic Nanoparticles

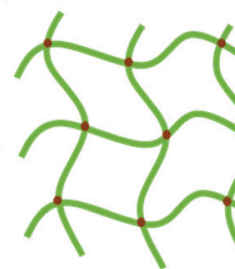

$X=$ Cross-Linker

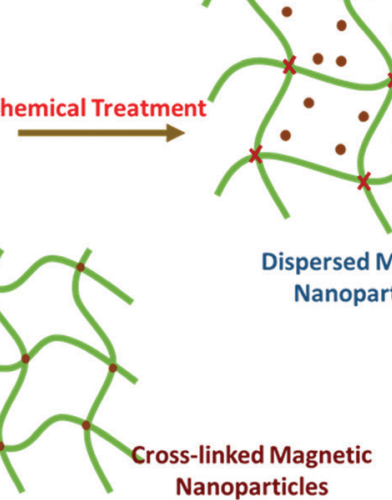

Fig. 11 (a) Effect of magnetic field on MNPs incorporated in the hydrogel [reproduced from ref. 3]. (b) Major preparation methods for synthesizing a magnetic nanoparticle-induced hydrogel and a regenerated nanoparticle-induced hydrogel [reproduced with permission from ref. 146, (C)2015 by the authors, open access under attribution 4.0 international (CC BY 4.0)].

the synthesis of magnetic stimulus hydrogels with suspension polymerization (Fig. 12).

\subsection{Synthesis of sound responsive hydrogels (SORHs)}

Among different environmental stimuli, smart hydrogels are also responsive to sound or ultrasound. ${ }^{166,167}$ Ultrasound refers to the sound beyond the limit of human hearing and has applications in many fields such as cleaning, mixing, and imaging. ${ }^{168,169}$ Particularly in the biomedical field (e.g., drug release, cancer therapy), its applications with hydrogels are prevalent. ${ }^{167,170-175}$ Polymers or hydrogels can be activated and allowed to burst due to their interaction with ultrasound waves, thereby releasing drug loads into specific tissues (Fig. 13a).

SORHs exhibit a reversible de-crosslinking-crosslinking behavior when interacting with sound waves. In the presence of ultrasound, crosslinks break and, conversely, regenerate upon the withdrawal, thus rendering the self-healing ability to SORHs (Fig. 13b). This mechanism can be incorporated to release drugs in a controlled manner. ${ }^{170}$
The synthesis of SORHs varies with their application. For example, Zhang et al. ${ }^{177}$ developed a hydrogel composite with an MXene $\left(\mathrm{Ti}_{3} \mathrm{C}_{2} \mathrm{~T}_{x}\right)$, which was found to be successful in monitoring the phonatory process or sound of the human voice. MXene $\left(\mathrm{Ti}_{3} \mathrm{C}_{2} \mathrm{~T}_{x}\right)$ nanosheets with PVA, water, and antidehydration agents were combined to fabricate this hydrogel.

Kwok et al. ${ }^{178}$ synthesized a SORH to facilitate on-demand drug release. They developed a methylene chain within the drug insulin polymer to produce the final ultrasound responsive hydrogel. Crosslinked hydrogel slabs were made via copolymerization of the monomer HEMA, 2-hydroxyethyl acrylate (HEA), poly(ethylene glycol) dimethacrylate (PEGDMA), and insulin. PEG was incorporated to form large pores so that the hydrogel can retain large protein molecules like insulin. Then the methylene chains were developed over the PHEMA surface by processing it with C-12 isocyanate, dibutyltin dilaurate (catalyst), and anhydrous tetrahydrofuran. ${ }^{178,179}$ Exposure of ultrasound to this insulin drug-containing hydrogel showed successful sound controlled drug release. ${ }^{178}$ 


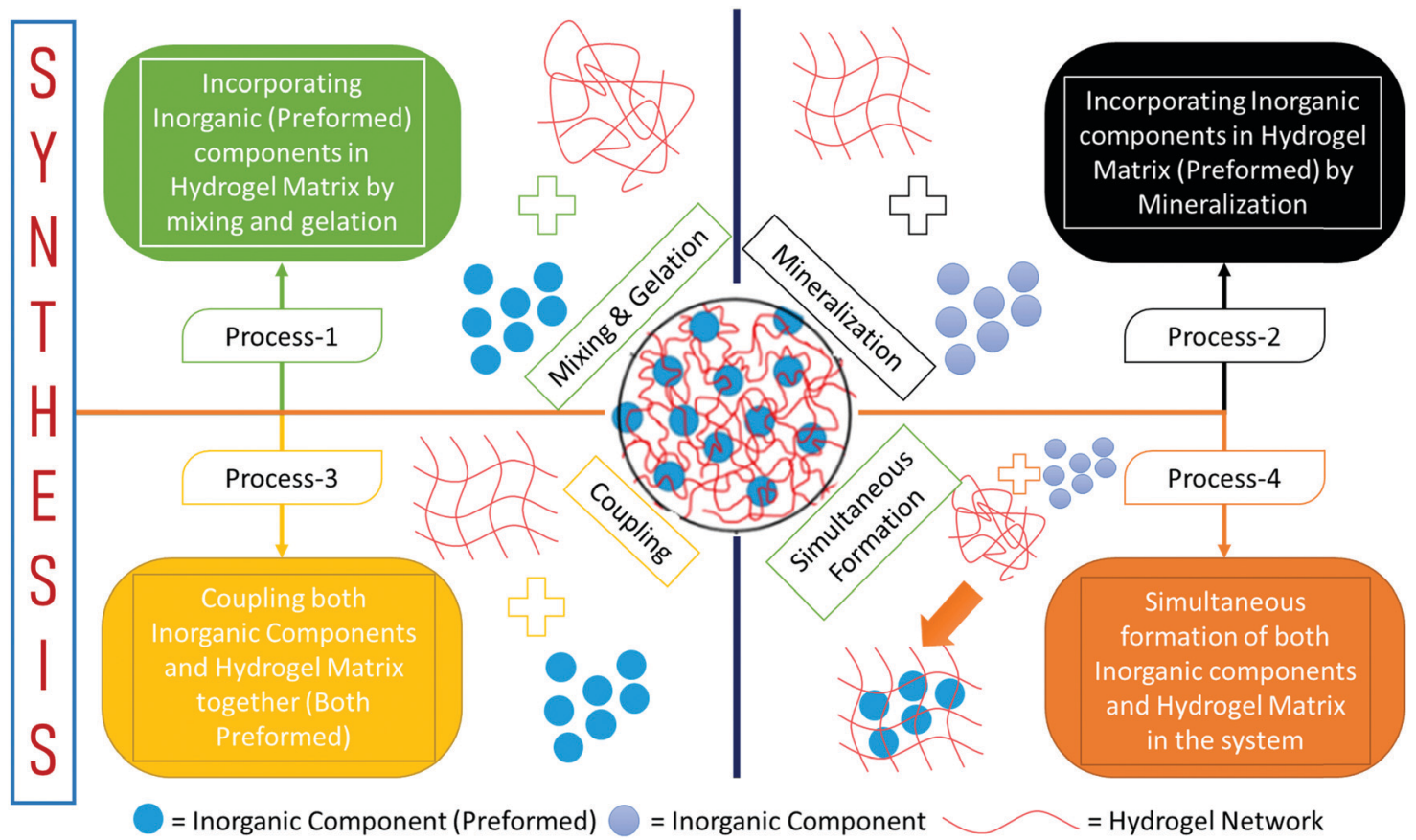

Fig. 12 Major synthesis processes of magnetic stimulus hydrogels with suspension polymerization (based on ref. 147 and 161-165).

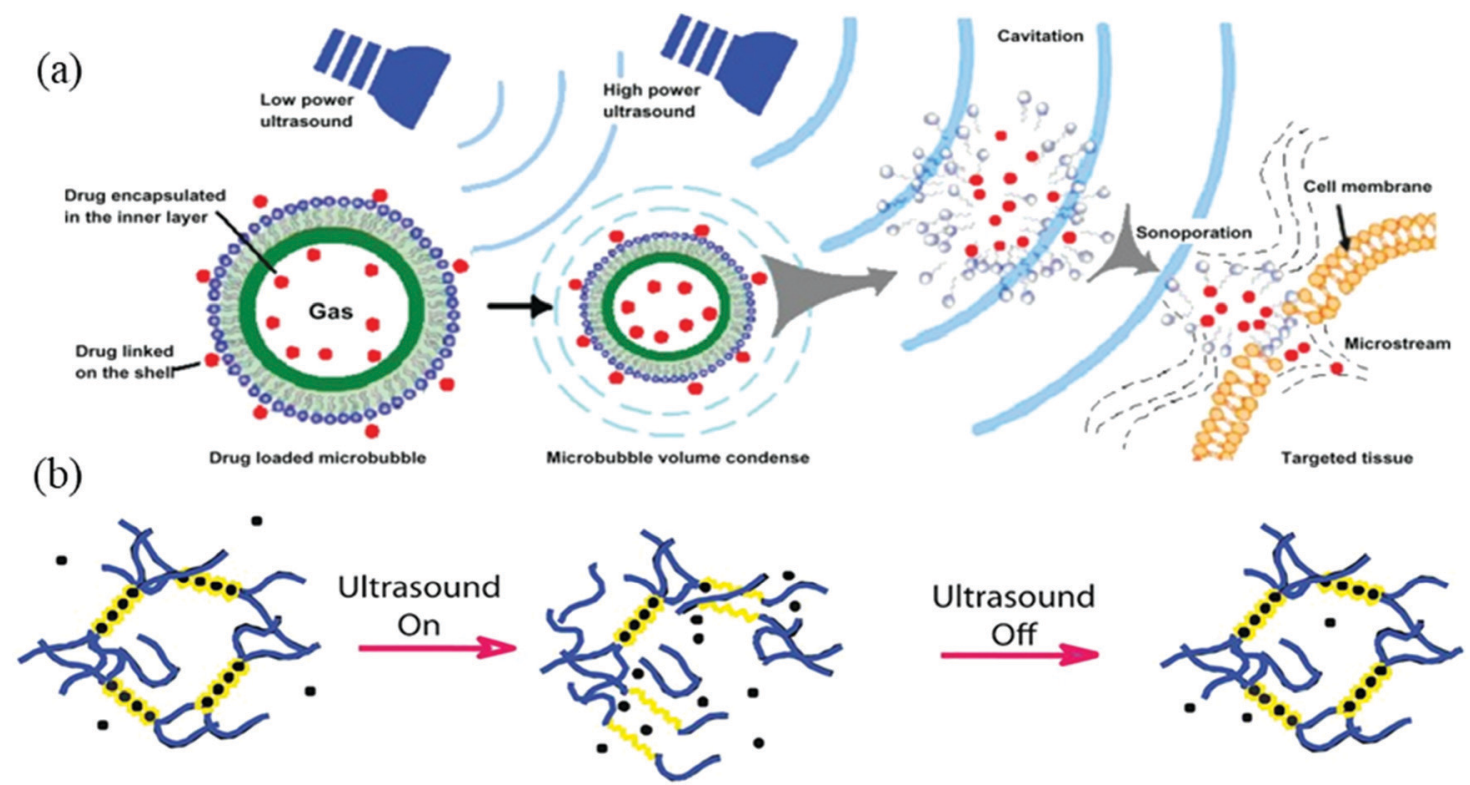

Fig. 13 (a) Schematic diagram of the working principle of low and high ultrasound on polymers for drug release [reprinted with permission from ref. 176, (C)Dovepress, 2013]. (b) Disruption and self-healing of an ultrasound responsive ionic cross-linked hydrogel [reprinted with permission from ref. 170, (C) PNAS, 2014].

\subsection{Synthesis of pressure responsive hydrogels (PRHs)}

The ability of hydrogels to detect the pressure exerted on them and exhibit various responses under various pressures is a novel characteristic. This behavior is apparent in super-elastic, cellular structured, and nanofibrous hydrogels, for example, hydrogels produced by the combination of alginate and flexible $\mathrm{SiO}_{2}$ nanofibers. Hydrogels with an ultrahigh water content (above 97\%) do not exhibit robust mechanical strength and significant recoverable deformation because of containing a high amount of water. These hydrogels are formed by assembling different polymer units, such as proteins, NPs, polysaccharides, polyelectrolytes, and so on, into 3D networks. Although they have a homogeneous distribution of networks, they tend to lose mechanical properties in a high watercontaining environment. In such a case, hydrogels of cellular fibrous networks can readily improve mechanical properties and exhibit a significant response when pressure is applied. ${ }^{180-184}$ 
Respective swelling/shrinkage and expansion/contraction are apparent upon the application of external pressure on hydrogels containing large mono-domains. A study reports the incorporation of a mechanical shearing technique for synthesizing half ester nanocrystallized cellulose (CNC). This includes UV-triggered polymerization of a monodomain anisotropic gel converted by shearing. When subjected to pressure between cross-polarizers, this hydrogel displays rapid and reversible color changes, accompanied by the degree of alignment observed as swelling. ${ }^{185,186}$

In another study, a $\mathrm{SiO}_{2}$ nanofibrous hydrogel was synthesized by incorporating four elements, namely, water, alginate, $\mathrm{SiO}_{2}$ nanofibers, and a metallic cation $\left(\mathrm{Al}^{3+}\right)$, by applying the sol-gel electrospinning technique. ${ }^{187}$ The pressure-responsive characteristics can be readily used for different advancements in the field of hydrogels such as flexible pressure sensors, tissue-engineered scaffolds within the range of pressure stimulus, drug delivery vehicles, artificial skin, and bio-actuators, to name a few. ${ }^{180}$

\subsection{Synthesis of pH-responsive hydrogels (pHRHs)}

pH-Responsive hydrogels are generally synthesized by utilizing polymers constructed using monomers containing ionizable pendant/functional groups of $-\mathrm{OH},-\mathrm{COOH},-\mathrm{NH}_{2},-\mathrm{CONH}_{2}$, $-\mathrm{N}<$, and $-\mathrm{SO}_{3} \mathrm{H}^{12,48,188,189}$ When such a hydrogel is exposed to a solvent (e.g., aqueous solution) of certain $\mathrm{pH}$ and ionic strength, its pendant/functional groups will get ionized with fixed charges and these charges will exhibit electrostatic repulsion, resulting in a reversible swelling-deswelling mechanism depending on the acidic or basic nature of the medium. ${ }^{48}$ The presence of anionic and cationic pendant groups in polymers influences $\mathrm{pH}$ depending on the swelling behavior of the hydrogels. Hydrogels with cationic pendant groups [e.g. CHT, poly $(N, N$-dimethylaminoethyl methacrylate) (PDMAEMA), and poly $(N, N$-diethylaminoethyl methacrylate) (PDEAEMA)] swell at $\mathrm{pH}<\mathrm{p} K_{\mathrm{a}}$ and deswell at $\mathrm{pH}>\mathrm{p} K_{\mathrm{a}}$ (Fig. 14a), whereas hydrogels with anionic pendant groups (e.g. albumin and PAAc) swell at $\mathrm{pH}>\mathrm{p} K_{\mathrm{a}}$ and

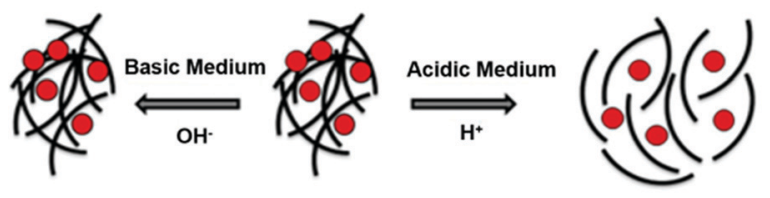

(a) Cationic $\mathrm{pH}$ responsive hydrogels
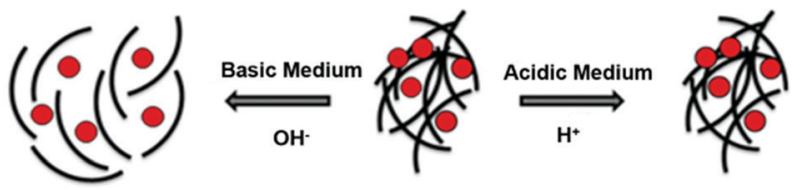

(b) Anionic $\mathrm{pH}$ responsive hydrogels

Fig. 14 The schematic representation of $\mathrm{pH}$-responsive hydrogels. (a) Cationic hydrogels swell at low pH and deswell at high $\mathrm{pH}$. (b) Anionic hydrogels swell at high $\mathrm{pH}$ and deswell at low $\mathrm{pH}$ [reprinted with permission from ref. 190, (C)2019 by the authors, open access under attribution 4.0 international (CC BY 4.0)].

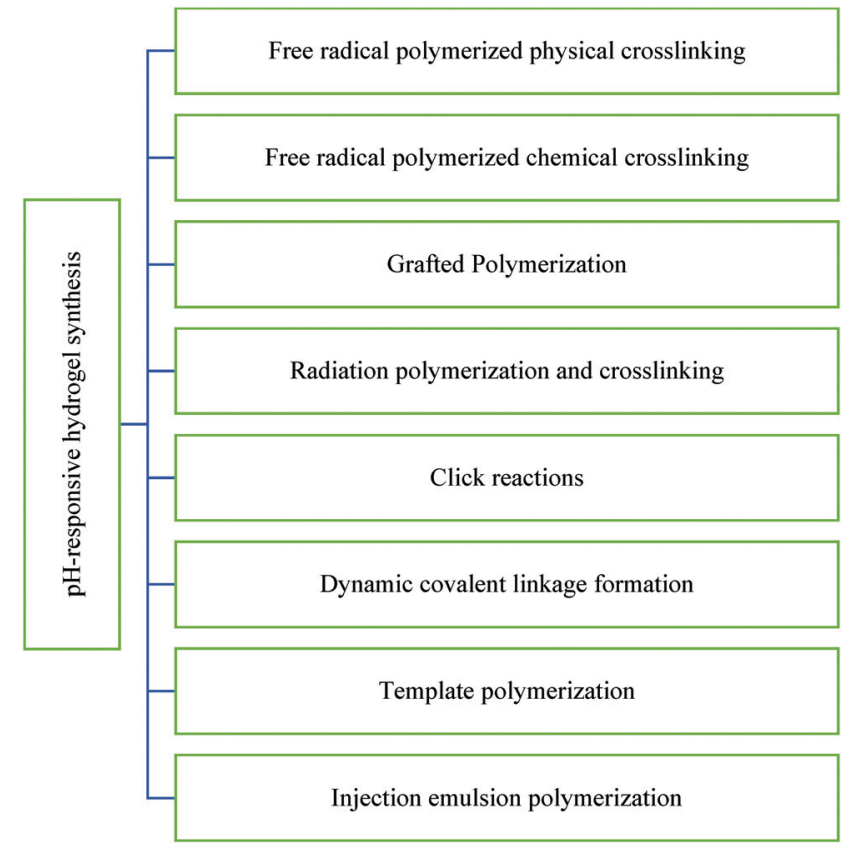

Fig. 15 Major approaches to synthesize $\mathrm{pH}$-responsive hydrogels (based on ref. 9, 188 and 193-200).

deswell at $\mathrm{pH}<\mathrm{p} K_{\mathrm{a}}$ (Fig. 14b). ${ }^{48,190,191}$ Both synthetic and natural polymers with ionizable functional groups can be utilized to synthesize hydrogels with pH-responsive behaviors. ${ }^{48}$ This pH-stimulated reversible shrinkage-expansion mechanism of hydrogels is utilized to deliver therapeutic drugs protectively. ${ }^{192}$

Numerous approaches can be adopted to synthesize $\mathrm{pH}$-responsive hydrogels such as free radical polymerized chemical crosslinking, ${ }^{188}$ free radical polymerized physical crosslinking, ${ }^{193}$ grafted polymerization, ${ }^{194}$ injection emulsion polymerization, ${ }^{9}$ radiation polymerization and crosslinking techniques, ${ }^{195}$ template polymerization, ${ }^{196}$ covalent linkages, ${ }^{197,198}$ click reactions, ${ }^{199}$ etc. The major advantage of these hydrogels is their capability to administer drugs (especially protein and peptide-based drugs) orally while protecting them through the gastrointestinal tract (Fig. 15). ${ }^{193}$

Hibbins et al. developed a novel drug delivering $\mathrm{pH}$-responsive hydro-porous hydrogel based on in situ free-radical copolymerization of the monomers AAm and methacrylic acid with MBAAm as the chemical crosslinking agent. ${ }^{188}$ Similar polymerization and crosslinking approaches were utilized by Shantha and Harding to fabricate pH-responsive hydrogels of $N$-vinylpyrrolidone (NVP), PEG diacrylate, and chitosan, where the $-\mathrm{NH}_{2}$ groups of chitosan were able to ionize in acidic medium ( $\mathrm{pH}$ 1.2). A combined process of graft polymerization and free radical polymerized chemical crosslinking was applied to synthesize dual responsive hydrogels (i.e. $\mathrm{pH}$ and temperature) by grafting cellulose nanowhiskers onto AAm (CNWs/AAm); afterward, CNWs/AAm was polymerized with NIPAAm in the presence of MBAAm crosslinkers to obtain the final hydrogels. ${ }^{194}$ Hydrogels based on the physical interactions of AAc and 2-(dimethylamino) ethyl methacrylate (DMAEMA) copolymers developed via free radical polymerization were also studied by Suhag et al. ${ }^{193}$ 
Hydrogels obtained through $\gamma$-irradiation initiated copolymerization and the crosslinking approach were reported to be more advantageous than those obtained via chemically initiated polymerization and crosslinking due to the exclusion of additives (i.e. initiators and crosslinkers). This approach produces sterilized hydrogels of non-carcinogenesis. Hydrogels of AAc and DMAEMA obtained via the radiation technique were reported and simulations were carried out in a buffer solution to study ketoprofen drug delivery in the colon. Most importantly, template polymerization can be performed to overcome the disadvantages of reduced bioactivity and inhomogeneity of chemically and physically crosslinked hydrogels, respectively. ${ }^{196} \mathrm{pH}$-responsive hydrogels via template polymerization of PAAc and DMAEMA can facilitate the immobilization of an enzyme (i.e. $\beta$-galactosidase). ${ }^{196}$

\subsection{Synthesis of redox responsive hydrogels (RRHs)}

SRHs have been developed with the ability to sense reactive oxygen species (ROS), which facilitate cell protection against oxidative stress. These SRHs, herein designated as RRHs, can sense and eliminate the ROS produced from cellular metabolism. ROS are highly reactive reagents and abundantly present in the human body. They play a significant role in cell signaling pathways but cause strong oxidative degradation to liquids, proteins, nucleic acids, etc. $^{201,202}$ As a result, excessive ROS generation disrupts body functions and is responsible for systemic diseases. ${ }^{203-208}$ When a redox-responsive hydrogel is mixed with an oxidant (e.g. NaClO), its viscosity reduces and a transition into a solution phase occurs; on the contrary, when a reductant (e.g. glutathione (GSH)) is added to this solution, its viscosity increases and gelation occurs. This concept is applied to mitigate the effect of ROS. A similar mechanism was also observed through electrochemicallyinduced redox reactions (Fig. 16). ${ }^{204,209}$

A synthesis process of such a redox responsive hydrogel includes the incorporation of redox-sensitive entities into a temperature-responsive environment during fabrication. A study reports that the functionalization of a copolymer fabricated by ring-opening polymerization can be done via a thiol-yne reaction to incorporate the redox-sensitive characteristic in the hydrogel. Under the stimuli of chemicals like $\mathrm{H}_{2} \mathrm{O}_{2}$, the resulting copolymer can show redox-sensitivity. ${ }^{204}$ The inclusion of redox-sensitive organo-metallic compounds can also be applied to synthesize RRHs. For example, Nakahata et al. developed a hydrogel based on host (PAAc/ $\beta$-CD)-guest (PAAc/FE) polymer chemistry by integrating redox-sensitive ferrocene (FE) with PAAc. ${ }^{209}$ According to another concept, disulphide linkage-based crosslinking is one of the popular approaches to fabricate redox-sensitive hydrogels based on thiol-disulphide exchange reactions. ${ }^{10}$

\subsection{Synthesis of glucose-responsive hydrogels (GRHs)}

Modern research into stimulus-responsive hydrogels has opened a new dimension towards advancements that were beyond imagination once. One of the most widespread and commercialized studies involves the synthesis of glucose-responsive hydrogels. These hydrogels can be very popularly used in advanced science such as selfmonitoring of blood glucose (SMBG) to regulate the blood glucose level of diabetic patients, ${ }^{210,211}$ and as effective insulin and
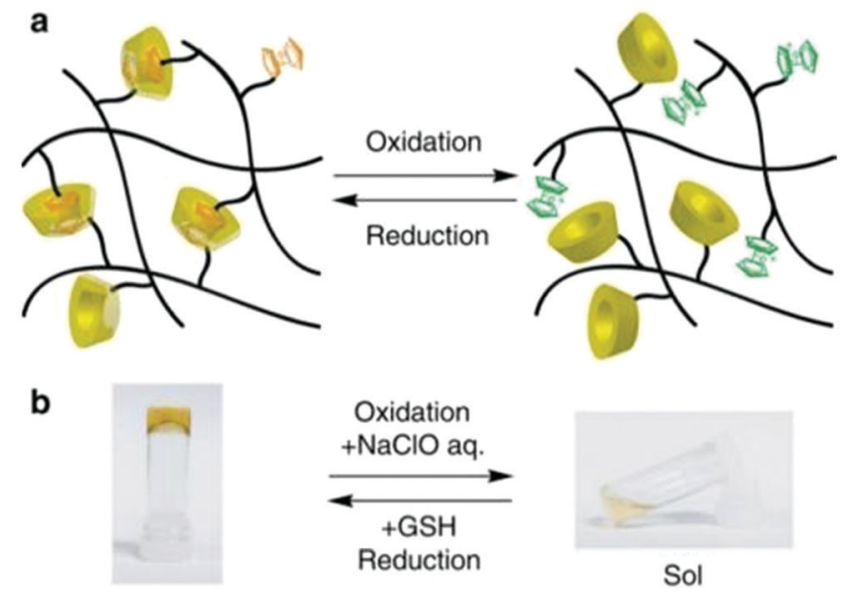

Gel

C
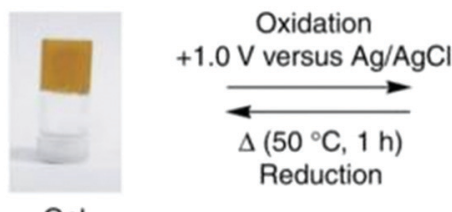

Gel

Fig. 16 Redox-responsive sol-gel transition. (a) Schematic illustration of sol-gel transition. (b) Sol-gel transition against chemical reagents $(\mathrm{NaClO}$ and glutathione). (c) Electrochemical oxidation (+1.0 V versus $\mathrm{Ag} / \mathrm{AgCl}$ ) and reduction induced sol-gel transition [reprinted with permission from ref. 209, (C) Springer Nature, 2011].

drug carriers. They can also be applied in the form of nanogels, microgels, micelles, vesicles, mesoporous NPs, etc. ${ }^{212}$ One of the popular synthetic methods is based on dynamic covalent linkages. A study shows that the PEO- $b$-PVP diblock polymer, $\alpha$-cyclodextrin $(\alpha-\mathrm{CD})$, and phenylboronic acid (PBA)-terminated PEO crosslinker can simply be mixed to form a hydrogel solution. While PVA and PBA together form the crosslinker required, the inclusion occurs between PEO and $\alpha$-CD. This reaction is responsible for both hydrogel formation and providing necessary stability. The hydrogel structure tends to dissolve in the presence of glucose and thus can be very effective to release loaded drug proteins in the intended environment (Fig. 17). ${ }^{213}$

In another study, free radical copolymerization has been employed for producing other GRHs. Preparing a stock solution of AAm and MBAAm in 4-(2-hydroxyethyl) piperazine-1-ethane sulfonic acid (HEPES) is the first step, followed by mixing $N$-(3-dimethyl aminopropyl acrylamide) (DMAPAAm) and $N, N, N^{\prime}, N^{\prime}$-tetramethylethylenediamine (TEMED) with the solution. Herein, 3-acrylamidophenylboronic acid (3-APB) acts as a free radical initiator. Free-radical crosslinking takes place in the solution and thus GRHs are produced. After confining the resulting hydrogel into a porous membrane, when a change in the concentration of glucose around it is brought, a transition is observed. The hydrogel senses the glucose stimulation through the porous structure. ${ }^{214,215}$

\subsection{Synthesis of $\mathrm{CO}_{2}$ responsive hydrogels $\left(\mathrm{CO}_{2} \mathrm{RHs}\right)$}

The surface properties of $\mathrm{CO}_{2}$-responsive hydrogels are controllable with the stimulation of $\mathrm{CO}_{2}$. In most cases, the modification 


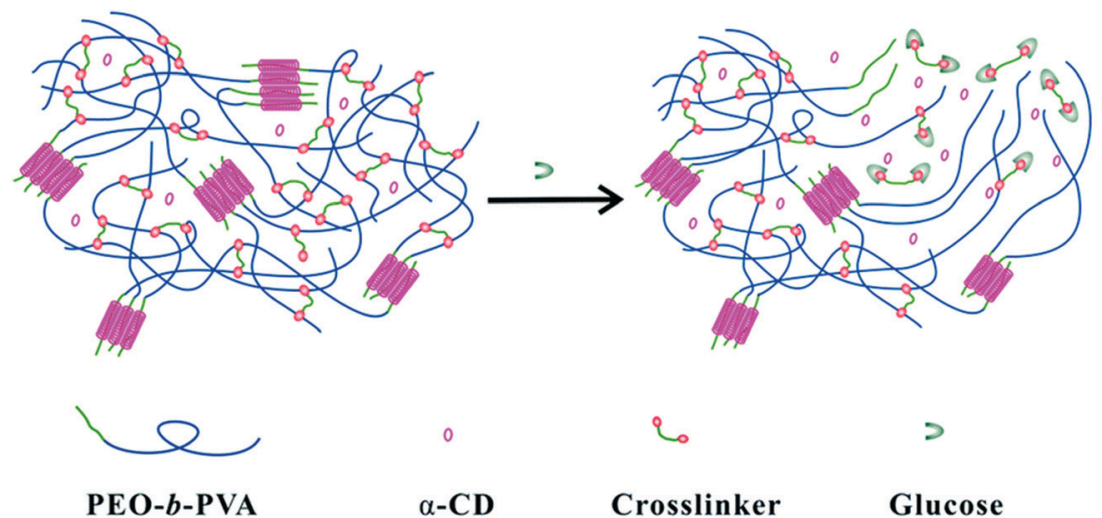

Fig. 17 Schematic illustration of the glucose response mechanism of the hydrogel formed with PEO- $b$-PVA, $\alpha$-CD, and a cross-linker [reprinted with permission from ref. 213, (C)The Royal Society of Chemistry, 2014].

comes in the form of a reversible switching technique. ${ }^{216}$ In oneway $\mathrm{CO}_{2}$ stimuli-responsive hydrogels can be prepared by crosslinking the gels with discrete metal-organic macrocycles (MOM) or metal-organo cages (MOC). This technique has added a new magnitude of versatility in the field of supramolecular selfassembled hydrogels.

In one study, a new family of star block copolymers (SBCP) prepared with $\mathrm{MOM}$ as the core show $\mathrm{CO}_{2}$ responsive behavior including $\mathrm{CO}_{2}$ triggered morphology transition, $\mathrm{CO}_{2}$ promoted hydrogel formation, and even $\mathrm{CO}_{2}$-induced thermo-responsive behavior. Moreover, the bubbling of $\mathrm{N}_{2}$ results in a hydrogel with a reverse sol-to-gel transition. ${ }^{217-226}$ Such $\mathrm{CO}_{2}$ responsive hydrogels have found applications in different sectors such as $\mathrm{CO}_{2}$ capture and monitoring, separation, encapsulation, and $\mathrm{CO}_{2}$ switchable vesicles. ${ }^{27-232}$ The reversible swellingdeswelling property in the presence of a green stimulus like $\mathrm{CO}_{2}$ is a topic of interest where external stimulation can be used to exhibit responsiveness (Fig. 18). ${ }^{233-238}$

In addition to $\mathrm{CO}_{2}$ responsive hydrogels, $\mathrm{CO}_{2}$-temperature dual stimuli-responsive hydrogels can be conveniently used in various circumstances and showed significant potential in targeted drug transport and controlled drug release. Lie et al. synthesized a $\mathrm{CO}_{2}$-temperature-responsive hydrogel from PDMAEMA with a $\beta$-CD via atom transfer radical polymerization (ATRP). This supramolecular triblock stimuli-responsive copolymer exhibits good biocompatibility with PNIPAAm and PDMAEMA hydrophilic segments and polycaprolactone (PCL) hydrophobic segments. The resultant triblock copolymer is responsive to carbon dioxide $\left(\mathrm{CO}_{2}\right)$ gas and temperature reversibly through self-assembly into cell vesicles. ${ }^{239}$

\subsection{Synthesis of enzyme responsive hydrogels (EZRHs)}

Since all the major changes occurring in living cells are because of enzymes, in the field of artificial materials enzymes are being used as a trigger to create biomimetic responsive materials. These include hydrogels that not only undergo structural changes but also interact with the environmental components upon exposure to different enzymes. ${ }^{36-40}$ To synthesize novel responsive polymers, enzyme and enzyme-catalyzed reactions have turned out to be potential triggering elements. ${ }^{38,240,241}$ Enzymes are biological substances that act as a natural trigger. Since enzymes are biomolecules, it is possible to release as per
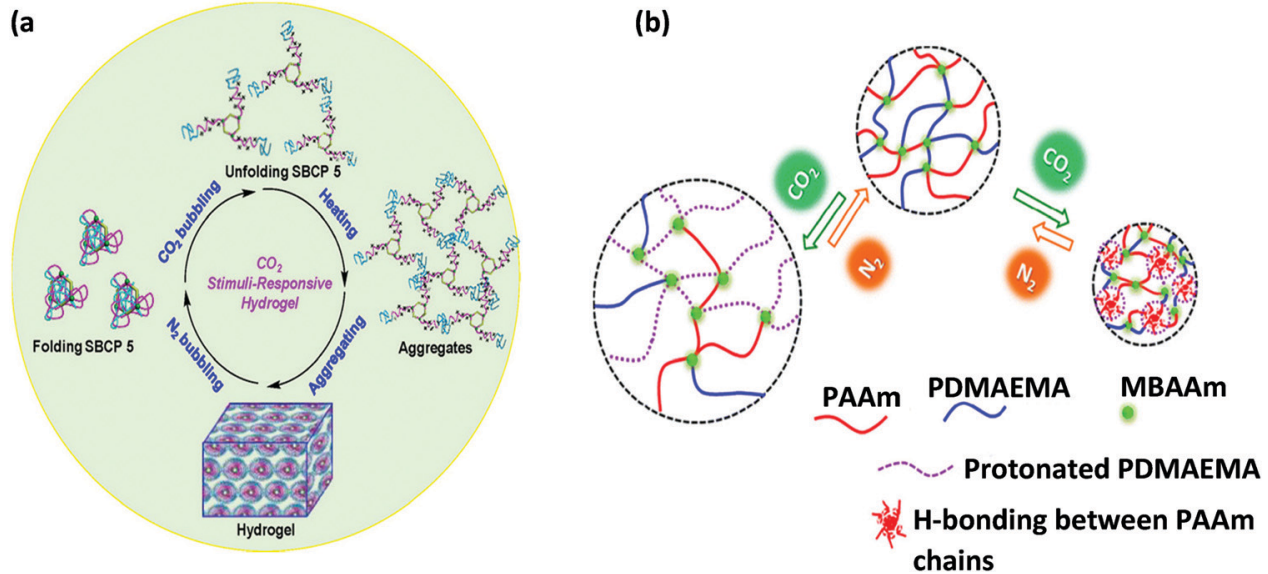

Fig. 18 (a) Schematic illustration of a $\mathrm{CO}_{2}$ responsive hydrogel of a star supramolecular block copolymer (SBCP) [reprinted with permission from ref. 217, (C)American Chemical Society, 2017]. (b) Schematic illustration of $\mathrm{CO}_{2}$ switchable swelling behaviors of P(AAm-CO-DMAEMA) hydrogels [reprinted with permission from ref. 233, CSpringer Nature, 2018]. 
requirement wherever necessary by controlling physical attributes and harmonizing the material response. ${ }^{242}$ Enzyme responsive hydrogels with low molecular weight gelators (LMWG) are recent developments in this field as the enzymatic process involves adaptation and reorganization of the gel surface. ${ }^{36,243}$

For the synthesis of EZRHs, one of the most popular techniques is the incorporation of an enzyme-catalyzed reaction. Here, an enzyme acts as a key biological catalyst capable of bringing about chemical or morphological changes within hydrogel cells. It can be used to obtain enzyme-mediated bio-responses, especially in the biomedical field. To synthesize such EZRHs, there are mainly three basic requirements. The hydrogel must contain embedded enzyme recognition elements like linkers. Next, the linkers must be accessible by the enzyme to ensure the enzymecatalyzed reaction. Finally, the enzyme linker reaction imparts physical or chemical changes, i.e. degradation or morphological transitions. $^{242,244,245}$

Another concept is that some hydrogels can release trapped biomaterials in the presence of an enzyme. This is possible due to the disintegration of hydrogel-forming polymer chains. Hydrogels with such characteristics can be synthesized in two ways: firstly, by a simple covalently cross-linked network of the normal polymer and secondly in the form of a supramolecular structure that takes place among multiple self-assembling molecules (hydrogelators). The hydrogelators interact to form nanofiber structures. The intermingling of these nanofiber structures is responsible for forming a hydrogel network in this way. ${ }^{243,246-248}$

The graphical illustration (Fig. 19) shows the action of the hydrogels in the presence of an enzyme. The hydrogel contains a linkage itself which links with the provided enzyme and brings about morphological changes in the hydrogel structure. This is applicable in both the intracellular cytoskeleton and extracellular matrices (ECM). This is an example of bio-simulation or bioactivation. ${ }^{243,249,250}$

Generally, the chemical synthesis process of a hydrogel includes covalent cross-linking among polymer chains. The formation of the hydrogel is done via two principal steps. Initially, the biodegradable component is dissolved into a liquid state. ${ }^{84,251,252}$ The physical hydrogel can be produced by ensuring physical interactions or cross-linking among biological components. As we know, some enzyme-responsive polymers typically contain enzyme reactive groups either in their main chain or as additional side groups. They exist in the form of labile linkages. These linkages cause modification and tuning of the transformation in the structure via different non-covalent interactions triggered by enzymes. ${ }^{84,241}$ Some of the physical networking processes are shown in Fig. 20.

Enzymes are specific in their actions and activated by hydrogel degradation. They are absorbed as biocatalysts to regulate the controlled release of drugs and biomolecules at desired locations. For a polymer to be enzyme responsive, some conditions must be met; for instance, an enzyme responsive substrate, a compound having a high influence on the kinetics of the enzyme-catalyst interaction. Finally, the enzyme-substrate reaction requires altering the material properties. ${ }^{254}$ Enzymatic action on the substrate as a consequence of the molecular interaction in terms of forming different chemical bonds such as hydrogen bonds, electrostatic interactions, van der Waals interactions, hydrophobic interactions, $\pi-\pi$ interactions, or any other combination of these bonds triggers the alteration of these surface properties (supramolecular architectures, self-assembly and swelling/shrinkage of hydrogels). ${ }^{255} \mathrm{~A}$ study shows the incorporation of urea and rhodamine 6G (RH6G) to formulate a urea-based hydrogel that demonstrates a typical sol-to-gel phase transition due to enzymatic hydrolysis in the presence of the enzyme $\beta$-galactosidase $\left(\beta\right.$-Gal). ${ }^{256}$ Another study reports a hydrogel formed of covalent cross-linking between the $\beta-(1 \rightarrow 4)$ linked D-glucose unit and chitin which can be incorporated for targeted medication release in response to 2 -acetamido-2-deoxy- $\beta$-D-glucose. ${ }^{84}$

\subsection{Synthesis of antigen responsive hydrogels (ARHs)}

Antigen responsive hydrogels exhibit a volume or mass transition in the presence of an antibody or its supplementary. Physical entrapment of the antigen in the hydrogel network, chemical conjugation of the antigen, and the utilization of the antibody-antigen pair as a reversible cross-linker are usually employed to fabricate them with great potential for application in biosensors. ${ }^{14,41}$

In the field of supramolecular hydrogels, it is possible to prepare an antigen-responsive structure. LMWG can be manipulated to exert self-assembly to construct supramolecular

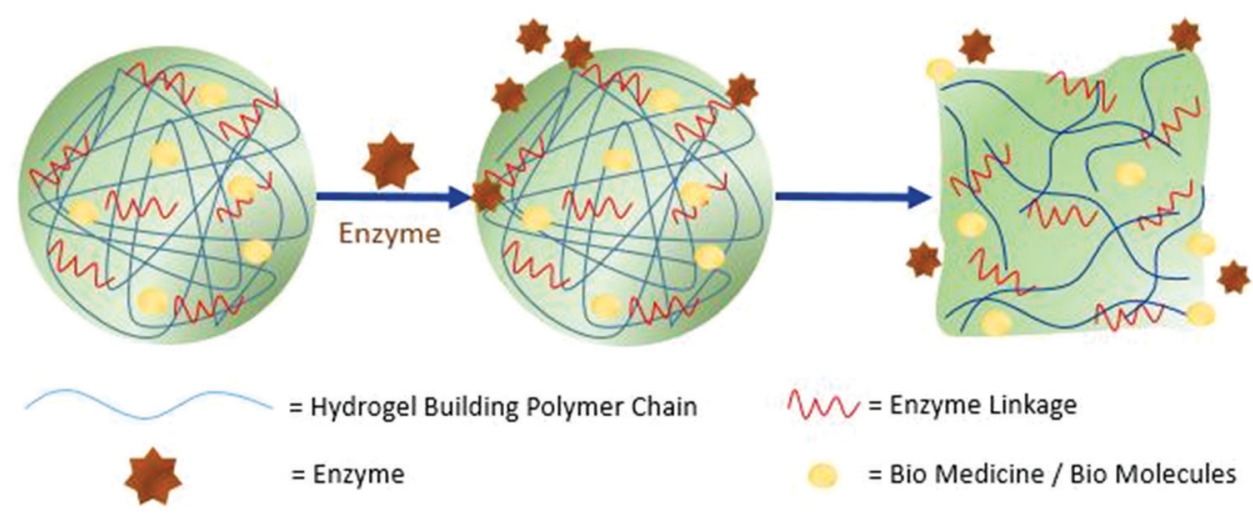

Fig. 19 Hydrogel responding to the enzyme and mechanism to release biomolecules [reproduced with permission from ref. 242, (CSAGE Publications, 2016]. 


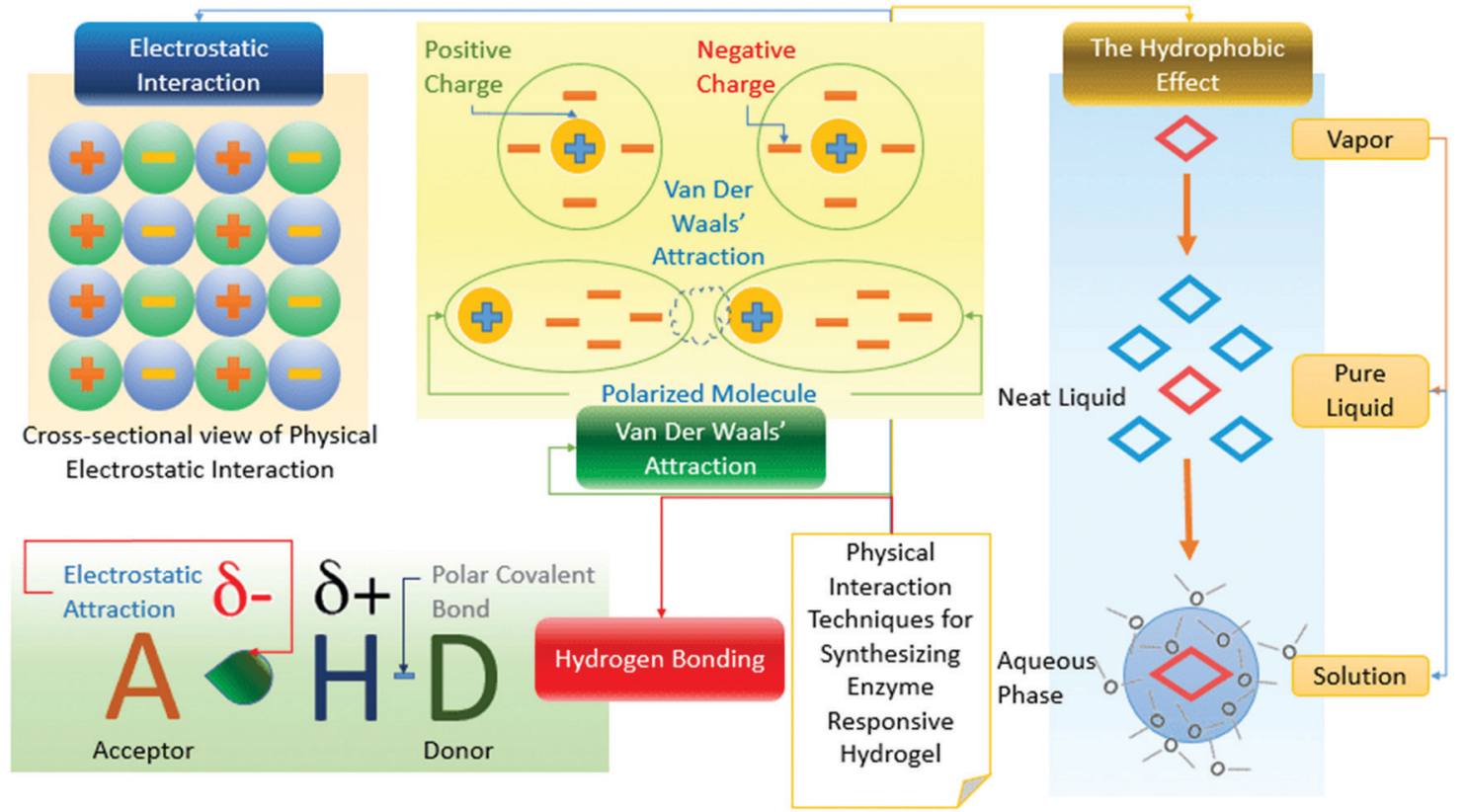

Fig. 20 Physical interaction processes for producing enzyme responsive hydrogels (based on ref. 84, 241 and 253).

hydrogels. The stability of a supramolecular hydrogel capsule in a cell culture medium allows it to further upgrade to an enzyme and a cell responsive hydrogel, which possesses an appropriate mechanism to release fluorescent drugs stimulated by prostate specific antigen (PS)-catalyzed proteolysis. It has good potential for application in the diagnosis of prostate cancer. ${ }^{15,257-260}$

A hydrogel-based smart membrane can be produced by grafting the dextran backbone in a fluorescein isothiocyanate (FITC) antigen and a sheep anti-FITC IgG antibody where the bio-specific interactions between IgG and FITC ensure additional stabilization of the structure. ${ }^{261} \mathrm{~A}$ recent study demonstrates the synthesis of a hydrogel from the copolymerization of IgG2a and NIPAAm through redox initiation and chemical crosslinking via MBAAm. ${ }^{14}$ Using a similar mechanism of change in their crosslinking density in response to target molecules, a target responsive hydrogel can be engineered. ${ }^{16}$ This novel hydrogel shows great potential for quantitative point-of-care testing with higher sensitivity and accuracy in detecting cocaine, ochratoxin A, and lead ions. The hydrogel was constructed as described in earlier studies ${ }^{262-264}$ with DNA grafted linear PAAm and cross-linking DNA for targeted recognition. The mechanism of this action is presented in Fig. 21 . The hydrogel was formed upon the hybridization of polymer strands and linker DNA (aptamer or DNAzyme). The hydrogel response to the target substance allows the release of the preloaded Pt NPs, which have good stability and excellent catalytic ability for decomposing $\mathrm{H}_{2} \mathrm{O}_{2}$ to $\mathrm{O}_{2}$. Then, the generated $\mathrm{O}_{2}$ in an enclosed environment leads to a significant pressure increase, which is rapidly traceable by a pressure meter (Table 2). ${ }^{265}$

The list of recently developed major stimuli-responsive hydrogels is given below.

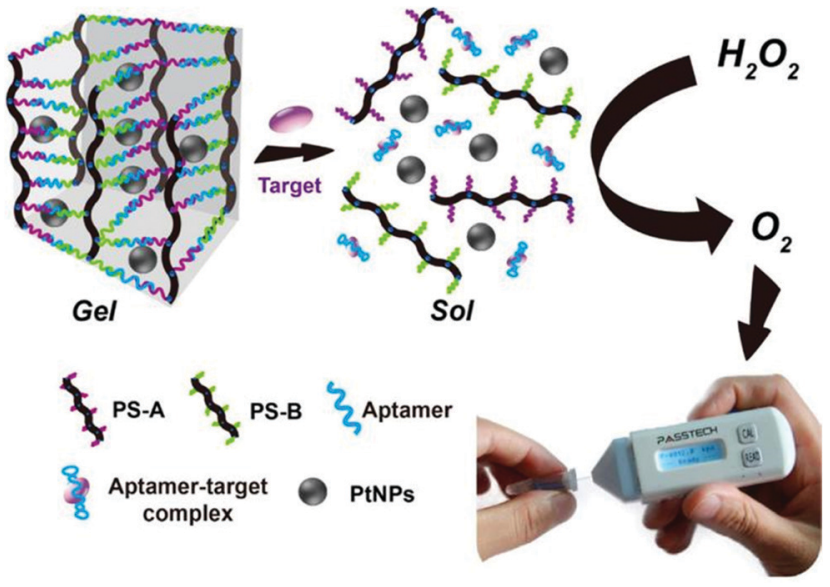

Fig. 21 Working principle of the target-responsive hydrogel pressurebased assay [reprinted with permission from ref. 265, (C)American Chemical Society, 2017].

\section{Synthesis of hydrogels for targeted applications}

Functional hydrogels are programmed by surface modifications that can partly endow hydrogels with desired properties while retaining the original intrinsic physicochemical properties of the hydrogel network. This surface functionalization is considered as an alternative strategy for the fabrication of multifunctional hydrogels for targeted applications. ${ }^{303,304}$ Functionalization of the surfaces of hydrogels can be done in three ways: the construction of a surface structure, physical incorporation of functional micro/ nanomaterials, and chemical grafting. . $^{127,305-313}$

The properties of hydrogels are easily tunable by modifying functional groups ${ }^{314}$ and incorporating functional materials. ${ }^{315-317}$ 


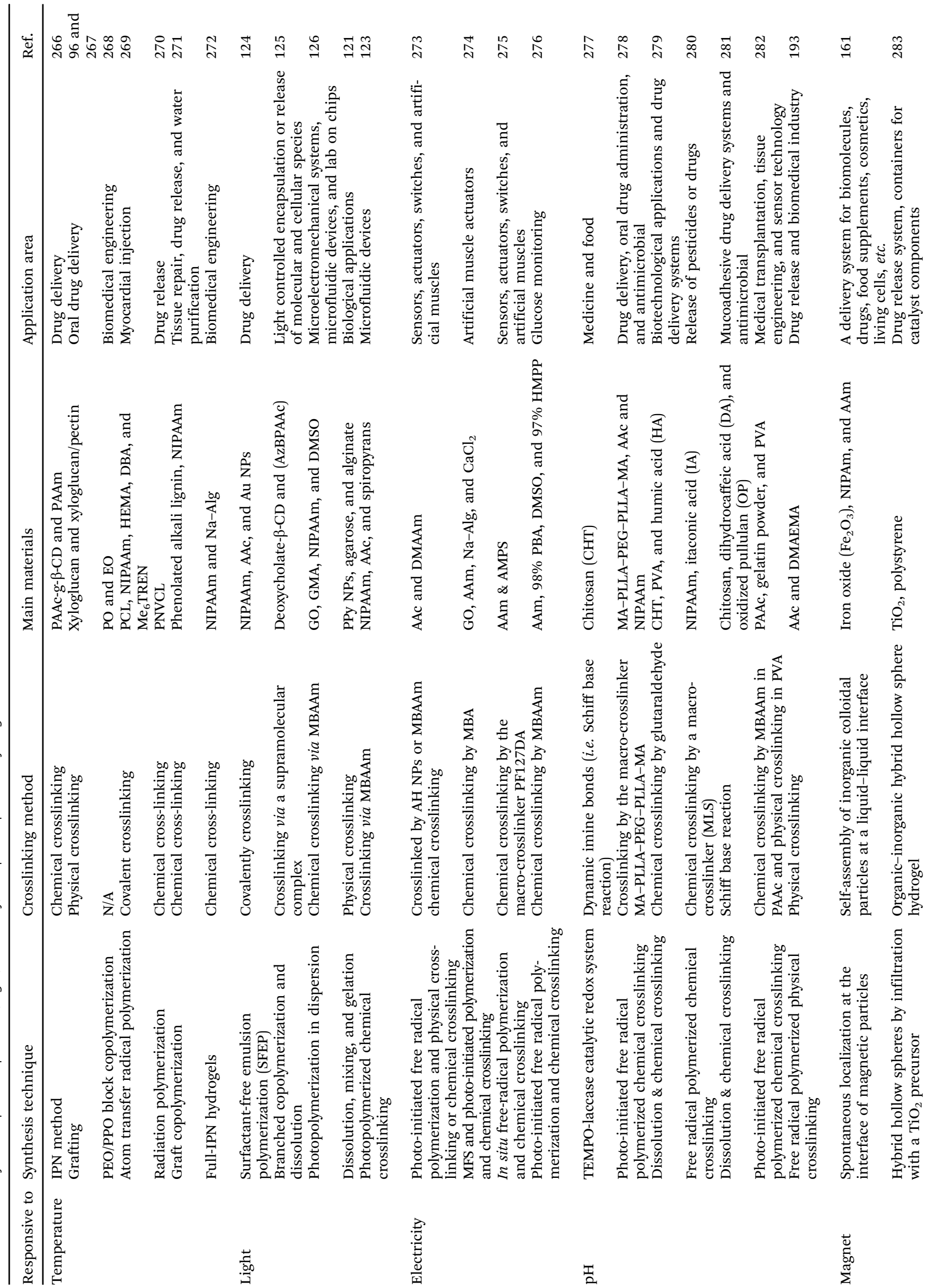




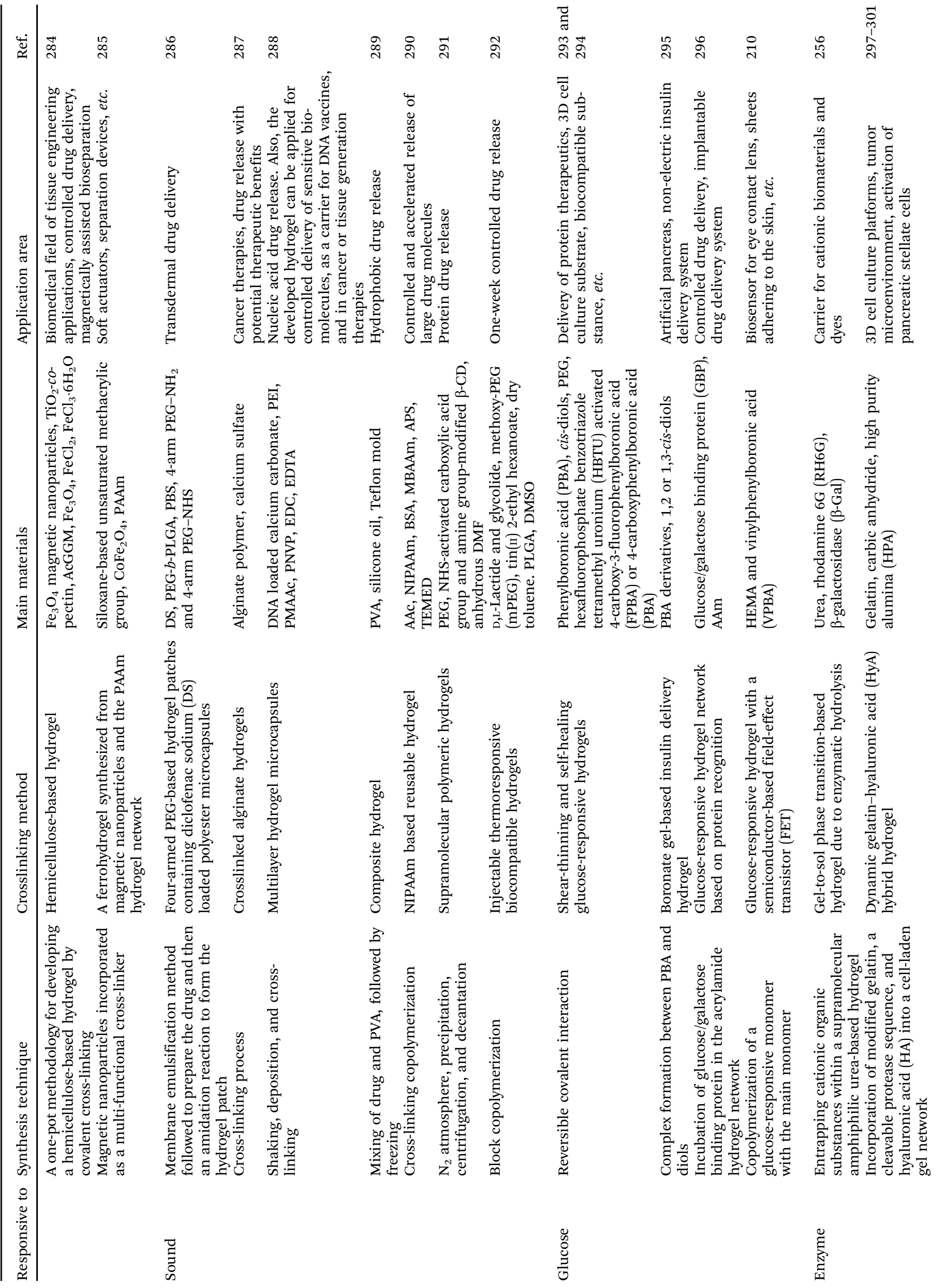




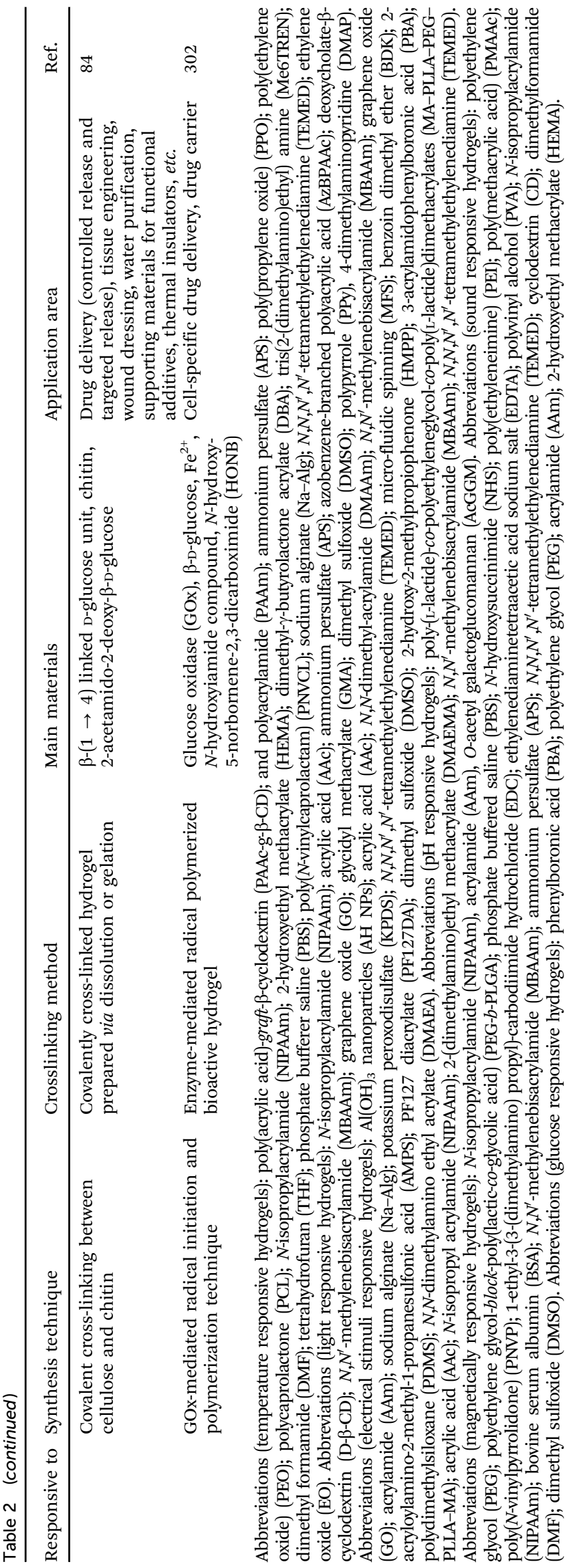

Thus, hydrogels that possess important features including selfhealing ${ }^{170,318}$ and extreme flexibility ${ }^{319-323}$ with superior mechanical properties ${ }^{324-326}$ and stretchability ${ }^{327,328}$ can be synthesized.

\subsection{Hydrogels for superior mechanical applications}

Hydrogels have immense applications in tissue engineering, wastewater treatment, wound healing, antimicrobial applications, ${ }^{329}$ and controlled drug release, but the lack of mechanical strength has limited their applications substantially. ${ }^{324,325}$ The bio-mimicking ability of hydrogels have made researchers explore the means of enhancing the mechanical properties of hydrogels. Since soft tissues such as tendons, ligaments, and other supporting tissues are tough materials, which are vulnerable to injury and incapable of regenerating spontaneously, materials with similar toughness and hydration properties could be a great choice for remodeling such injuries. ${ }^{326}$ To utilize hydrogels in mechanical strength demanding applications, increasing the toughness of hydrogels is a prerequisite. Many of the reported hydrogels are weak, brittle, and have low toughness, which somewhat limits their applications. ${ }^{330,331}$ Therefore, techniques of double networking, ${ }^{332}$ interpenetrated networking, ${ }^{329}$ triple networking, ${ }^{33}$ synergistic copolymerization effects, ${ }^{334}$ and nano-additive enforced networking ${ }^{325}$ have been employed to tune the mechanical properties of hydrogels. For instance, Yan et al. developed double networked hydrogels of PAAm and gelatin reinforced with GO nanosheets (gelating/PAAm/GO) (Fig. 22a). Due to the hydrophilic nature of GO, it functions as a multi-crosslinker with PAAm and can interact with gelatin via electrostatic and/or hydrogen bonding interactions, which significantly increases its elasticity, fracture stress/strain, and softening properties relative to the neat PAAm and gelatin/ PAAm hydrogels. The presence of GO made the hydrogel denser, resulting in the reduction of the swelling property. Additionally, the interactions between GO and gelatin caused the deterioration of self-recovery properties. ${ }^{332}$ A semi-interpenetrating networked hydrogel of BC and CHT (Fig. 22b) was developed by Wahid et al. The CHT part of the hydrogel was cross-linked by glutaraldehyde, while the BC part adhered via hydrogen bonding. The resulted hydrogel demonstrated better mechanical and thermal properties than the neat hydrogels of BC and CHT. The scanning electron microscopic image exhibited a dense network structure, which could be due to the enhanced entanglement of bacterial cellulose in cross-linked chitosan networks. ${ }^{329}$ Triple-networked (Fig. 22c) hydrogels of PVA, PVP, and PAAc-Zn ${ }^{2+}$ obtained via similar physical-chemical crosslinking techniques were developed by $\mathrm{Li}$ et al. Formation of hydrogen bonding between PVA and PVP chains along with chemical-crosslinking of PAAc resulted in triple-networked hydrogels with superior tensile and frictional properties to those of neat PVA and PVP/PVA hydrogels. $^{333}$ A combination of hydrophilic and hydrophobic polymeric segments can endow hydrogels with versatile properties. For example, hydrogel containing hydrophobic rich segments can provide hydrogel with stiffness and strength, whereas low hydrophilic segments can provide properties like stretchability and toughness. A mechanically enhanced copolymeric hydrogel fabricated from hydrophobic phenyl acrylate and hydrophilic AAm monomers was reported by Mredha et al. (Fig. 22c) 


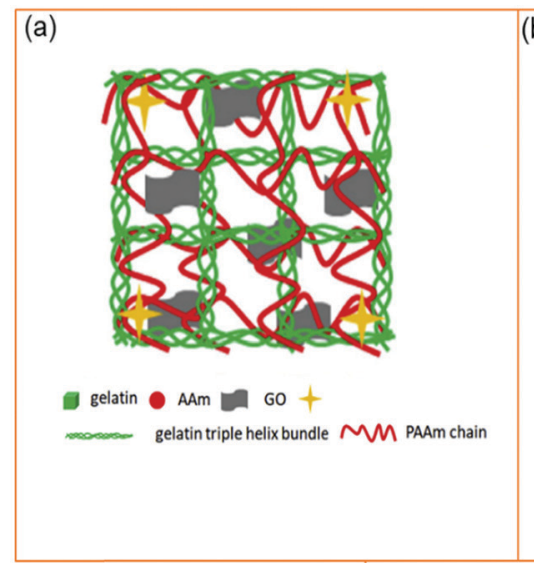

(d)
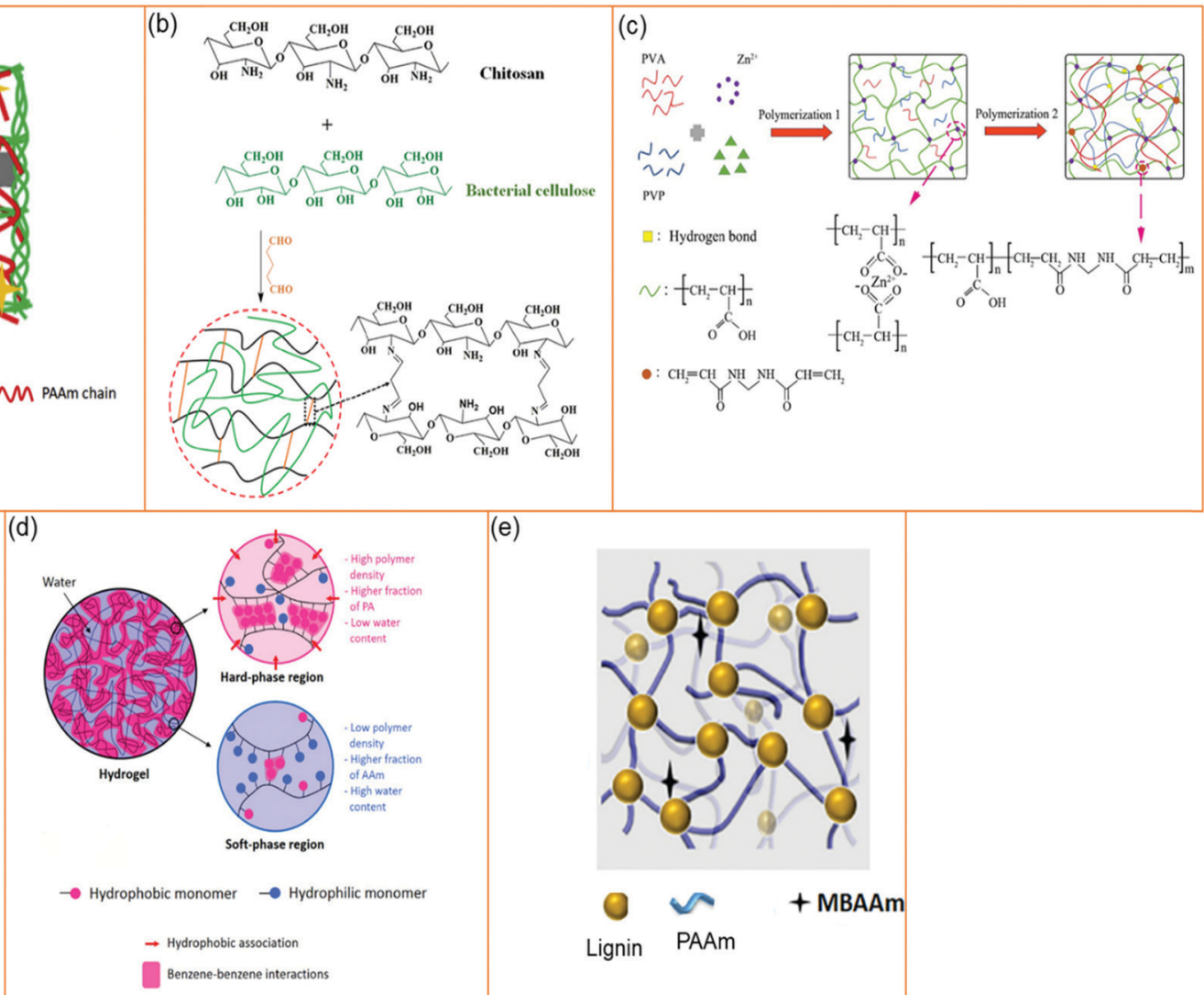

(e)

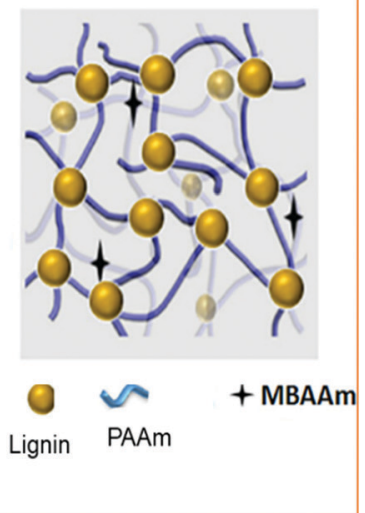

Fig. 22 Means of tuning the mechanical properties of hydrogels. (a) Double networking [reprinted with permission from ref. 332, (C)Elsevier, 2018]. (b) Interpenetrated networking [reprinted with permission from ref. 329, (C)Elsevier, 2019]. (b) Triple networking [reprinted with permission from ref. 333, (C)Elsevier, 2019]. (d) Synergistic effect of copolymers [reprinted with permission from ref. 334, (C)Elsevier, 2018]. (e) Nano-additive enforced networking [reprinted with permission from ref. 325, (c) Elsevier, 2019].

Formation of lower water content and higher phenyl acrylate containing hard regions with high water content and higher AAm containing soft regions was observed. ${ }^{334}$ The presence of nanomaterials within hydrogel networks can significantly enhance the mechanical properties of hydrogels. The hydrogels reported by Chen et al. incorporated lignin nanoparticles within PAAm hydrogel networks. Presence of the lignin nanocomposite endowed the hydrogels with better compressive stress enabling them to distribute the applied load efficiently. The improvement was mainly due to the presence of nanonetworks and hydrogen bonding between the hydrogel forming materials. ${ }^{325}$

To use hydrogels in loadbearing areas, researchers have developed numerous methods, such as chemical cross-linking, hydrogel networking (i.e. interpenetrating and double networking), and nano-additives, to improve their mechanical properties. ${ }^{324-326}$ Table 3 summarizes the synthesis methods/techniques, hydrogel types, process flow, test results, and applications of several hydrogels with superior mechanical properties.

\subsection{Hydrogels for antimicrobial applications}

Tailoring high-performance and multi-functional properties of hydrogels, especially natural polymer hydrogels, has drawn attention recently. ${ }^{339,340}$ Different types of techniques like double-network hydrogels, ${ }^{341}$ nanocomposite hydrogels, ${ }^{342}$ macromolecular microsphere composite hydrogels, ${ }^{343}$ polyampholyte hydrogels, etc. ${ }^{344,345}$ have been developed to impart functional properties. The produced hydrogels have the functional properties of high swelling in water, soft pliable nature, elastic properties, self-healing performance, and compatibility with human physiology. These improved properties have added a new dimension in the field of drug delivery, tissue engineering, food packaging products, cosmetics, and biomedical engineering. ${ }^{346-350}$ Many studies were performed to develop hydrogels as alternative materials for antibacterial applications. For example, the desired properties of hydrogels, such as hydrophilicity and porosity, can be integrated by selecting the types of monomers and crosslinkers. Moreover, some types of hydrogels also have inherent antibacterial properties. Based on the hydrogel matrices and antibacterial agents, antibacterial hydrogels are divided into (i) inorganic nanoparticle-containing hydrogels, (ii) antibacterial agentcontaining hydrogels, and (iii) hydrogels with inherent antibacterial capabilities. ${ }^{351,352}$ However, antimicrobial hydrogels can be synthesized in the ways mentioned in Fig. 23 .

Incorporation of metals is one of the most pristine and widely used techniques to functionalize antimicrobial properties, but with the recent development of nanoscience, the incorporation 
Table 3 Preparation of hydrogels with superior mechanical properties

\begin{tabular}{|c|c|c|c|c|c|}
\hline $\begin{array}{l}\text { Synthesis method/ } \\
\text { techniques }\end{array}$ & Hydrogel type & Cross-linking method & Main materials & Applications & \\
\hline Chemical cross-linking & $\begin{array}{l}\text { Cellulosic nanomaterials } \\
\text { (cellulose nanocrystals, } \\
\text { bacterial cellulose fibers, and } \\
\text { TEMPO-oxidized cellulose } \\
\text { nanofibers) dispersed } \\
\text { interpenetrating hydrogels }\end{array}$ & $\begin{array}{l}\text { Ionic cross-linked } \\
\text { networks }\end{array}$ & $\begin{array}{l}\text { PAAm, polyelectrolyte } \\
\text { Na-Alg }\end{array}$ & Wastewater treatment & \\
\hline Quinone & Nanofiber-reinforced gelatin & Chemical cross-linking & $\begin{array}{l}\text { Deacetaldehyde chitin } \\
\text { nano-fibrillated } \\
\text { suspension, DI water, } \\
\text { PTFE membrane }\end{array}$ & $\begin{array}{l}\text { Agricultural and biomedical } \\
\text { fields }\end{array}$ & \\
\hline Physical cross-linking & $\begin{array}{l}\text { RSF based double networked } \\
\text { hydrogels }\end{array}$ & RSF/SDS network & $\begin{array}{l}\text { AAm, Irgacure 2959, SDS, } \\
\text { NaCl, RSF, PTFE spacer }\end{array}$ & $\begin{array}{l}\text { Strain sensors, touch screen } \\
\text { pen, and the electronic skin } \\
\text { of artificial robots }\end{array}$ & \\
\hline Physical cross-linking & $\begin{array}{l}\text { The 3D-printed tough hydrogel } \\
\text { of MAAc and NPAM }\end{array}$ & $\begin{array}{l}\text { Hydrogen bonded } \\
\text { cross-linking }\end{array}$ & $\begin{array}{l}\text { DMSO, MAAc, NPAM, photo- } \\
\text { initiator IRGACURE } 2959\end{array}$ & $\begin{array}{l}\text { Soft robots, implant devices, } \\
\text { and tissue engineering }\end{array}$ & \\
\hline $\begin{array}{l}\text { Chemical-physical } \\
\text { crosslinking }\end{array}$ & $\begin{array}{l}\text { Silicon dioxide/PVA composite } \\
\text { hydrogels }\end{array}$ & $\begin{array}{l}\text { Injection molding of } \\
\text { the hydrolyzed solution }\end{array}$ & PVA, MTMS, HCl & $\begin{array}{l}\text { Artificial articular cartilage, } \\
\text { drug delivery, and } \\
\text { biosensors }\end{array}$ & \\
\hline Chemical cross-linking & $\begin{array}{l}\text { Hydrophobic and hydrophilic } \\
\text { monomer-based hydrogels }\end{array}$ & $\begin{array}{l}\text { MBAAm cross-linked } \\
\text { network }\end{array}$ & $\begin{array}{l}\text { Phenyl acrylate, AAm, } \\
\text { DMSO medium, MBAAm, } \\
\text { 2,2-azobisisobutyronitrile }\end{array}$ & $\begin{array}{l}\text { Diverse load-bearing } \\
\text { applications }\end{array}$ & \\
\hline $\begin{array}{l}\text { Chemical-physical } \\
\text { crosslinking }\end{array}$ & $\begin{array}{l}\text { Triple-network hydrogels of } \\
\text { PVP/PVA/PAAc }\end{array}$ & $\begin{array}{l}\text { MBAAm cross-linked } \\
\text { network }\end{array}$ & $\begin{array}{l}\text { PVP, PVA, AAc, MBAAm, } \\
\mathrm{ZnCl}_{2}\end{array}$ & $\begin{array}{l}\text { Engineering applications } \\
\text { with better mechanical } \\
\text { properties and lower friction } \\
\text { coefficients }\end{array}$ & \\
\hline Chemical cross-linking & $\begin{array}{l}\text { Non-swellable gradient } \\
\text { hydrogels }\end{array}$ & $\begin{array}{l}\text { HCL cross-linked } \\
\text { network }\end{array}$ & $\begin{array}{l}\text { Sodium pyrophosphate } \\
\text { dispersion, LAPONITE }{ }^{\circledR} \text {, } \\
\text { PAAm, HCL }\end{array}$ & Biomedical applications & \\
\hline
\end{tabular}

Abbreviations: $N, N^{\prime}$-methylene bis-acrylamide (MBAAm); sodium dodecyl sulfate (SDS); regenerated silk fibroin (RSF); methacrylic acid (MAAc); $N$ (pyridine-2-yl) acrylamide (NPAM); dimethyl sulfoxide (DMSO); bacterial cellulose (BC); methyltrimethoxysilane (MTMS); polyvinylpyrrolidone (PVP).

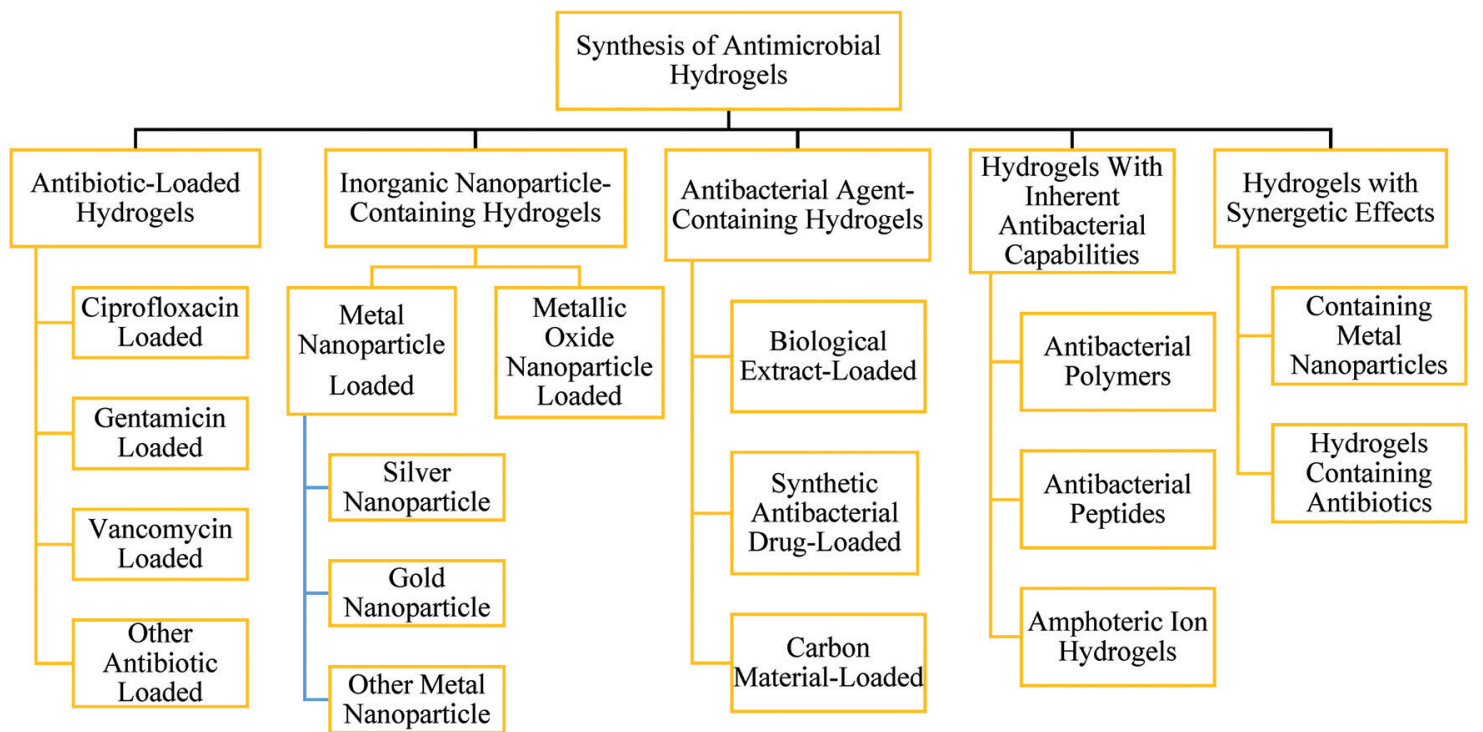

Fig. 23 Synthesis of antimicrobial hydrogels (based on ref. 351).

of metals, especially $\mathrm{Ag}$, $\mathrm{Au}, \mathrm{Cu}$, and $\mathrm{Zn}$, with hydrogels is done mainly in the form of NPs. ${ }^{351,353} \mathrm{Ag}$ is most widely used due to its good antibacterial properties and relatively low toxicity. However, other metals, such as gold, copper, and zinc, have their advantages 


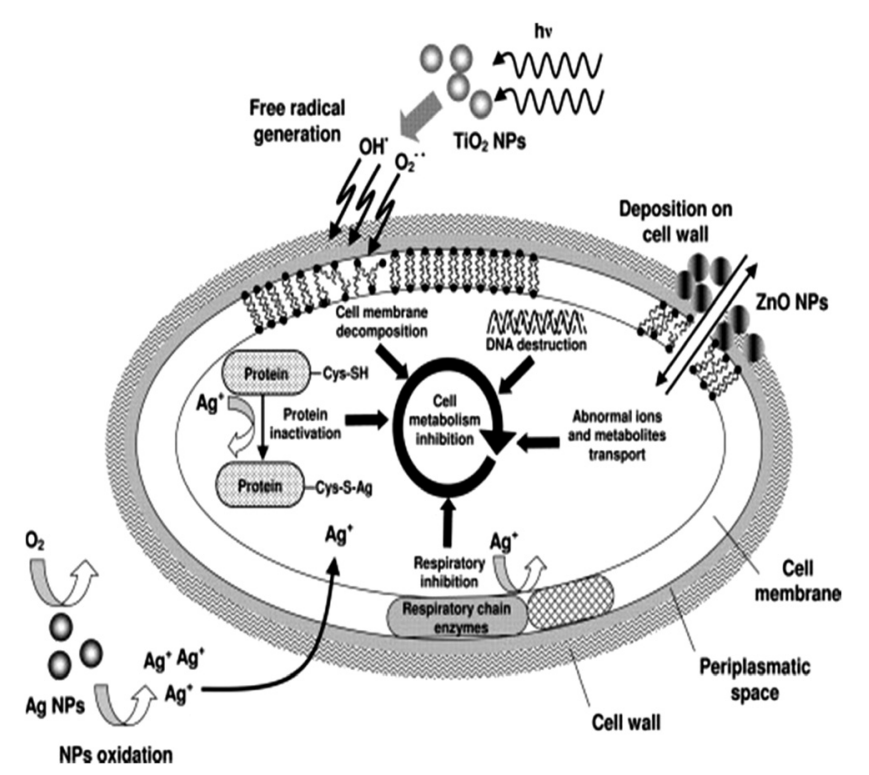

Fig. 24 Antibacterial mechanisms of metals and metal oxide NPs [reprinted with permission from ref. 354, (C)Elsevier, 2013].

and provides antibacterial properties as well. ${ }^{352}$ It is hypothesized that the interaction between silver ions $\left(\mathrm{Ag}^{+}\right)$and the thiol group in proteins of the bacterial cell membrane is responsible for affecting the bacterial cell viability by inhibiting the replication of DNA (Fig. 24). ${ }^{351}$

Both natural and synthetic polymers are used as the matrix of hydrogels containing Ag NPs. Polysaccharides, mainly alginate, chitin, CHT, and CMC, are common natural polymers. ${ }^{351}$ The antimicrobial action of $\mathrm{CHT}$ is more rapid against fungi and algae than toward bacteria. ${ }^{354-356}$ The resistance against microbes depends on several intrinsic factors such as the type of $\mathrm{CHT},{ }^{357}$ the degree of CHT polymerization, the host, the natural nutrient constituency, the chemical or nutrient composition of the substrates or both, and the environmental conditions (e.g., substrate water activity, moisture or both). ${ }^{358}$

Both chitin and CHT have antimicrobial and metal-binding properties. Chitin- or CHT-based hydrogels such as the CHT/ 2-glycerophosphate/nano-silver hydrogel and silver molybdate nanoparticle/chitin matrix $\left(\mathrm{Ag}_{2} \mathrm{Mo}_{2} \mathrm{O}_{7} /\right.$ chitin $)$ hydrogels are resistant to $E$. coli. ${ }^{359,360}$ The other polysaccharide hydrogels include the iota-carrageenan-based Ag NP hydrogel and the Ag NP-loaded PVA/gum acacia hydrogel; both actively show good antibacterial activity against the Gram-negative bacterium E. coli. ${ }^{361,362}$ The recent developments of antibacterial hydrogels incorporating metal particles and their oxides are summarized in Table 4.

\subsection{Hydrogels for cell adhesive applications}

The structure of hydrogels is analogous to that of biological soft tissues which have excellent potential to be used as scaffolds for cell growth and proliferation. ${ }^{380,381}$ A magnetic PAAm hydrogel synthesized by integrating magnetic nanoparticles into gelatin can act as a cell adhesive hydrogel interface. Furthermore, this gel can act as a multi-array cell culture matrix. The order, degree, and distribution of cell adhesives, as well as cell-cell and cell-matrix interactions throughout the multilayer matrix, determine the cell behavior including emulating the extracellular matrix (ECM). It is possible to induce a different form of hepatocyte 3D spheroids and thus transition by controlling cell adhesion affecting the cell behavior. A magnetic anisotropic hydrogel structure can be formed using $\mathrm{Fe}_{3} \mathrm{O}_{4}$ MNPs, AAm monomers, MBAAm, and tetraethyl ethylenediamine all mixed in water. The solution is subjected to ultrasonic agitation in a polytetrafluoroethylene (PTFE) module. PAAm gelation is induced by heating (approx. at $50{ }^{\circ} \mathrm{C}$ ) after the exposure of the resulting solution to a magnetostatic field for a certain time. This hydrogel with a superior cell adhesive functionality is thought to hold great potential for anticancer drug and hypothermia therapy. ${ }^{382-385}$ A peptide modified PEG scaffold is a cell-adhesive hydrogel scaffold that can act as a vessel for human blood-driven endothelial progenitor cells (EPC). It is a potential cell source for applications like vascular tissue engineering. A mild photocrosslinking process is used to encapsulate the EPC within a PEG-based hydrogel. After cell culture and network formation to prepare EPC, a solution is formed by reacting the cell adhesive peptide ligand, arginyl glycyl aspartic acid (RGDS), with acrylate-PEG-succinimidyl valerate (Acryl-PEG-SVA) to provide purified RGDS conjugated PEG (PEG-RGDS). ${ }^{18}$ A matrix metalloproteinase (MMP) sensitive peptide sequence (PQ) was also reacted with Acryl-PEG-SVA to give the Acryl-PEG-PQ-PEG-Acryl (PEG-PQ) conjugate. A solution of both PEG-PQ and PEG-RGDS was formed by dissolving both into PBS. Later, the hydrogel was formed by exposure to white light (Fig. 25a). ${ }^{386,387}$

A polydopamine-polyacrylamide (PDA-PAAm) single network hydrogel with super-stretchability, high toughness, cell affinity, and tissue adhesiveness properties was synthesized. The PDAPAAm hydrogel was prepared in the following two steps. In the first step, PDA was prepared by oxidizing dopamine (DA) under alkali conditions. In the second step, AAm was polymerized and crosslinked to form PDA-PAAm hydrogels (Fig. 25b). ${ }^{388}$

An alginate-based cell adhesive bio-hydrogel (AdhHG) is an important potential discovery in the field of biomedical engineering. Such hydrogels are capable of encapsulating and delivering mesenchymal stem cells (MSC) to the desired location and thus contribute to tissue engineering and regenerative medicine. Cell adhesion plays an important role in both cell regeneration and sealing tissue or coating implants in the desired location. L-DOPA amino acid (DA) modified alginate hydrogels show strong adhesion to cells. First, a methacrylate alginate hydrogel is synthesized by polymerization of the methacryloyl group in the alginate chain. DA hydrochloride is integrated to induce the crosslinking ability. The adhesive property is further improved by reacting with collagen emulating short peptides to form AdhHG. Crosslinking is carried out in the $\mathrm{Ca}^{2+}$ medium. Finally, the hydrogel is formed by photopolarization through exposure to blue-green light. ${ }^{389-392}$ Similarly, a novel peptide-based hydrogel containing cell adhesion and cell proliferation properties is expected to show inherent antibacterial characteristics and act as a potential scaffold for cutaneous wound healing. The hydrogel is synthesized from a series of peptides, Poly (Lys) $)_{x}(\mathrm{Ala})_{y}$. These are derived from ring-opening polymerization of 
Table 4 Information on hydrogels with different metal NPs

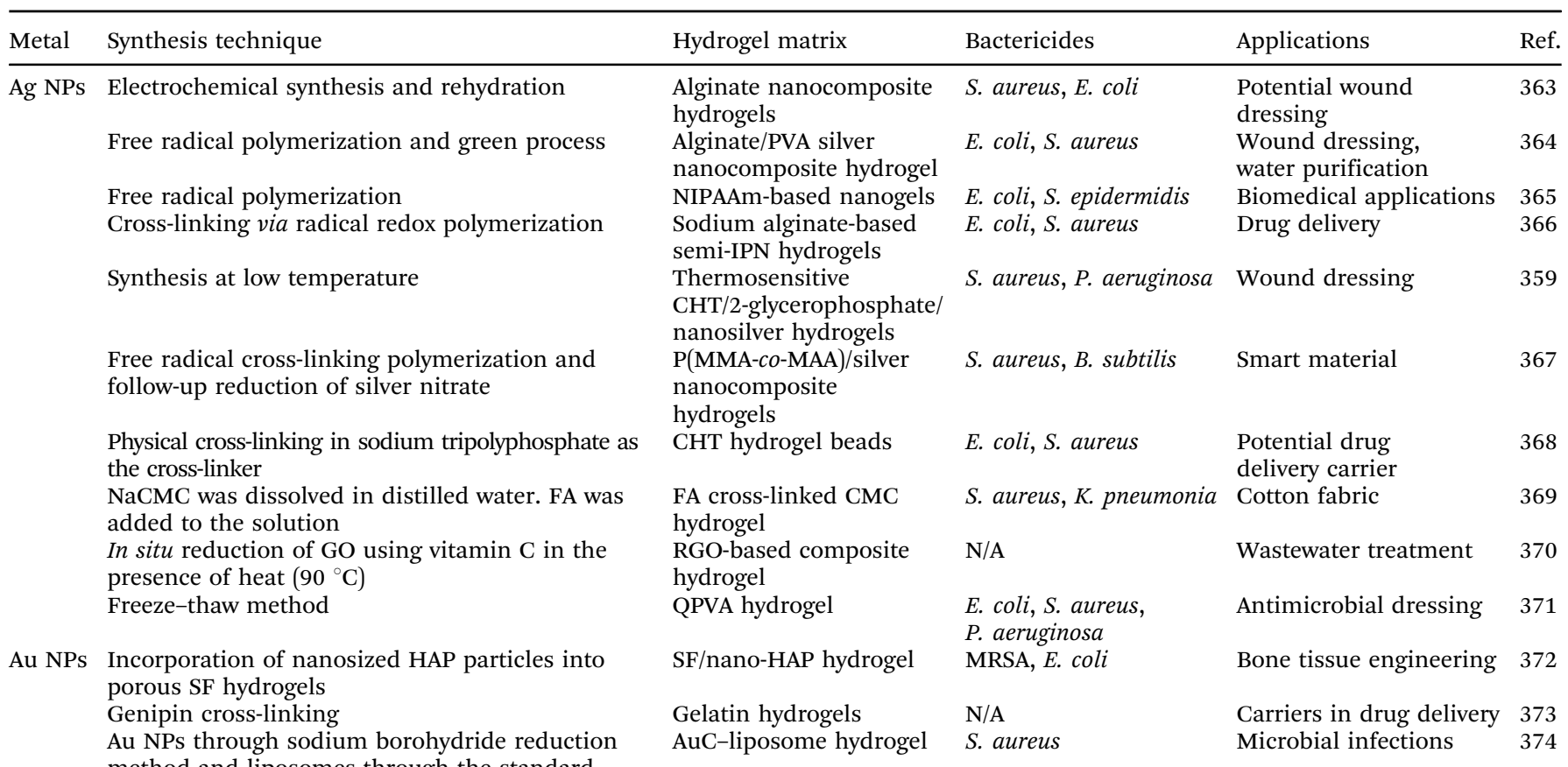

method and liposomes through the standard extrusion method
ZnO The hydrogel was made from ZnO NWs and the combination of CHT and AAc. ZnO NWs were prepared by a hydrothermal strategy using zinc acetate

CHT-based composite $\quad$ E. coli, S. aureus hydrogel

Ni NPs Nickel NPs prepared by a hydrothermal method $\mathrm{MgO} \quad \mathrm{KC}$ was blended with Na-CMC dissolved in distilled water
Alginate hydrogel

AG with IPN structure

CMCh hydrogel

Ni NP chitin nanogels

CHT-co-AAc hydrogels were prepared by free-radical graft polymerization

CHT pellet was mixed with alginate solution as a freeze-dry process

ZnO-PEGMA and AG-N3 IPN nanocomposite hydrogels were synthesized under UV irradiation CMCh solution cross-linked with Modified $\kappa \mathrm{C}$ hydrogel epichlorohydrin at $80{ }^{\circ} \mathrm{C}$
C. albicans, MRSA

Gram-positive and
Gram-negative bacteria
Gram-positive and
Gram-negative
bactericides
S. aureus
N/A

Biomaterials, cosmetics, 354 food packaging
Abbreviations: FA, fumaric acid; GA, gum acacia; HEMA-2, hydroxyethyl methacrylate; IPN, interpenetrating polymer network; MRSA, methicillinresistant $S$. aureus; PBS, phosphate buffered saline; PMAAc, poly(methacrylic acid); QPVA, quaternized polyvinyl alcohol; RGO, reduced graphene oxide; NW, nanowires; AAc, acrylic acid; SF, silk fibroin; CMCh, carboxymethyl chitosan; $\kappa \mathrm{C}$, $\kappa$-carrageenan; PEGMA, poly(ethylene glycol) methyl ether methacrylate; Ni NPs, nickel nanoparticles; AG-N3, 4-azidobenzoic agarose; NaCMC, CMC sodium salt; HAP, hydroxyapatite.
$N$-carboxylic anhydride (NCA), i.e. NCA-Lys and NCA-Ala monomers. PEG-amide succinimidyl glutarate (ASG) is chemically cross-linked with peptides to form a hydrogel exhibiting cell adhesion properties. Wound dressings containing such hydrogels provide not only resistance against infections but also a suitable physiological environment for cell generation. ${ }^{393-396}$

Another general cell adhesive hydrogel synthesis process starts with prepolymer solutions and several cross-linking methods including chemical, enzymatic, or photoreactions (Fig. 26A). For a successful tissue engineering process, an additional method is also required including tailoring biomechanical properties, tailoring degradability, tailoring bioactivity, and finally cell culture. Biomechanical properties can be improved by increasing the polymer concentration and by changing the architecture like linear, branched, etc. (Fig. 26B). The degradation properties of hydrogels can be controlled by the integration of crosslinkers in polymer networks. For instance, the incorporation of a matrix metalloproteinase sensitive peptide sequence in hydrogels makes them prone to cell-mediated degradation (Fig. 26C). The bioactivity, another important property for cell adhesion and proliferation, of hydrogels can be improved by binding bioactive compounds with hydrogels (Fig. 26D). ${ }^{397}$ For example, a collagen-binding peptide is incorporated in an alginate hydrogel. ${ }^{398}$

\subsection{Hydrogels for self-healing applications}

Self-healing is the capability of materials to recover from their damage themselves. Self-healing materials are considered as the next-generation materials for high-performance structures. 
a.
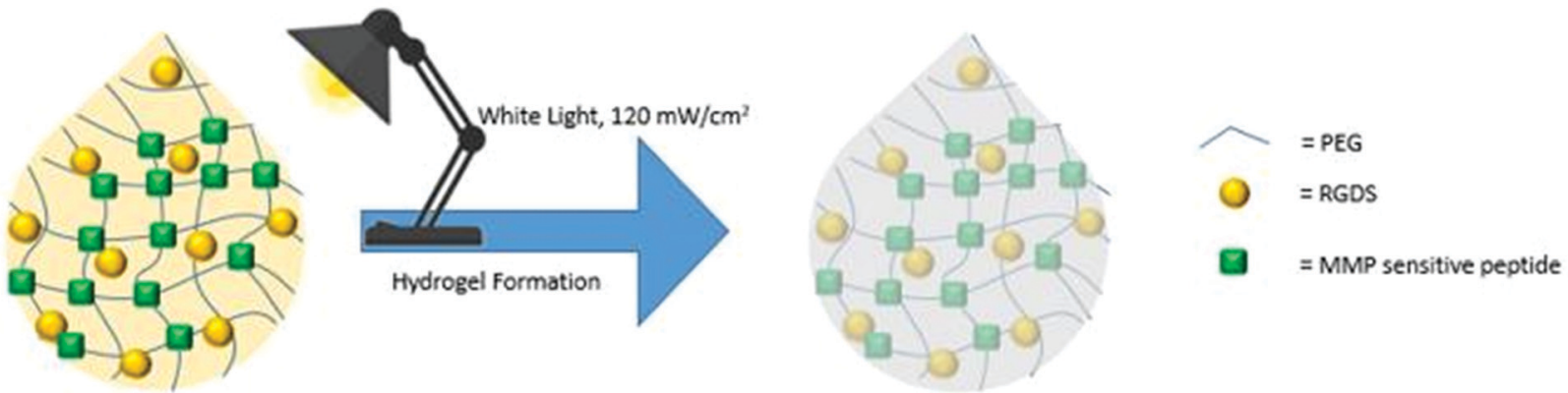

Step 1

b.
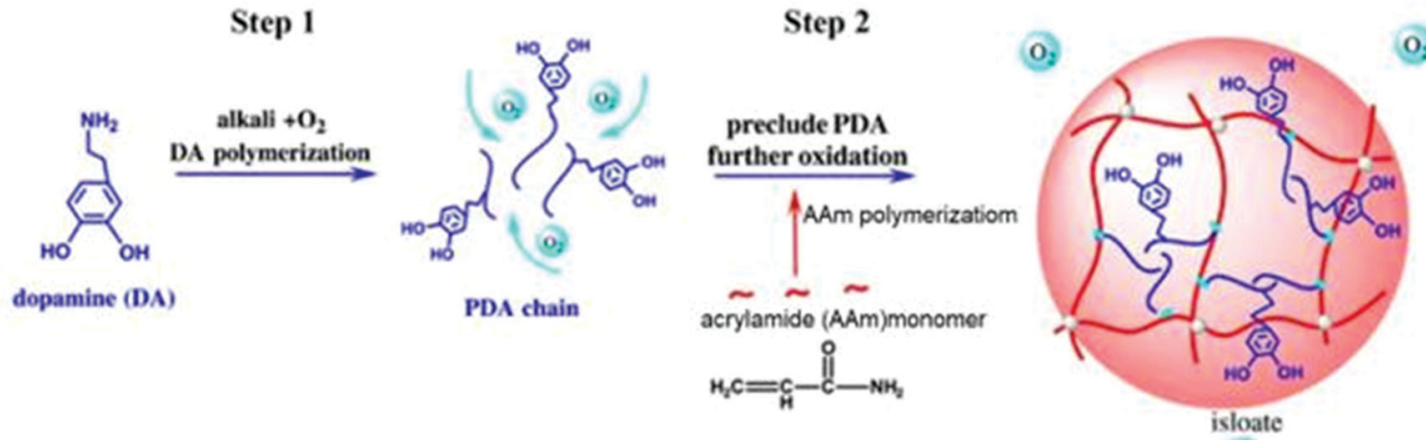

$\mathrm{O}_{2}$

PDA-PAAm hydrogel

Fig. 25 (a) Schematic diagram of hydrogel synthesis from the PEG-RGDS and PEG-PQ solution [reprinted with permission from ref. 386, (C)Springer Nature, 2015]. (b) Synthesis of PDA-PAAm hydrogels [reprinted with permission from ref. 388, (C) Springer Nature, 2017].
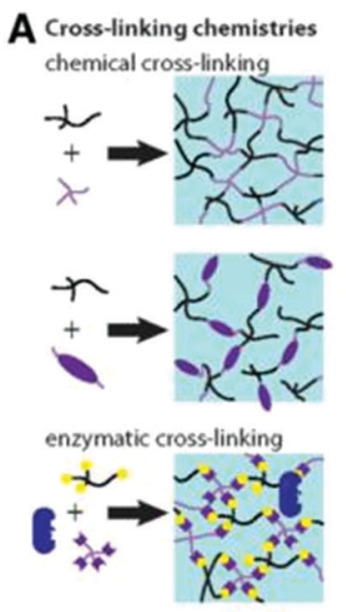

photo cross-linking
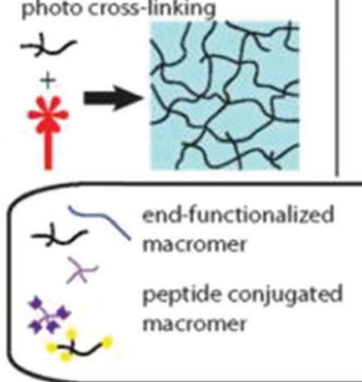

B Tailoring biomechanical properties

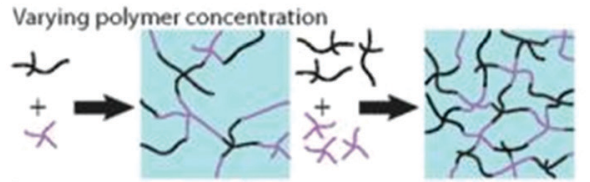

Varying macromer architecture

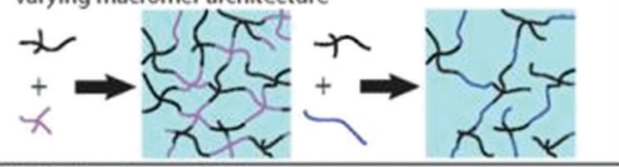

CTailoring degradability

non-MMP sensitive/non-degradable

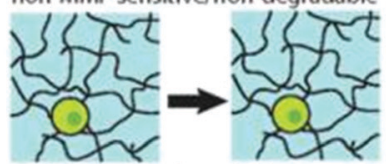

MMP-sensitive/degradable
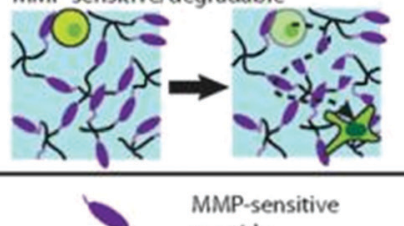

peptide

peptide, growth factor
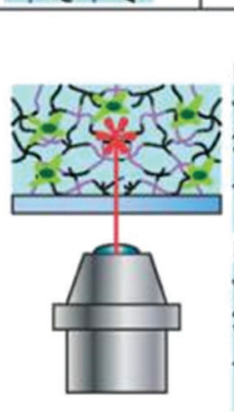

羊 laser, UV light

enzyme
D Tailoring bioactivity

tethering single bioactive compound

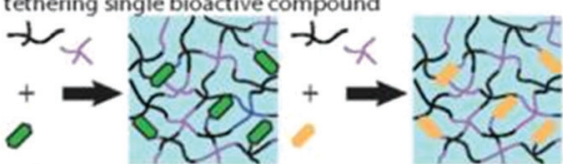

tethering combinations of bioactive compound

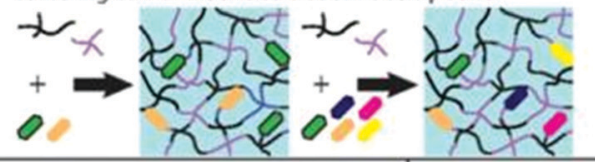

E 3D cell culture

3D culture

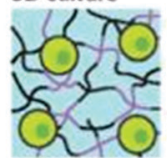

xtw

photo-degradation

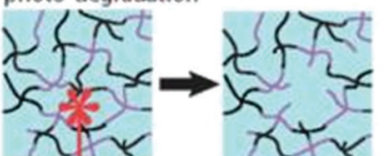

co-culture

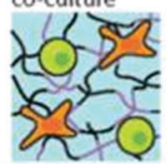

(2) stemcell

IS supportive/niche cell

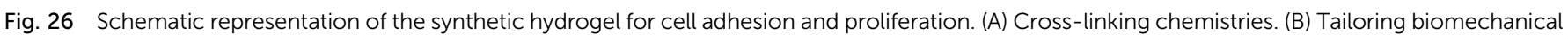
properties. (C) Tailoring degradability. (D) Tailoring bioactivity. (E) 3D cell culture [reprinted with permission from ref. 398, C)AlphaMed Press, 2015]. 


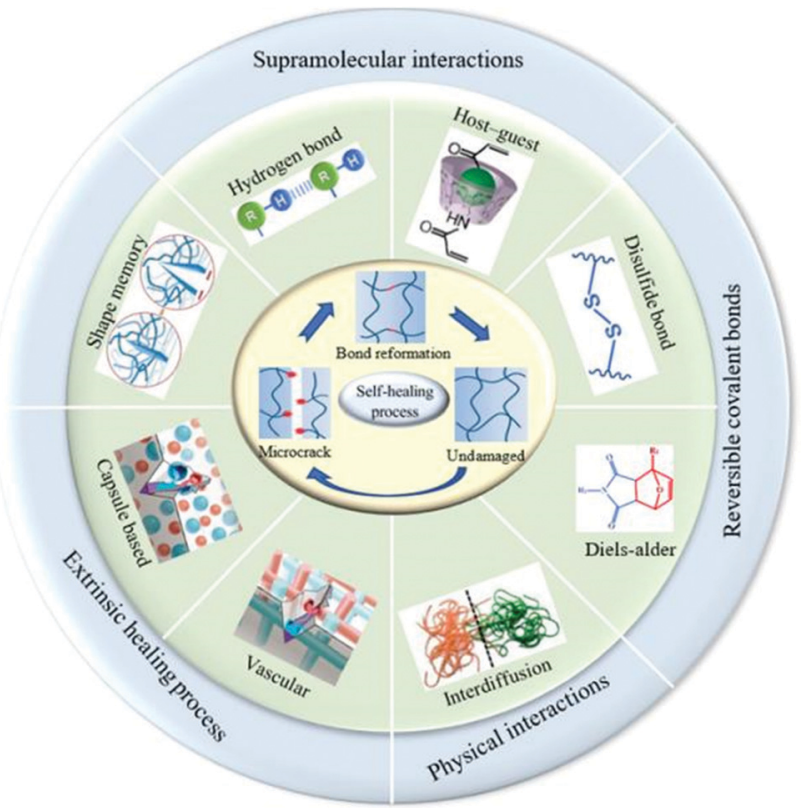

Fig. 27 Chemistry of the synthesis of self-healing hydrogels. ${ }^{400}$

This fascinating property can also be induced in hydrogels. Several underlying mechanisms of self-healing hydrogels are mainly divided into two broad categories: dynamic covalent bonds and non-covalent interactions (Fig. 27). Self-healing hydrogels possess dynamic covalent bonds that are mostly synthesized from DielsAlder reaction, coordination bonds, imine bonds, boronate ester bonds, and disulfide bonds, whereas noncovalent interaction methods include hydrogel bonds, host-guest interactions, hydrophobic interactions, and electrostatic interactions. ${ }^{399}$

The chemistry of self-healing can be successfully incorporated in both natural and synthetic polymers (Fig. 28). The generally used natural polymers to synthesize self-healing hydrogels are polysaccharide-based polymers including alginate, chitosan, and hyaluronic acid. Self-healing hydrogels with natural polymers are normally biocompatible. Synthetic polymers including PEG, PAAc, PVA, and PAAm give stronger and more elastic selfhealing hydrogels. ${ }^{401}$

A multifunctional composite self-healing hydrogel can be developed from a series of Li-alginate/poly(acrylamide-co-stearyl methacrylate) [Li-alginate/P(AAm-co-SMA)] hydrogels with a fully physically cross-linked interpenetrating network. ${ }^{402}$ In addition to their excellent stretchability and self-healing ability, the produced hydrogels exhibit the maximum fracture energy that enables them to be used as fire-resistant materials. ${ }^{403} \mathrm{~A}$ rapid self-healing hydrogel was developed by aligning the polymer network with dangling hydrocarbon side chains containing polar functional groups. These groups can be hydrophilic and hydrophobic moieties that allow the side chains to mediate hydrogen bonding across two separate hydrogel pieces or a rupture in the hydrogel. A polysaccharide derivative crosslinked with PVA forms a hydrogel that is capable of displaying rapid self-healing behavior when subjected to rupture. The hydrogel synthesis technique involves the extraction of bioactive laminarins (polysaccharides) from alginic acid, fucoidan, or some other seaweeds. These laminarins contain $\beta$-glucan which is modified by reacting with phenylboronic acid. Later, the resultant biopolymer and PVA are cross-linked by boronate esterification and form a self-healing hydrogel. ${ }^{404,405}$

Another type of self-healing hydrogel called a fluorochromic hydrogel that responds to light and ferric $\left(\mathrm{Fe}^{3+}\right)$ ions shows decent self-healing capability. Such a hydrogel is synthesized via the physical crosslinking of PVA. $\gamma$-Cyclodextrin-spiropyran ( $\gamma$-CD-SP), a fluorophore, forms hydrogen bonds with PVA and thus is integrated into the PVA gel. The presence of tannic acid creates numerous binding sites to the PVA chain. This helps to

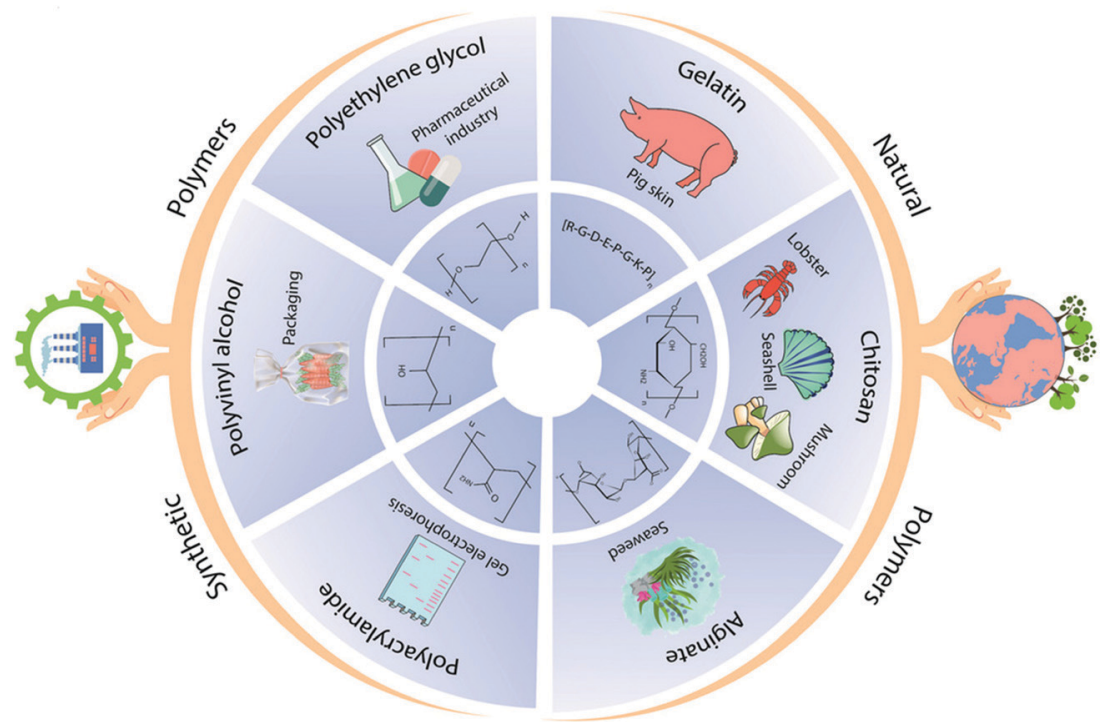

Fig. 28 Synthetic and natural polymers used to synthesize self-healable hydrogels are highlighted here [reprinted with permission from ref. 401, (C) John Wiley and Sons, 2019]. 


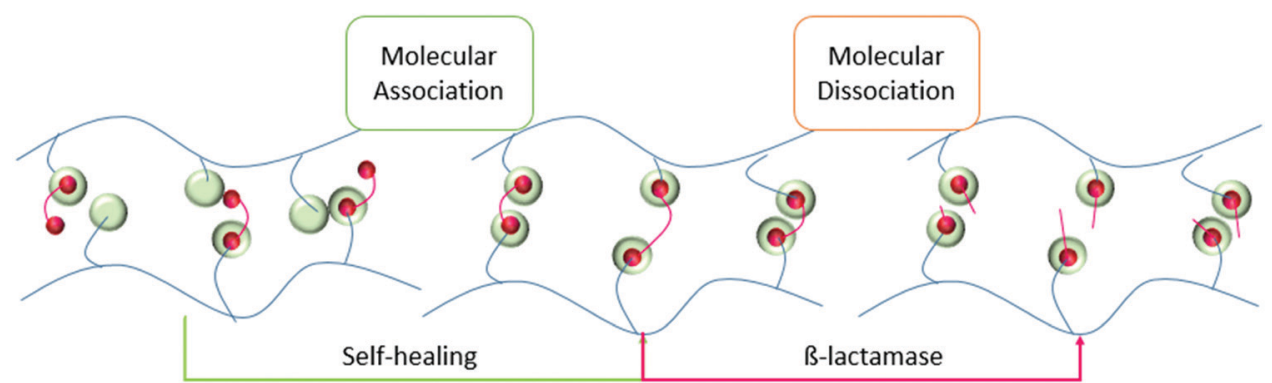

Fig. 29 Schematic diagram of molecular association and dissociation [reprinted with permission from ref. 409, (C)American Chemical Society, 2020].

Table 5 Preparation of hydrogels for special applications

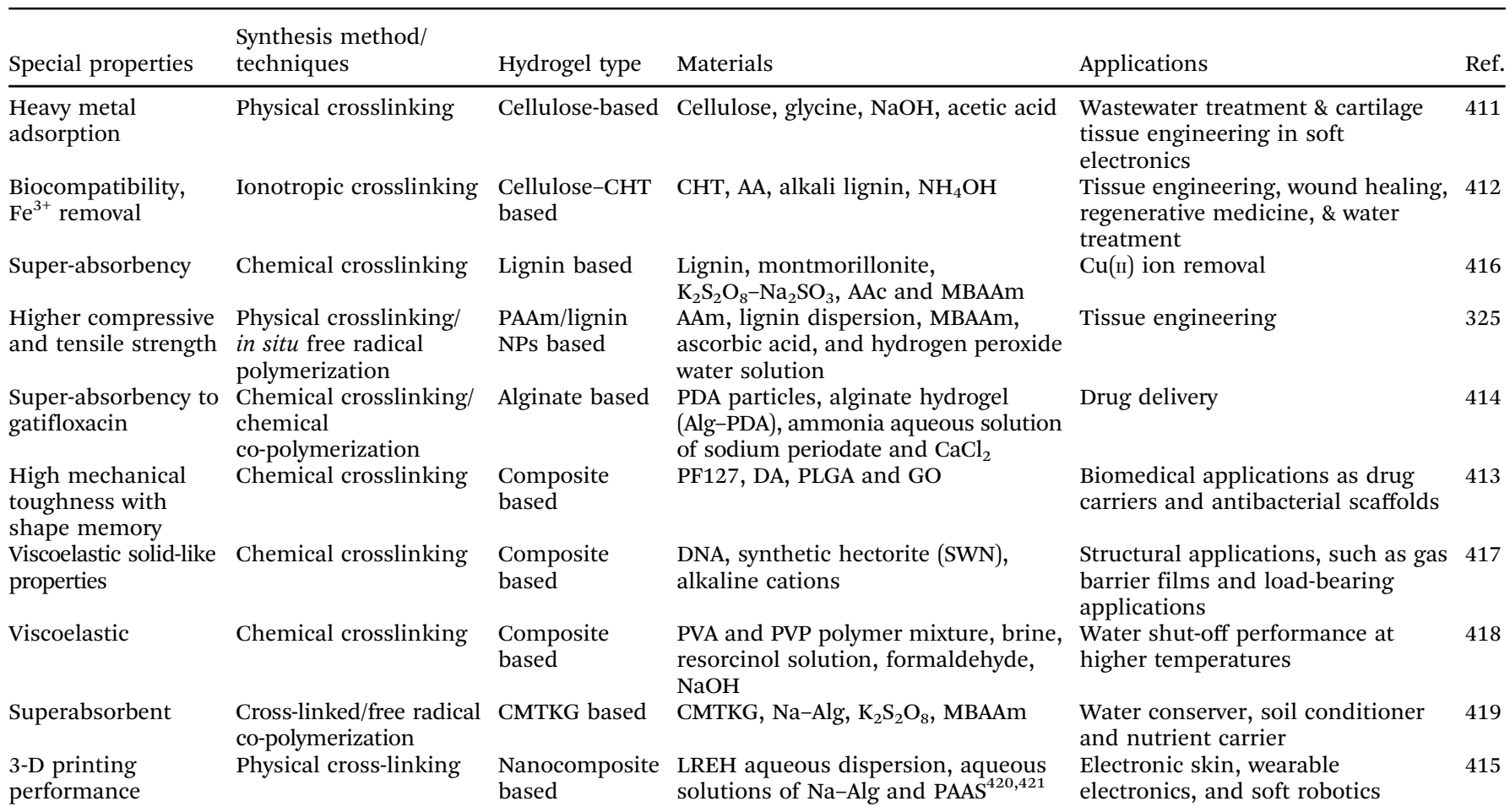

Abbreviations: chitosan (CHT), acetic acid (AA), acrylic acid (AAc), $N, N^{\prime}$-methylenebisacrylamide (MBAAm), polydopamine (PDA), Pluronic F127 diacrylate (PF127 DA), poly(lactide-co-glycolide) (PLGA); graphene oxide (GO); polyvinylpyrrolidone (PVP), polyvinyl alcohol (PVA), sodium alginate (Na-Alg); layered rare-earth hydroxide (LREH); sodium polyacrylate (PAAS); alginate hydrogel (Alg), carboxymethyl tamarind kernel gum (CMTKG).

improve both the mechanical strength and self-healing ability of the hydrogel (Fig. 29). ${ }^{406-408}$

Similarly, a self-healing hydrogel based on CNC can be synthesized via a one-pot polymerization technique. Herein, sodium alginate along with CNC acts as a macro-cross-linker. The reaction is initiated by introducing the aldehyde group via mild oxidization of both $\mathrm{CNC}$ and sodium alginate. Next, a Schiff-base linkage is incorporated to bind the CNC surface with the oxidized sodium alginate core. The hydrogel is capable of self-healing within several hours of dissociation at room temperature. $^{400,410}$

\subsection{Other applications}

Hydrogels are emerging materials that have attracted significant fundamental and applied interest for wastewater treatment, ${ }^{411}$ tissue engineering, ${ }^{325,412}$ drug delivery, ${ }^{413,414}$ wearable electronics, ${ }^{415}$ and energy-storage materials. ${ }^{314}$ Apart from the aforementioned synthetic processes, the following recent works of functional hydrogels have extended their applications in numerous fields (Table 5).

\section{Future prospects and conclusion}

Hydrogels, a unique class of soft materials, have significant potential to be used in a wide range of applications including biomedicine, skin, and personal care products. Due to their significant potential, over the past few decades, rapid integration of 3D structures and easy customization with advanced synthesis techniques have spurred the popularity of hydrogels with a wide variety of applications, thus attracting research attention. To cope with these exponential demands, researchers are continuously developing new design and synthesis strategies. In this paper, 
some recently developed hydrogels and their fabrication techniques have been summarized. Researchers are developing several processes to synthesize stimuli-responsive and functional hydrogels. However, numerous complexities associated with hydrogels mimicking the natural 3D structure have been reported. Multi-stimuli (physical, chemical, and biological)-responsive hydrogels mimicking the natural 3D structure and improvements in their responsive characteristics could be developed in future research. Additionally, these 3D structured hydrogel fabrication techniques inevitably destroyed the intrinsic hydrophilicity and biocompatibility of a hydrogel. These research booms involve the fabrication of diverse hydrogels in combination with different polymers, which also directs to the explanations of new mechanisms of the external stimuli-responsive hydrogel. The scope for developing smart hydrogels with desired functional and intact intrinsic physicochemical properties is yet to be explored.

In particular, substantial research is required to develop novel smart hydrogels with complex but programmed selffolding, twisting, and bending behaviors. An adverse immune response occurs when hydrogen scaffolds are inserted into a body which may lead to the rejection of scaffolds. Thus, future research should focus on synthesizing such hydrogels that can control and reduce immune cells like macrophages and adjust the plasticity and reprogramming to form/repair/reconstruct tissues. Another important property of natural hydrogels is having less toxicity. However, during the manufacturing process, different solvents have been used which may increase the toxicity level. Future research should focus more on incorporating natural materials in cross-linked hydrogels. Future research should also emphasize on scaling the size of hydrogels down to the single-cell sampling level. This is important as the present sequencing in bulk samples provides information on the population level, losing key information about biological subsets within the sample. It is possible to individualize sequencing 'omic' data on a cell-by-cell level by partitioning single cells into separate wells or droplets.

Injectable hydrogels have recently attracted the significant attention of researchers as they offer several benefits including cytocompatibility, non-invasive administration, tunable mechanical properties, high permeability, controllable degradability, and injectability, and these hydrogels can be used as scaffolds or as carriers of therapeutic agents such as drugs, cells, and proteins. However, several essential challenges still need to be overcome to use these injectable hydrogels successfully. Two important properties for the effective application of injectable hydrogels are strength and degradation. Although researchers are now producing highstrength hydrogels, the balance of strength with degradation is crucial for hydrogels. The degradation rate of hydrogels should be well adjusted with cell adhesion and proliferation. Also, developing advanced controllable electro-sensitive hydrogels with a faster response rate for smart drug delivery is another area to explore further in depth.

Finally, we may conclude that significant developments have been made over the past few decades to improve the properties of hydrogels and these improvements need to be continued in the near future to improve, modify, and create a new paradigm of application opportunities. Therefore, the authors of the manuscript feel that a comprehensive overview of synthesis processes and understanding the strategies of tuning special functional properties of smart hydrogels are a pressing need.

\section{Conflicts of interest}

The authors have no potential conflicts of interest.

\section{Acknowledgements}

This research did not receive any specific grant from funding agencies in the public, commercial, or non-profit sectors.

\section{References}

1 J. Hu, H. Meng, G. Li and S. I. Ibekwe, A review of stimuliresponsive polymers for smart textile applications, Smart Mater. Struct., 2012, 21(5), 1-23.

2 M. Vockley, Game-changing technologies: 10 promising innovations for healthcare, Biomed. Instrum. Technol., 2017, 51(2), 96-108, DOI: 10.2345/0899-8205-51.2.96.

3 N. P. Murphy and K. J. Lampe, Mimicking biological phenomena in hydrogel-based biomaterials to promote dynamic cellular responses, J. Mater. Chem. B, 2015, 3(40), 7867-7880.

4 S. Tang, B. M. Richardson and K. S. Anseth, Dynamic covalent hydrogels as biomaterials to mimic the viscoelasticity of soft tissues, Prog. Mater. Sci., 2020, 100738, DOI: 10.1016/j.pmatsci.2020.100738.

5 A. Skardal, M. Devarasetty, H. W. Kang, I. Mead, C. Bishop and T. Shupe, et al., A hydrogel bioink toolkit for mimicking native tissue biochemical and mechanical properties in bioprinted tissue constructs, Acta Biomater., 2015, 25, 24-34, DOI: 10.1016/j.actbio.2015.07.030.

6 S. K. Samal, M. Dash, P. Dubruel and S. Van Vlierberghe, Smart polymer hydrogels: Properties, synthesis and applications, Smart Polymers and their Applications, Elsevier Ltd, 2014, pp. 237-270.

7 N. N. Ferreira, L. M. B. Ferreira, V. M. O. Cardoso, F. I. Boni, A. L. R. Souza and M. P. D. Gremião, Recent advances in smart hydrogels for biomedical applications: From self-assembly to functional approaches, Eur. Polym. J., 2018, 99, 117-133.

8 J. R. McLaughlin, N. L. Abbott and C. A. Guymon, Responsive superabsorbent hydrogels via photopolymerization in lyotropic liquid crystal templates, Polymer, 2018, 142, 119-126, DOI: 10.1016/j.polymer.2018.03.016.

9 A. Riedinger, M. Pernia Leal, S. R. Deka, C. George, I. R. Franchini and A. Falqui, et al., "Nanohybrids" Based on pH-Responsive Hydrogels and Inorganic Nanoparticles for Drug Delivery and Sensor Applications, Nano Lett., 2011, 11(8), 3136-3141.

10 S. Dutta, P. Samanta and D. Dhara, Temperature, pH and redox responsive cellulose based hydrogels for protein delivery, Int. J. Biol. Macromol., 2016, 87, 92-100, DOI: 10.1016/j.ijbiomac.2016.02.042. 
11 Y. Zhu, Y. Matsumura, M. Velayutham, L. M. Foley, T. K. Hitchens and W. R. Wagner, Reactive oxygen species scavenging with a biodegradable, thermally responsive hydrogel compatible with soft tissue injection, Biomaterials, 2018, 177, 98-112, DOI: 10.1016/j.biomaterials.2018.05.044.

12 R. Zhang, M. Tang, A. Bowyer, R. Eisenthal and J. Hubble, A novel $\mathrm{pH}$ - and ionic-strength-sensitive carboxy methyl dextran hydrogel, Biomaterials, 2005, 26(22), 4677-4683. Available from: http://www.sciencedirect.com/science/arti cle/pii/S014296120401052X.

13 J. Kolosnjaj-Tabi, L. Gibot, I. Fourquaux, M. Golzio and M. P. Rols, Electric field-responsive nanoparticles and electric fields: physical, chemical, biological mechanisms and therapeutic prospects, Adv. Drug Delivery Rev., 2019, 138, 56-67, DOI: 10.1016/j.addr.2018.10.017.

14 Z. R. Lu, P. Kopečkovci and J. Kopeček, Antigen responsive hydrogels based on polymerizable antibody $\mathrm{Fab}^{\prime}$ fragment, Macromol. Biosci., 2003, 3, 296-300.

15 M. Ikeda, R. Ochi, A. Wada and I. Hamachi, Supramolecular hydrogel capsule showing prostate specific antigen-responsive function for sensing and targeting prostate cancer cells, Chem. Sci., 2010, 1(4), 491-498.

16 H. Yang, H. Liu, H. Kang and W. Tan, Engineering TargetResponsive Hydrogels Based on Aptamer-Target Interactions, J. Am. Chem. Soc., 2008, 130, 6320-6321.

17 S. L. Haag and M. T. Bernards, Polyampholyte Hydrogels in Biomedical Applications, Gels, 2017, 3(4), 41.

$18 \mathrm{~J}$. Ma, X. Li and Y. Bao, Advances in cellulose-based superabsorbent hydrogels, RSC Adv., 2015, 5, 59745-59757.

19 M. R. Guilherme, F. A. Aouada, A. R. Fajardo, A. F. Martins, A. T. Paulino and M. F. T. Davi, et al., Superabsorbent hydrogels based on polysaccharides for application in agriculture as soil conditioner and nutrient carrier: A review, Eur. Polym. J., 2015, 365-385.

20 K. Soleimani, A. D. D. Tehrani and M. Adeli, Bioconjugated graphene oxide hydrogel as an effective adsorbent for cationic dyes removal, Ecotoxicol. Environ. Saf., 2018, 147, 34-42.

21 K. Deng, C. Bellmann, Y. Fu, M. Rohn, M. Guenther and G. Gerlach, Miniaturized force-compensated hydrogel-based pH sensors, Sens. Actuators, B, 2018, 255(3), 3495-3504.

22 Y. Cheng, K. Ren, D. Yang and J. Wei, Bilayer-type fluorescence hydrogels with intelligent response serve as temperature/pH driven soft actuators, Sens. Actuators, B, 2018, 255, 3117-3126. Available from: http:/www.sciencedirect. com/science/article/pii/S0925400517318038.

23 X. Wang, H. Hu, Z. Yang, L. He, Y. Kong and B. Fei, et al., Smart hydrogel-functionalized textile system with moisture management property for skin application, Smart Mater. Struct., 2014, 23, 125027.

24 D. Snoeck, L. Pel and N. De Belie, The water kinetics of superabsorbent polymers during cement hydration and internal curing visualized and studied by NMR, Sci. Rep., 2017, 7, 9514.

25 I. Cunha, R. Barras, P. Grey, D. Gaspar, E. Fortunato and R. Martins, et al., Reusable Cellulose-Based Hydrogel Sticker
Film Applied as Gate Dielectric in Paper Electrolyte-Gated Transistors, Adv. Funct. Mater., 2017, 27, 1606755.

26 B. Smitha, S. Sridhar and A. A. Khan, Polyelectrolyte complexes of chitosan and poly(acrylic acid) as proton exchange membranes for fuel cells, Macromolecules, 2004, 37(6), 2233-2239.

27 R. Das, S. Ghorai and S. Pal, Flocculation characteristics of polyacrylamide grafted hydroxypropyl methyl cellulose: An efficient biodegradable flocculant, Chem. Eng. J., 2013, 229, 144-152.

28 S. Chatterjee and P. Chi-leung Hui, Stimuli-Responsive Hydrogels: An Interdisciplinary Overview, Hydrogels - Smart Materials for Biomedical Applications, IntechOpen, 2019.

29 M. Akhtar and M. Hanif, Journal NR-SP, 2016 U. Methods of synthesis of hydrogels: A review, Saudi Pharm. J., 2016, 24(5), 554-559.

30 W. Zhao, X. Jin, Y. Cong, Y. Liu and J. Fu, Degradable natural polymer hydrogels for articular cartilage tissue engineering, J. Chem. Technol. Biotechnol., 2013, 88, 327-339.

31 E. M. Ahmed, Hydrogel: Preparation, characterization, and applications: A review, J. Adv. Res., 2015, 6, 105-121.

32 N. A. Peppas, P. Bures, W. Leobandung and H. Ichikawa, Hydrogels in pharmaceutical formulations, Eur. J. Pharm. Biopharm., 2000, 27-46.

33 L. A. Sharpe, A. M. Daily, S. D. Horava and N. A. Peppas, Therapeutic applications of hydrogels in oral drug delivery, Expert Opin. Drug Delivery, 2014, 11, 901-915.

34 N. Kashyap, N. Kumar and M. N. V. R. Kumar, Hydrogels for pharmaceutical and biomedical applications, Crit. Rev. Ther. Drug Carrier Syst., 2005, 22, 107-149.

35 N. Sood, A. Bhardwaj, S. Mehta and A. Mehta, Stimuliresponsive hydrogels in drug delivery and tissue engineering, Drug Delivery, 2016, 23(3), 748-770.

36 M. Zelzer, S. J. Todd, A. R. Hirst, T. O. McDonald and R. V. Ulijn, Enzyme responsive materials: Design strategies and future developments, Biomater. Sci., 2013, 1, 11-39.

37 D. Roy, J. N. Cambre and B. S. Sumerlin, Future perspectives and recent advances in stimuli-responsive materials, Prog. Polym. Sci., 2010, 35, 278-301.

38 J. E. Ghadiali and M. M. Stevens, Enzyme-Responsive Nanoparticle Systems, Adv. Mater., 2008, 20(22), 4359-4363.

39 R. J. Williams, R. J. Mart and R. V. Ulijn, Exploiting biocatalysis in peptide self-assembly, Biopolymers, 2010, 94(1), 107-117.

40 M. Zelzer and R. V. Ulijn, Next-generation peptide nanomaterials: Molecular networks, interfaces and supramolecular functionality, Chem. Soc. Rev., 2010, 39, 3351-3357.

41 T. Miyata, N. Asami and T. Uragani, A reversibly antigenresponsive hydrogen, Nature, 1999, 399(6738), 766-768.

42 S. H. Um, J. B. Lee, N. Park, S. Y. Kwon, C. C. Umbach and D. Luo, Enzyme-catalysed assembly of DNA hydrogel, Nat. Mater., 2006, 5(10), 797-801, DOI: 10.1038/nmat1741.

43 D. Wang, Y. Hu, P. Liu and D. Luo, Bioresponsive DNA Hydrogels: Beyond the Conventional Stimuli Responsiveness, Acc. Chem. Res., 2017, 50(4), 733-739.

44 X. Xiong, C. Wu, C. Zhou, G. Zhu, Z. Chen and W. Tan, Responsive DNA-based hydrogels and their applications, Macromol. Rapid Commun., 2013, 34(16), 1271-1283. 
45 J. Shin, A. G. Cherstvy and R. Metzler, Sensing viruses by mechanical tension of DNA in responsive hydrogels, Phys. Rev. $X, 2014,4(2), 1-13$.

46 L. Klouda and A. G. Mikos, Thermoresponsive hydrogels in biomedical applications, Eur. J. Pharm. Biopharm., 2008, 68, 34-45.

47 S. J. Buwalda, K. W. M. Boere, P. J. Dijkstra, J. Feijen, T. Vermonden and W. E. Hennink, Hydrogels in a historical perspective: From simple networks to smart materials, J. Controlled Release, 2014, 190, 254-273.

48 M. C. Koetting, J. T. Peters, S. D. Steichen and N. A. Peppas, Stimulus-responsive hydrogels: Theory, modern advances, and applications, Mater. Sci. Eng., R, 2015, 1-49.

49 A. M. Villalba-Rodríguez, K. Dhama and H. M. N. Iqbal, Biomaterials-based hydrogels and their drug delivery potentialities, Int. J. Pharmacol., 2017, 13(7), 864-873.

50 Q. Chai, Y. Jiao and X. Yu, Hydrogels for Biomedical Applications: Their Characteristics and the Mechanisms behind Them, Gels, 2017, 3(1), 6. Available from: https:// www.ncbi.nlm.nih.gov/pubmed/30920503.

51 L. J. Del Valle, A. Díaz and J. Puiggalí, Hydrogels for Biomedical Applications: Cellulose, Chitosan, and Protein/Peptide Derivatives, Gels, 2017, 3(3), 27. Available from: https:/www.ncbi.nlm.nih.gov/pubmed/30920524.

52 R. Sanchez-Orozco, B. Timoteo-Cruz, T. Torres-Blancas and F. Urena-Nunez, Valorization of Superabsorbent Polymers from Used Disposable Diapers as Soil Moisture Retainer, Int. J. Res. Granthaalayah, 2017, 5(4), 105-117, DOI: 10.29121/granthaalayah.v5.i4.2017.1800.

53 F. Yokoyama, I. Masada, K. Shimamura, T. Ikawa and K. Monobe, Morphology and structure of highly elastic poly(vinyl alcohol) hydrogel prepared by repeated freezingand-melting, Colloid Polym. Sci., 1986, 264, 595-601.

54 M. Rizwan, R. Yahya, A. Hassan, M. Yar, A. D. Azzahari and V. Selvanathan, $\mathrm{pH}$ sensitive hydrogels in drug delivery: Brief history, properties, swelling, and release mechanism, material selection and applications, Polymers, 2017, 9(4), 1-37, DOI: 10.3390/polym9040137.

55 E. Mah and R. Ghosh, Thermo-responsive hydrogels for stimuli-responsive membranes, Processes, 2013, 238-262.

56 L. Liu, W. D. Yao, Y. F. Rao, X. Y. Lu and J. Q. Gao, $\mathrm{pH}$-responsive carriers for oral drug delivery: Challenges and opportunities of current platforms, Drug Delivery, 2017, 569-581.

57 J. Liu and Y. Yin, Temperature Responsive Hydrogels: Construction and Applications Abstract Construction Method of, Polym. Sci., 2015, 1(13), 1-6.

58 A. G. Venkatesan, A. Baji and S. Ramakrishna, Smart functional polymers - A new route towards creating a sustainable environment, RSC Adv., 2014, 4, 53352-53364.

59 K. Bauri, M. Nandi and P. De, Amino acid-derived stimuliresponsive polymers and their applications, Polym. Chem., 2018, 9(11), 1257-1287.

60 I. M. El-Sherbiny, I. A. Khalil and I. H. Ali, Updates on Stimuli-Responsive Polymers: Synthesis Approaches and Features BT, in Polymer Gels: Science and Fundamentals. ed. V. K. Thakur and M. K. Thakur, Springer Singapore, Singapore, 2018, pp. 129-146, DOI: 10.1007/978-981-106086-1_4.

61 A. M. A. Hasan and M. E.-S. Abdel-Raouf, Cellulose-Based Superabsorbent Hydrogels BT, in Cellulose-Based Superabsorbent Hydrogels, ed. M. I. H. Mondal, Springer International Publishing, Cham, 2019, pp. 245-267, DOI: 10.1007/978-3-319-77830-3_11.

62 N. Annabi, A. Tamayol, J. A. Uquillas, M. Akbari, L. E. Bertassoni and C. Cha, et al., 25th anniversary article: Rational design and applications of hydrogels in regenerative medicine, Adv. Mater., 2014, 26(1), 85-124.

63 M. F. Akhtar, M. Hanif and N. M. Ranjha, Methods of synthesis of hydrogels ... A review, Saudi Pharm. J., 2016, 24(5), 554-559, DOI: 10.1016/j.jsps.2015.03.022.

64 N. D. Tsihlis, J. Murar, M. R. Kapadia, S. S. Ahanchi, C. S. Oustwani and J. E. Saavedra, et al., Hydrogels: Methods of Preparation, J. Vasc. Surg., 2010, 51(5), 1248-1259.

65 J. M. Seidel and S. M. Malmonge, Synthesis of polyHEMA hydrogels for using as biomaterials. Bulk and solution radical-initiated polymerization techniques, Mater. Res. J. Mater., 2000, 3, 79-83.

66 W. E. Hennink and C. F. van Nostrum, Novel crosslinking methods to design hydrogels, Adv. Drug Delivery Rev., 2002, 54(1), 13-36. Available from: http:/www.sciencedirect. com/science/article/pii/S0169409X0100240X.

67 T. Billiet, M. Vandenhaute, J. Schelfhout, S. Van Vlierberghe and P. Dubruel, A review of trends and limitations in hydrogel-rapid prototyping for tissue engineering, Biomaterials, 2012, 33, 6020-6041.

68 A. A. Abdel-Azim, M. S. Farahat, A. M. Atta and A. A. AbdelFattah, Preparation and properties of two-component hydrogels based on 2-acrylamido-2-methylpropane sulphonic acid, Polym. Adv. Technol., 1998, 9(5), 282-289.

69 N. Ranganathan, R. Joseph Bensingh, M. Abdul Kader and S. K. Nayak, Synthesis and Properties of Hydrogels Prepared by Various Polymerization Reaction Systems BT, in Cellulose-Based Superabsorbent Hydrogels, ed. M. I. H. Mondal, Springer International Publishing, Cham, 2018, pp. 1-25, DOI: 10.1007/978-3-319-76573-0_18-1.

$70 \mathrm{~J}$. Li, X. Jia and L. Yin, Hydrogel: Diversity of Structures and Applications in Food Science, Food Rev. Int., 2021, 1-59, DOI: 10.1080/87559129.2020.1858313.

71 M. A. Macchione, C. Biglione and M. Strumia, Design, Synthesis and Architectures of Hybrid Nanomaterials for Therapy and Diagnosis Applications, Polymers, 2018, 10(5), 527. Available from: https://pubmed.ncbi.nlm.nih.gov/30966561.

72 C. E. Carraher, Introduction to Polymer Chemistry, CRC Press, 4th edn, 2017. Available from: https://books.goo gle.com/books?id=TL3ZDQAAQBAJ.

73 B. M. Shin, J.-H. Kim and D. J. Chung, Synthesis of $\mathrm{pH}-$ responsive and adhesive super-absorbent hydrogel through bulk polymerization, Macromol. Res., 2013, 21(5), 582-587, DOI: $10.1007 / \mathrm{s} 13233-013-1051-4$.

74 D. S. Achilias and G. D. Verros, Modeling of diffusioncontrolled reactions in free radical solution and bulk 
polymerization: Model validation by dsc experiments, J. Appl. Polym. Sci., 2010, 116(3), 1842-1856.

75 M. Chanda, Introduction to Polymer Science and Chemistry: A Problem-Solving Approach, CRC Press, 2nd edn, 2013.

$76 \mathrm{~J}$. R. Ebdon Introduction to polymers (second edition) R. J. Young and P. A. Lovell Chapman and Hall, London, 1991. pp. 443, price £16.95. ISBN 0-412-30640-9 (PB); ISBN 0-412-30630-1 (HB). Polym Int [Internet]. 1992;27(2):207-8. Available from: https://doi.org/10.1002/pi.4990270217.

77 N. Ranganathan, R. Joseph Bensingh, M. Abdul Kader and S. K. Nayak, Synthesis and Properties of Hydrogels Prepared by Various Polymerization Reaction Systems, in Cellulose-Based Superabsorbent Hydrogels, ed. M. I. H. Mondal, Springer International Publishing, Cham, 2018, pp. 1-25, DOI: 10.1007/978-3-319-76573-0_18-1.

78 M. Chanda, Introduction to Polymer Science and Chemistry: A Problem-Solving Approach, 2006.

79 M. Liu, R. Liang, F. Zhan, Z. Liu and A. Niu, Preparation of superabsorbent slow release nitrogen fertilizer by inverse suspension polymerization, Polym. Int., 2007, 56(6), 729-737, DOI: $10.1002 /$ pi.2196.

80 C. E. Carraher, Carraher's polymer chemistry, 2018.

81 R. Young and P. Lovell, Introduction to polymers, 2011, Available from: https://books.google.com/books?hl=en\&lr=\& id=7BbSBQAAQBAJ\&oi=fnd\&pgPP1\&dq=introduction++polymers \&ots=RKLmu7R1MD\&sig=d0ih56bPI0RqfLnvBqJYSiNaMPI.

82 H. A. Essawy, M. B. M. Ghazy, F. A. El-Hai and M. F. Mohamed, Superabsorbent hydrogels via graft polymerization of acrylic acid from chitosan-cellulose hybrid and their potential in controlled release of soil nutrients, Int. J. Biol. Macromol., 2016, 89, 144-151, DOI: 10.1016/j.ijbiomac.2016.04.071.

83 M. W. Tibbitt, A. M. Kloxin, L. A. Sawicki and K. S. Anseth, Mechanical Properties and Degradation of Chain and StepPolymerized Photodegradable Hydrogels, Macromolecules, 2013, 46(7), 2785-2792, DOI: 10.1021/ma302522x.

84 X. Shen, J. L. Shamshina, P. Berton, G. Gurau and R. D. Rogers, Hydrogels based on cellulose and chitin: Fabrication, properties, and applications, Green Chem., 2015, 18(1), 53-75.

85 M. Mondal and K. Trivedy, The silk proteins, sericin and fibroin in silkworm, Bombyx mori Linn., - a review, Casp. J. Environ. Sci., 2007, 5(2), 63-76.

86 H. M. James and E. Guth, Theory of the elastic properties of rubber, J. Chem. Phys., 1943, 11, 455.

87 K. P. Menard and N. Menard, Dynamic Mechanical Analysis, Encyclopedia of Analytical Chemistry, 2017, pp. 1-25 (Major Reference Works). , DOI: 10.1002/9780470027318.a2007.pub3.

88 F. A. Morrison, Understanding Rheology, Oxford Univ Press, 2001. Available from: https://global.oup.com/ushe/product/ understanding-rheology-9780195141665?cc=ca\&lang=en\&.

89 S. Bucatariu, G. Fundueanu, I. Prisacaru, M. Balan, I. Stoica and V. Harabagiu, et al., Synthesis and characterization of thermosensitive poly(N-isopropylacrylamide-co-hydroxyethylacrylamide) microgels as potential carriers for drug delivery, J. Polym. Res., 2014, 21(11), 1-12, DOI: 10.1007/s10965-014-0580-7.

90 Y. Qiu and K. Park, Environment-sensitive hydrogels for drug delivery, Adv. Drug Delivery Rev., 2001, 53(3), 321-339.
91 Y. Samchenko, Z. Ulberg and O. Korotych, Multipurpose smart hydrogel systems, Adv. Colloid Interface Sci., 2011, 168(1-2), 247-262.

92 H. Katono, K. Sanui, N. Ogata, T. Okano and Y. Sakurai, Drug release OFF behavior and deswelling kinetics of thermo-responsive IPNs composed of poly(acrylamide-cobutyl methacrylate) and poly(acrylic acid), Polym. J., 1991, 23(10), 1179-1189.

93 S. Chatterjee, P. Chi-leung Hui and C. Kan, Thermoresponsive Hydrogels and Their Biomedical Applications: Special Insight into Their Applications in Textile Based Transdermal Therapy, Polymers, 2018, 10(5), 480, DOI: 10.3390/ polym 10050480 .

94 A. S. Hoffman, Hydrogels for biomedical applications, $A d v$. Drug Delivery Rev., 2002, 54(1), 3-12.

95 M. W. Tibbitt and K. S. Anseth, Hydrogels as extracellular matrix mimics for 3D cell culture, Biotechnol. Bioeng., 2009, 103(4), 655-663.

96 L. Klouda, Thermoresponsive hydrogels in biomedical applications A seven-year update, Eur. J. Pharm. Biopharm., 2015, 97, 338-349.

97 B. Özkahraman, I. Acar and G. Güçlü, Synthesis and characterization of poly (VCL-HEA-IA) terpolymer for drug release applications, J. Polym. Mater., 2016, 33(2), 351-363.

98 X.-Z. Zhang, D.-Q. Wu and C.-C. Chu, Synthesis, characterization and controlled drug release of thermosensitive IPN-PNIPAAm hydrogels, Biomaterials, 2004, 25(17), 3793-3805. Available from: http:/www.sciencedirect.com/ science/article/pii/S0142961203009955.

99 J. Wei, Y. Li and T. Ngai, Tailor-made microgel particles: Synthesis and characterization, Colloids Surf., A, 2016, 489, 122-127. Available from: http:/www.sciencedirect.com/ science/article/pii/S0927775715303010.

100 S. Dogu and W. Oppermann, Influence of observation temperature on light scattering of poly-N-isopropylacrylamide hydrogels, Soft Matter, 2012, 8(9), 2705-2713, DOI: 10.1039/ C2SM07316A.

101 W. H. Blackburn and L. A. Lyon, Size-controlled synthesis of monodisperse core/shell nanogels, Colloid Polym. Sci., 2008, 286(5), 563-569, DOI: 10.1007/s00396-007-1805-7.

102 T. Iizawa, H. Taketa, M. Maruta, T. Ishido, T. Gotoh and S. Sakohara, Synthesis of porous poly(N-isopropylacrylamide) gel beads by sedimentation polymerization and their morphology, J. Appl. Polym. Sci., 2007, 104(2), 842-850, DOI: $10.1002 /$ app.25605.

103 E. Isikci Koca, G. Bozdag, G. Cayli, D. Kazan and P. Cakir Hatir, Thermoresponsive hydrogels based on renewable resources, J. Appl. Polym. Sci., 2019, 48861.

104 M. S. H. Akash, K. Rehman, H. Sun and S. Chen, Assessment of release kinetics, stability and polymer interaction of poloxamer 407-based thermosensitive gel of interleukin-1 receptor antagonist, Pharm. Dev. Technol., 2014, 19(3), 278-284.

105 S. J. Bae, J. M. Suh, Y. S. Sohn, Y. H. Bae, S. W. Kim and B. Jeong, Thermogelling poly(caprolactone-6-ethylene glycolb-caprolactone) aqueous solutions, Macromolecules, 2005, 38(12), 5260-5265. 
106 S. E. Stabenfeldt, A. J. García and M. C. LaPlaca, Thermoreversible laminin-functionalized hydrogel for neural tissue engineering, J. Biomed. Mater. Res., Part A, 2006, 77(4), 718-725.

107 H. Chen and M. Fan, Novel Thermally Sensitive pH-dependent Chitosan/ Carboxymethyl Cellulose Hydrogels, J. Bioact. Compat. Polym., 2008, 23(1), 38-48.

108 N. Bhattarai, H. R. Ramay, J. Gunn, F. A. Matsen and M. Zhang, PEG-grafted chitosan as an injectable thermosensitive hydrogel for sustained protein release, J. Controlled Release, 2005, 103(3), 609-624.

109 L. L. Y. Chiu and M. Radisic, Controlled release of thymosin $\beta 4$ using collagen-chitosan composite hydrogels promotes epicardial cell migration and angiogenesis, J. Controlled Release, 2011, 155(3), 376-385.

110 F. P. W. Melchels, M. A. N. Domingos, T. J. Klein, J. Malda, P. J. Bartolo and D. W. Hutmacher, Additive manufacturing of tissues and organs, Prog. Polym. Sci., 2012, 37, 1079-1104.

111 R. Suntornnond, J. An, W. Y. Yeong and C. K. Chua, Biodegradable Polymeric Films and Membranes Processing and Forming for Tissue Engineering, Macromol. Mater. Eng., 2015, 300(9), 858-877.

112 J. An, J. E. M. Teoh, R. Suntornnond and C. K. Chua, Design and 3D Printing of Scaffolds and Tissues, Engineering, 2015, 1(2), 261-268.

113 S. V. Murphy, A. Skardal and A. Atala, Evaluation of hydrogels for bio-printing applications, J. Biomed. Mater. Res., Part A, 2013, 101(1), 272-284.

114 J. Malda, J. Visser, F. P. Melchels, T. Jüngst, W. E. Hennink and W. J. A. Dhert, et al., 25th Anniversary Article: Engineering Hydrogels for Biofabrication, Adv. Mater., 2013, 25(36), 5011-5028.

115 R. Suntornnond, J. An and C. K. Chua, Bioprinting of Thermoresponsive Hydrogels for Next Generation Tissue Engineering: A Review, Macromol. Mater. Eng., 2017, 302(1), 1600266.

116 J. Zaragoza, B. Nasim, V. O’brien, A. Chang, M. Blanco and A. Zabalegui, et al., Experimental Investigation of Mechanical and Thermal Properties of Silica Nanoparticle-Reinforced Poly(acrylamide) Nanocomposite Hydrogels, PLoS One, 2015, 10(8), e0136293.

117 L.-Y. Chu, R. Xie, X.-J. Ju and W. Wang, Smart Hydrogel Functional Materials, 2013.

118 J. Sun, Y. Guo, R. Xing, T. Jiao, Q. Zou and X. Yan, Synergistic in vivo photodynamic and photothermal antitumor therapy based on collagen-gold hybrid hydrogels with inclusion of photosensitive drugs, Colloids Surf., A, 2017, 514(5), 155-160.

119 X. Wang, C. Wang, Q. Zhang and Y. Cheng, Near infrared light-responsive and injectable supramolecular hydrogels for on-demand drug delivery, Chem. Commun., 2016, 52(5), 978-981.

120 N. Roshan and M. Rahul, Photosensitive hydrogels for advanced drug delivery, Int. J. Rev. Artic. Pharm. Innov., 2013, 3(2), 11.

121 R. C. Luo, Z. H. Lim, W. Li, P. Shi and C. H. Chen, Nearinfrared light triggerable deformation-free polysaccharide double network hydrogels, Chem. Commun., 2014, 50(53), 7052-7055.

122 L. Li, J. M. Scheiger and P. A. Levkin, Design and Applications of Photoresponsive Hydrogels, Adv. Mater., 2019, 31(26), 1-17, DOI: $10.1002 /$ adma.201807333.

123 J. Ter Schiphorst, S. Coleman, J. E. Stumpel, A. Ben Azouz, D. Diamond and A. P. H. J. Schenning, Molecular Design of Light-Responsive Hydrogels, for in Situ Generation of Fast and Reversible Valves for Microfluidic Applications, Chem. Mater., 2015, 27(17), 5925-5931.

$124 \mathrm{~J}$. H. Kim and T. R. Lee, Thermo- and pH-responsive hydrogel-coated gold nanoparticles, Chem. Mater., 2004, 16(19), 3647-3651.

125 Y. L. Zhao and J. Fraser Stoddart, Azobenzene-based lightresponsive hydrogel system, Langmuir, 2009, 25(15), 8442-8446.

126 C. W. Lo, D. Zhu and H. Jiang, An infrared-light responsive graphene-oxide incorporated poly(N-isopropylacrylamide) hydrogel nanocomposite, Soft Matter, 2011, 7(12), 5604-5609.

127 L. Han, Y. Zhang, X. Lu, K. Wang, Z. Wang and H. Zhang, Polydopamine Nanoparticles Modulating Stimuli-Responsive PNIPAM Hydrogels with Cell/Tissue Adhesiveness, ACS Appl. Mater. Interfaces, 2016, 8(42), 29088-29100.

128 Y. Wu, K. Wang, S. Huang, C. Yang and M. Wang, NearInfrared Light-Responsive Semiconductor Polymer Composite Hydrogels: Spatial/Temporal-Controlled Release via a Photothermal "sponge" Effect, ACS Appl. Mater. Interfaces, 2017, 9(15), 13602-13610.

129 A. Guiseppi-Elie, Electroconductive hydrogels: Synthesis, characterization and biomedical applications, Biomaterials, 2010, 31(10), 2701-2716, DOI: 10.1016/j.biomaterials.2009.12.052.

130 J. P. Gong, T. Nitta and Y. Osada, Electrokinetic modeling of the contractile phenomena of polyelectrolyte gels. one-dimensional capillary model, J. Phys. Chem., 1994, 98(38), 9583-9587.

131 M. Zrínyi, J. Fehér and G. Filipcsei, Novel gel actuator containing $\mathrm{TiO} 2$ particles operated under static electric field, Macromolecules, 2000, 33(16), 5752-5753.

132 Y. K. Yew, T. Y. Ng, H. Li and K. Y. Lam, Analysis of pH and electrically controlled swelling of hydrogel-based microsensors/actuators, Biomed. Microdevices, 2007, 9(4), 487-499.

133 Y. Osada, H. Okuzaki and H. Hori, A polymer gel with electrically driven motility, Nature, 1992, 355(6357), 242-244.

134 W. Zhang, P. Feng, J. Chen, Z. Sun and B. Zhao, Electrically conductive hydrogels for flexible energy storage systems, Prog. Polym. Sci., 2019, 88, 220-240, DOI: 10.1016/ j.progpolymsci.2018.09.001.

135 Y. Zhou, C. Wan, Y. Yang, H. Yang, S. Wang and Z. Dai, et al., Highly Stretchable, Elastic, and Ionic Conductive Hydrogel for Artificial Soft Electronics, Adv. Funct. Mater., 2019, 29(1), 1-8.

136 Z. Wang, H. Zhou, J. Lai, B. Yan, H. Liu and X. Jin, et al., Extremely stretchable and electrically conductive hydrogels with dually synergistic networks for wearable strain sensors, J. Mater. Chem. C, 2018, 6(34), 9200-9207.

137 H. A. Alhadrami, Biosensors: Classifications, medical applications, and future prospective, Biotechnol. Appl. Biochem., 2018, 65(3), 497-508. 
138 M. X. Chu, K. Miyajima, D. Takahashi, T. Arakawa, K. Sano and S. Sawada, et al., Soft contact lens biosensor for in situ monitoring of tear glucose as non-invasive blood sugar assessment, Talanta, 2011, 83(3), 960-965. Available from: http://www.sciencedirect.com/science/article/pii/ S0039914010008519.

139 P. Mehrotra, Biosensors and their applications - A review, J. Oral. Biol. Craniofac. Res., 2016, 6(2), 153-159. Available from: http://www.sciencedirect.com/science/article/ pii/S2212426815001323.

140 A. Kaushik and M. A. Mujawar, Point of Care Sensing Devices: Better Care for Everyone, Sensors, 2018, 18(12), 4303. Available from: https://pubmed.ncbi.nlm.nih.gov/30563249.

141 G. Kaklamani, D. Kazaryan, J. Bowen, F. Iacovella, S. H. Anastasiadis and G. Deligeorgis, On the electrical conductivity of alginate hydrogels, Regener. Biomater., 2018, 5(5), 293-301.

142 E. C. G. Frachini and D. F. S. Petri, Magneto-responsive hydrogels: Preparation, characterization, biotechnological and environmental applications, J. Braz. Chem. Soc., 2019, 30(10), 2010-2028.

143 J. Zhang, Q. Huang and J. Du, Recent advances in magnetic hydrogels, Polym. Int., 2016, 65(12), 1365-1372.

144 K. Hu, J. Sun, Z. Guo, P. Wang, Q. Chen and M. Ma, et al., A novel magnetic hydrogel with aligned magnetic colloidal assemblies showing controllable enhancement of magnetothermal effect in the presence of alternating magnetic field, Adv. Mater., 2015, 27(15), 2507-2514.

145 O. Ozay, S. Ekici, Y. Baran, N. Aktas and N. Sahiner, Removal of toxic metal ions with magnetic hydrogels, Water Res., 2009, 43(17), 4403-4411.

146 M. Häring, J. Schiller, J. Mayr, S. Grijalvo, R. Eritja and D. Díaz, Magnetic Gel Composites for Hyperthermia Cancer Therapy, Gels, 2015, 1(2), 135-161.

147 Y.-Y. Liang, L.-M. Zhang, W. Jiang and W. Li, Embedding Magnetic Nanoparticles into Polysaccharide-Based Hydrogels for Magnetically Assisted Bioseparation, ChemPhysChem, 2007, 8(16), 2367-2372.

148 G. Beaune and C. Ménager, In situ precipitation of magnetic fluid encapsulated in giant liposomes, J. Colloid Interface Sci., 2010, 343(1), 396-399.

149 M. K. Shin, S. I. Kim, S. J. Kim, S. Y. Park, Y. H. Hyun and Y. P. Lee, et al., Controlled magnetic nanofiber hydrogels by clustering ferritin, Langmuir, 2008, 24(21), 12107-12111.

150 G. Giani, S. Fedi and R. Barbucci, Hybrid Magnetic Hydrogel: A Potential System for Controlled Drug Delivery by Means of Alternating Magnetic Fields, Polymers, 2012, 4(2), 1157-1169.

151 S. Kango, S. Kalia, A. Celli, J. Njuguna, Y. Habibi and R. Kumar, Surface modification of inorganic nanoparticles for development of organic-inorganic nanocomposites - A review, Prog. Polym. Sci., 2013, 38, 1232-1261.

152 M. F. Horst, M. D. Ninago and V. Lassalle, Magnetically responsive gels based on crosslinked gelatin: An overview on the synthesis, properties, and their potential in water remediation, Int. J. Polym. Mater. Polym. Biomater., 2018, 67(11), 647-659.
153 T. Glaser, V. B. Bueno, D. R. Cornejo, D. F. S. Petri and H. Ulrich, Neuronal adhesion, proliferation and differentiation of embryonic stem cells on hybrid scaffolds made of xanthan and magnetite nanoparticles, Biomed. Mater., 2015, 10(4), 045002.

154 P. S. Castro, M. Bertotti, A. F. Naves, L. H. Catalani, D. R. Cornejo and G. D. Bloisi, et al., Hybrid magnetic scaffolds: The role of scaffolds charge on the cell proliferation and Ca2+ ions permeation, Colloids Surf., B, 2017, 156, 388-396.

155 R. Muzzalupo, L. Tavano, C. O. Rossi, N. Picci and G. A. Ranieri, Novel pH sensitive ferrogels as new approach in cancer treatment: Effect of the magnetic field on swelling and drug delivery, Colloids Surf., B, 2015, 134, 273-278.

156 J. I. Kim, C. J. Chun, B. Kim, J. M. Hong, J. K. Cho and S. H. Lee, et al., Thermosensitive/magnetic poly(organophosphazene) hydrogel as a long-term magnetic resonance contrast platform, Biomaterials, 2012, 33(1), 218-224.

157 Y. Li, G. Huang, X. Zhang, B. Li, Y. Chen and T. Lu, et al., Magnetic Hydrogels and Their Potential Biomedical Applications, Adv. Funct. Mater., 2013, 23(6), 660-672.

158 Y. Xia, T. D. Nguyen, M. Yang, B. Lee, A. Santos and P. Podsiadlo, et al., Self-assembly of self-limiting monodisperse supraparticles from polydisperse nanoparticles, Nat. Nanotechnol., 2011, 6(9), 580-587.

159 S. Laurent, S. Dutz, U. O. Häfeli and M. Mahmoudi, Magnetic fluid hyperthermia: Focus on superparamagnetic iron oxide nanoparticles, Adv. Colloid Interface Sci., 2011, 166, 8-23.

160 C. S. S. R. Kumar and F. Mohammad, Magnetic nanomaterials for hyperthermia-based therapy and controlled drug delivery, Adv. Drug Delivery Rev., 2011, 63, 789-808.

161 H. Liu, C. Wang, Q. Gao, X. Liu and Z. Tong, Magnetic hydrogels with supracolloidal structures prepared by suspension polymerization stabilized by $\mathrm{Fe} 2 \mathrm{O} 3$ nanoparticles, Acta Biomater., 2010, 6(1), 275-281, DOI: 10.1016/j.actbio. 2009.06.018.

162 D. Ogomi, T. Serizawa and M. Akashi, Controlled release based on the dissolution of a calcium carbonate layer deposited on hydrogels, J. Controlled Release, 2005, 103(2), 315-323.

163 D. S. Couto, Z. Hong and J. F. Mano, Development of bioactive and biodegradable chitosan-based injectable systems containing bioactive glass nanoparticles, Acta Biomater., 2009, 5(1), 115-123.

164 C. Wang, H. Liu, Q. Gao, X. Liu and Z. Tong, Alginatecalcium carbonate porous microparticle hybrid hydrogels with versatile drug loading capabilities and variable mechanical strengths, Carbohydr. Polym., 2008, 71(3), 476-480.

165 N. Häntzschel, F. Zhang, F. Eckert, A. Pich and M. A. Winnik, Poly(N-vinylcaprolactam-co-glycidyl methacrylate) aqueous microgels labeled with fluorescent LaF3:Eu nanoparticles, Langmuir, 2007, 23(21), 10793-10800.

166 A. K. Nayak and B. Das, Introduction to polymeric gels, Polymeric Gels, Elsevier, 2018, pp. 3-27.

167 B. Mishra, M. Upadhyay, A. S. Reddy, B. Vasant and M. Muthu, Hydrogels: An introduction to a controlled drug 
delivery device, synthesis and application in drug delivery and tissue engineering, Austin J. Biomed. Eng., 2017, 4(1), 1-13.

168 M. O. Lamminen, H. W. Walker and L. K. Weavers, Mechanisms and factors influencing the ultrasonic cleaning of particle-fouled ceramic membranes, J. Membr. Sci., 2004, 237(1-2), 213-223.

169 L. V. Wang and S. Hu, Photoacoustic tomography: In vivo imaging from organelles to organs, Science, 2012, 335, 1458-1462.

170 N. Huebsch, C. J. Kearney, X. Zhao, J. Kim, C. A. Cezar and Z. Suo, et al., Ultrasound-triggered disruption and selfhealing of reversibly cross-linked hydrogels for drug delivery and enhanced chemotherapy, Proc. Natl. Acad. Sci. U. S. A., 2014, 111(27), 9762-9767.

171 Y. Zhang, R. Jiang, A. Fang, Y. Zhao, T. Wu and X. Cao, et al., A highly transparent, elastic, injectable sericin hydrogel induced by ultrasound, Polym. Test., 2019, 77, 105890.

172 K. P. Mercado, M. Helguera, D. C. Hocking and D. Dalecki, Noninvasive Quantitative Imaging of Collagen Microstructure in Three-Dimensional Hydrogels Using High-Frequency Ultrasound, Tissue Eng., Part C, 2015, 21(7), 671-682.

173 L. Yan, L. Wang, S. Gao, C. Liu, Z. Zhang and A. Ma, et al., Celery cellulose hydrogel as carriers for controlled release of short-chain fatty acid by ultrasound, Food Chem., 2019, 309, 125717.

174 W. C. Huang, C. J. Bettinger, K. Rhee and C. J. Bettinger, Ultrasound-Mediated Self-Healing Hydrogels Based on Tunable Metal-Organic Bonding, Biomacromolecules, 2017, 18(4), 1162-1171.

175 Z. Sun, C. Song, C. Wang, Y. Hu and J. Wu, Hydrogel-Based Controlled Drug Delivery for Cancer Treatment: A Review, Mol. Pharmaceutics, 2020, 17(2), 373-391.

176 Y. Z. Zhao, L. N. Du, C. T. Lu, Y. G. Jin and S. P. Ge, Potential and problems in ultrasound-responsive drug delivery systems, Int. J. Nanomed., 2013, 8, 1621-1633.

177 Y. Z. Zhang, K. H. Lee, D. H. Anjum, R. Sougrat, Q. Jiang and H. Kim, et al., MXenes stretch hydrogel sensor performance to new limits, Sci. Adv., 2018, 4(6), eaat0098.

178 C. S. Kwok, P. D. Mourad, L. A. Crum and B. D. Ratner, Self-assembled molecular structures as ultrasonicallyresponsive barrier membranes for pulsatile drug delivery, J. Biomed. Mater. Res., 2001, 57(2), 151-164.

179 C. S. Kwok, P. D. Mourad, L. A. Crum and B. D. Ratner, Surface modification of polymers with self-assembled molecular structures: Multitechnique surface characterization, Biomacromolecules, 2000, 1(1), 139-148.

180 Y. Si, L. Wang, X. Wang, N. Tang, J. Yu and B. Ding, UltrahighWater-Content, Superelastic, and Shape-Memory NanofiberAssembled Hydrogels Exhibiting Pressure-Responsive Conductivity, Adv. Mater., 2017, 29, 1700339.

181 Z. Shao and F. Vollrath, Surprising strength of silkworm silk, Nature, 2002, 418(6899), 741.

182 E. Steven, W. R. Saleh, V. Lebedev, S. F. A. Acquah, V. Laukhin and R. G. Alamo, et al., Carbon nanotubes on a spider silk scaffold, Nat. Commun., 2013, 4(1), 1-8.
183 J. Visser, F. P. W. Melchels, J. E. Jeon, E. M. Van Bussel, L. S. Kimpton and H. M. Byrne, et al., Reinforcement of hydrogels using three-dimensionally printed microfibres, Nat. Commun., 2015, 6(1), 1-10.

184 T. A. Schaedler, A. J. Jacobsen, A. Torrents, A. E. Sorensen, J. Lian and J. R. Greer, et al., Ultralight metallic microlattices, Science, 2011, 334(6058), 962-965.

185 T. Hiratani, O. Kose, W. Y. Hamad and M. J. Maclachlan, Stable and sensitive stimuli-responsive anisotropic hydrogels for sensing ionic strength and pressure, Mater. Horiz., 2018, 5(6), 1076-1081.

186 X. Y. Lin, Z. J. Wang, P. Pan, Z. L. Wu and Q. Zheng, Monodomain hydrogels prepared by shear-induced orientation and subsequent gelation, RSC Adv., 2016, 6(97), 95239-95245.

187 X. Wang, B. Ding, G. Sun, M. Wang and J. Yu, Electrospinning/netting: A strategy for the fabrication of threedimensional polymer nano-fiber/nets, Prog. Mater. Sci., 2013, 58, 1173-1243.

188 A. R. Hibbins, P. Kumar, Y. E. Choonara, P. P. D. Kondiah, T. Marimuthu and L. C. du Toit, et al., Design of a versatile pH-responsive hydrogel for potential oral delivery of gastric-sensitive bioactives, Polymers, 2017, 9(10), 1-19, DOI: $10.3390 /$ polym9060189.

189 G. Kocak, C. Tuncer and V. Bütün, PH-Responsive polymers, Polym. Chem., 2017, 8(1), 144-176.

190 S. Chatterjee and P. C. Hui, Delivery and Textile Application, Molecules, 2019, 24(14), 2547.

191 N. Ninan, A. Forget, V. P. Shastri, N. H. Voelcker and A. Blencowe, Antibacterial and Anti-Inflammatory $\mathrm{pH}$-Responsive Tannic Acid-Carboxylated Agarose Composite Hydrogels for Wound Healing, ACS Appl. Mater. Interfaces, 2016, 8(42), 28511-28521.

192 Y. Dong, W. Wang, O. Veiseh, E. A. Appel, K. Xue and M. J. Webber, et al., Injectable and Glucose-Responsive Hydrogels Based on Boronic Acid-Glucose Complexation, Langmuir, 2016, 32(34), 8743-8747.

193 D. Suhag, R. Bhatia, S. Das, A. Shakeel, A. Ghosh and A. Singh, et al., Physically cross-linked pH-responsive hydrogels with tunable formulations for controlled drug delivery, RSC Adv., 2015, 5(66), 53963-53972.

194 A. Hebeish, S. Farag, S. Sharaf and T. I. Shaheen, Radically new cellulose nanocomposite hydrogels: Temperature and pH responsive characters, Int. J. Biol. Macromol., 2015, 81, 356-361, DOI: 10.1016/j.ijbiomac.2015.08.014.

195 A. El-Hag Ali Said, Radiation synthesis of interpolymer polyelectrolyte complex and its application as a carrier for colon-specific drug delivery system, Biomaterials, 2005, 26(15), 2733-2739.

196 S. K. Gunasekar, J. S. Haghpanah and J. K. Montclare, Review Assembly of bioinspired helical protein fibers, Polym. Adv. Technol., 2008, 454-468.

197 L. Li, J. Gu, J. Zhang, Z. Xie, Y. Lu and L. Shen, et al., Injectable and biodegradable $\mathrm{pH}$-responsive hydrogels for localized and sustained treatment of human fibrosarcoma, ACS Appl. Mater. Interfaces, 2015, 7(15), 8033-8040.

198 Y. Zhang, L. Tao, S. Li and Y. Wei, Synthesis of multiresponsive and dynamic chitosan-based hydrogels for 
controlled release of bioactive molecules, Biomacromolecules, 2011, 12(8), 2894-2901.

199 J. Huang and X. Jiang, Injectable and Degradable pH-Responsive Hydrogels via Spontaneous Amino-Yne Click Reaction, ACS Appl. Mater. Interfaces, 2018, 10(1), 361-370.

200 K. L. Shantha and D. R. K. Harding, Preparation and in-vitro evaluation of poly[ $\mathrm{N}$-vinyl-2-pyrrolidone-polyethylene glycol diacrylate]-chitosan interpolymeric $\mathrm{pH}$-responsive hydrogels for oral drug delivery, Int. J. Pharm., 2000, 207(1-2), 65-70.

201 X. J. Loh and O. A. Scherman, in Polymeric and Self Assembled Hydrogels, ed. X. J. Loh and O. A. Scherman, Royal Society of Chemistry, 2012, (Monographs in Supramolecular Chemistry).

202 B. D. Fairbanks, M. P. Schwartz, A. E. Halevi, C. R. Nuttelman, C. N. Bowman and K. S. Anseth, A versatile synthetic extracellular matrix mimic via thiol-norbornene photopolymerization, Adv. Mater., 2009, 21(48), 5005-5010.

203 S. V. Wegner, F. C. Schenk, S. Witzel, F. Bialas and J. P. Spatz, Cobalt Cross-Linked Redox-Responsive PEG Hydrogels: From Viscoelastic Liquids to Elastic Solids, Macromolecules, 2016, 49(11), 4229-4235.

204 L. Liu, Y. Pei, C. He and L. Chen, Synthesis of novel thermo- and redox-sensitive polypeptide hydrogels, Polym. Int., 2017, 66(5), 712-718, DOI: 10.1002/pi.5313.

205 R. Cheng, F. Feng, F. Meng, C. Deng, J. Feijen and Z. Zhong, Glutathione-responsive nano-vehicles as a promising platform for targeted intracellular drug and gene delivery, J. Controlled Release, 2011, 152(1), 2-12, DOI: 10.1016/j.jconrel.2011.01.030.

206 F. Meng, W. E. Hennink and Z. Zhong, Reduction-sensitive polymers and bioconjugates for biomedical applications, Biomaterials, 2009, 30(12), 2180-2198.

207 F. Schafer and G. Buettner, Redox Environment of the Cell, Free Radical Biol. Med., 2001, 30(11), 1191-1212.

208 C. Legros, M. C. De Pauw-Gillet, K. C. Tam, S. Lecommmandoux and $\mathrm{D}$. Taton, $\mathrm{PH}$ and redox responsive hydrogels and nanogels made from poly(2-ethyl-2-oxazoline), Polym. Chem., 2013, 4, 4801-4808.

209 M. Nakahata, Y. Takashima, H. Yamaguchi and A. Harada, Redox-responsive self-healing materials formed from host-guest polymers, Nat. Commun., 2011, 2(1), 1-6, DOI: 10.1038/ncomms1521.

210 T. Kajisa and T. Sakata, Glucose-responsive hydrogel electrode for biocompatible glucose transistor, Sci. Technol. Adv. Mater., 2017, 18(1), 26-33.

211 K. M. Bratlie, R. L. York, M. A. Invernale, R. L. Langer and D. G. Anderson, Materials for diabetes therapeutics, $A d v$. Healthcare Mater., 2012, 1(3), 267-284.

212 R. Ma and L. Shi, Phenylboronic acid-based glucoseresponsive polymeric nanoparticles: Synthesis and applications in drug delivery, Polym. Chem., 2014, 5, 1503-1518.

213 T. Yang, R. Ji, X. X. Deng, F. S. Du and Z. C. Li, Glucoseresponsive hydrogels based on dynamic covalent chemistry and inclusion complexation, Soft Matter, 2014, 10(15), 2671-2678.

214 G. Lin, S. Chang, H. Hao, P. Tathireddy, M. Orthner and J. Magda, et al., Osmotic swelling pressure response of smart hydrogels suitable for chronically implantable glucose sensors, Sens. Actuators, B, 2010, 144(1), 332-336.

215 S. Tierney, S. Volden and B. T. Stokke, Glucose sensors based on a responsive gel incorporated as a Fabry-Perot cavity on a fiber-optic readout platform, Biosens. Bioelectron., 2009, 24(7), 2034-2039.

216 O. Garcia-Valdez, T. Brescacin, J. Arredondo, J. Bouchard, P. G. Jessop and P. Champagne, et al., Grafting CO2-responsive polymers from cellulose nanocrystals: Via nitroxide-mediated polymerisation, Polym. Chem., 2017, 8(28), 4124-4131.

217 W. Zheng, G. Yang, N. Shao, L. J. Chen, B. Ou and S. T. Jiang, et al., CO2 stimuli-responsive, injectable block copolymer hydrogels cross-linked by discrete organoplatinum(II) metallacycles via stepwise post-assembly polymerization, J. Am. Chem. Soc., 2017, 139(39), 13811-13820.

218 Y. Wang, Y. Gu, E. G. Keeler, J. V. Park, R. G. Griffin and J. A. Johnson, Star PolyMOCs with Diverse Structures, Dynamics, and Functions by Three-Component Assembly, Angew. Chem., Int. Ed., 2017, 56(1), 188-192.

219 J. A. Foster, R. M. Parker, A. M. Belenguer, N. Kishi, S. Sutton and C. Abell, et al., Differentially addressable cavities within metal-organic cage-cross-linked polymeric hydrogels, J. Am. Chem. Soc., 2015, 137(30), 9722-9729.

220 K. Kawamoto, S. C. Grindy, J. Liu, N. Holten-Andersen and J. A. Johnson, Dual role for 1,2,4,5-tetrazines in polymer networks: Combining Diels-Alder reactions and metal coordination to generate functional supramolecular gels, ACS Macro Lett., 2015, 4(4), 458-461.

221 Y. Wang, M. Zhong, J. V. Park, A. V. Zhukhovitskiy, W. Shi and J. A. Johnson, Block Co-PolyMOCs by Stepwise Self-Assembly, J. Am. Chem. Soc., 2016, 138(33), 10708-10715.

222 A. V. Zhukhovitskiy, M. Zhong, E. G. Keeler, V. K. Michaelis, J. E. P. Sun and M. J. A. Hore, et al., Highly branched and loop-rich gels via formation of metal-organic cages linked by polymers, Nat. Chem., 2016, 8(1), 33-41.

223 X. Yan, S. Li, T. R. Cook, X. Ji, Y. Yao and J. B. Pollock, et al., Hierarchical self-assembly: Well-defined supramolecular nanostructures and metallohydrogels via amphiphilic discrete organoplatinum(II) metallacycles, J. Am. Chem. Soc., 2013, 135(38), 14036-14039.

224 W. Zheng, L. J. Chen, G. Yang, B. Sun, X. Wang and B. Jiang, et al., Construction of Smart Supramolecular Polymeric Hydrogels Cross-linked by Discrete Organoplatinum(II) Metallacycles via Post-Assembly Polymerization, J. Am. Chem. Soc., 2016, 138(14), 4927-4937.

225 Z. Y. Li, Y. Zhang, C. W. Zhang, L. J. Chen, C. Wang and H. Tan, et al., Cross-linked supramolecular polymer gels constructed from discrete multi-pillar[5]arene metallacycles and their multiple stimuli-responsive behavior, J. Am. Chem. Soc., 2014, 136(24), 8577-8589.

226 X. Yan, S. Li, J. B. Pollock, T. R. Cook, J. Chen and Y. Zhang, et al., Supramolecular polymers with tunable topologies via hierarchical coordination-driven self-assembly and hydrogen bonding interfaces, Proc. Natl. Acad. Sci. U. S. A., 2013, 110(39), 15585-15590. 
227 G. Yu, Y. Lu, X. Liu, W. J. Wang, Q. Yang and H. Xing, et al., Polyethylenimine-assisted extraction of $\alpha$-tocopherol from tocopherol homologues and CO2-triggered fast recovery of the extractant, Ind. Eng. Chem. Res., 2014, 53(41), 16025-16032.

228 Y. Ma and L. Y. L. Yung, Detection of dissolved CO2 based on the aggregation of gold nanoparticles, Anal. Chem., 2014, 86(5), 2429-2435.

229 Q. Yan and Y. Zhao, CO2-stimulated diversiform deformations of polymer assemblies, J. Am. Chem. Soc., 2013, 135(44), 16300-16303.

230 W. Lu, J. P. Sculley, D. Yuan, R. Krishna, Z. Wei and H.-C. Zhou, Polyamine-Tethered Porous Polymer Networks for Carbon Dioxide Capture from Flue Gas, Angew. Chem., Int. Ed., 2012, 51(30), 7480-7484.

231 Q. Yan, R. Zhou, C. Fu, H. Zhang, Y. Yin and J. Yuan, CO2-Responsive Polymeric Vesicles that Breathe, Angew. Chem., Int. Ed., 2011, 50(21), 4923-4927.

232 B. Ochiai, K. Yokota, A. Fujii, D. Nagai and T. Endo, Reversible trap - Release of $\mathrm{CO} 2$ by polymers bearing DBU and DBN moieties, Macromolecules, 2008, 41(4), 1229-1236.

233 H. J. Zhang, Y. N. Zhang, B. Yang and L. G. Wang, Swelling or deswelling? Composition-dependent $\mathrm{CO} 2$-responsive swelling behaviors of poly(acrylamide-co-2-dimethylaminoethyl methacrylate) hydrogels, Colloid Polym. Sci., 2018, 296(2), 393-403.

234 L. Wang, J. Shang, S. Liu, L. Liu, S. Zhang and Y. Deng, Environmentally benign and effective syntheses of N-substituted carbamates via alcoholysis of disubstituted ureas over $\mathrm{TiO} 2 / \mathrm{SiO} 2$ catalyst, Pure Appl. Chem., 2011, 84(3), 461-471.

235 L. Wang, H. Li, S. Xin, P. He, Y. Cao and F. Li, et al., Highly efficient synthesis of diethyl carbonate via one-pot reaction from carbon dioxide, epoxides and ethanol over KI-based binary catalyst system, Appl. Catal., A, 2014, 471, 19-27.

236 D. Nagai, A. Suzuki, Y. Maki and H. Takeno, Reversible chain association/dissociation via a $\mathrm{CO} 2$ responsive crosslinking/ decrosslinking system, Chem. Commun., 2011, 47(31), 8856-8858.

237 J. Cheng, G. Shan and P. Pan, Triple Stimuli-Responsive N-Isopropylacrylamide Copolymer toward Metal Ion Recognition and Adsorption via a Thermally Induced Sol-Gel Transition, Ind. Eng. Chem. Res., 2017, 56(5), 1223-1232.

238 X. Q. Wang, R. Hong, C. F. Wang, P. F. Tan, W. Q. Ji and S. Chen, Ultrafast mechano-responsive photonic hydrogel towards multicolor displays via the pressure sensation, Mater. Lett., 2017, 189, 321-324.

239 B. W. Liu, H. Zhou, S. T. Zhou, H. J. Zhang, A. C. Feng and C. M. Jian, et al., Synthesis and self-assembly of CO2temperature dual stimuli-responsive triblock copolymers, Macromolecules, 2014, 47(9), 2938-2946.

$240 \mathrm{~J} . \mathrm{Hu}, \mathrm{G}$. Zhang and S. Liu, Enzyme-responsive polymeric assemblies, nanoparticles and hydrogels, Chem. Soc. Rev., 2012, 41(18), 5933-5949.

241 M. E. Hahn and N. C. Gianneschi, Enzyme-directed assembly and manipulation of organic nanomaterials, Chem. Commun., 2011, 47(43), 11814-11821.

242 R. Chandrawati, Enzyme-responsive polymer hydrogels for therapeutic delivery, Exp. Biol. Med., 2016, 241(9), 972-979, DOI: $10.1177 / 1535370216647186$.
243 Y. M. Abul-Haija and R. V. Ulijn, Enzyme-responsive hydrogels for biomedical applications, Soft Matter, 2014, (2), 112-134.

244 N. C. Inestrosa, A. Alvarez, C. A. Pérez, R. D. Moreno, M. Vicente and C. Linker, et al., Acetylcholinesterase accelerates assembly of amyloid- $\beta$-peptides into Alzheimer's fibrils: Possible role of the peripheral site of the enzyme, Neuron, 1996, 16(4), 881-891.

245 V. Turk, J. Kos and B. Turk, Cysteine cathepsins (proteases) On the main stage of cancer?, Cancer Cell, 2004, 5, 409-410.

246 O. Wichterle and D. Lím, Hydrophilic Gels for Biological Use, Nature, 1960, 185(4706), 117-118.

247 G. A. Silva, C. Czeisler, K. L. Niece, E. Beniash, D. A. Harrington and J. A. Kessler, et al., Selective Differentiation of Neural Progenitor Cells by High-Epitope Density Nanofibers, Science, 2004, 303(5662), 1352-1355.

248 B. D. Ratner, A. S. Hoffman, F. J. Schoen and J. E. Lemons, Biomaterials science: an introduction to materials in medicine, Chem. Eng., 2004, 26.

249 M. Dong and Y. Chen, The stimuli-responsive properties of hydrogels based on natural polymers, Hydrogels Based on Natural Polymers, Elsevier Inc., 2019, pp. 173-222.

250 A. Tanaka, Y. Fukuoka, Y. Morimoto, T. Honjo, D. Koda and M. Goto, et al., Cancer cell death induced by the intracellular self-assembly of an enzyme-responsive supramolecular gelator, J. Am. Chem. Soc., 2015, 137(2), 770-775.

251 D. Ishii, D. Tatsumi, T. Matsumoto, K. Murata, H. Hayashi and $\mathrm{H}$. Yoshitani, Investigation of the structure of cellulose in $\mathrm{LiCl} / \mathrm{DMAc}$ solution and its gelation behavior by smallangle X-ray scattering measurements, Macromol. Biosci., 2006, 6(4), 293-300.

252 H. Song, Y. Niu, Z. Wang and J. Zhang, Liquid crystalline phase and gel-sol transitions for concentrated microcrystalline cellulose (MCC)/1-ethyl-3-methylimidazolium acetate (EMIMAc) solutions, Biomacromolecules, 2011, 12(4), 1087-1096.

253 Molecular interactions (noncovalent interactions).

254 R. Koprowski, Book review of "The Biomedical Engineering Handbook" fourth edition, edited by Joseph D. Bronzino, Donald R. Peterson. Biomed. Eng. Online. 2016;15(1): 1. , DOI: $10.1186 / \mathrm{s} 12938-015-0119-0$.

255 G. Bartkowiak and I. Frydrych, Superabsorbents and their medical applications, Handbook of Medical Textiles, 2011.

256 T. Maki, R. Yoshisaki, S. Akama and M. Yamanaka, Enzyme responsive properties of amphiphilic urea supramolecular hydrogels, Polym. J., 2020, 2020, 1-8.

257 Z. Yang and B. Xu, Supramolecular hydrogels based on biofunctional nanofibers of self-assembled small molecules, J. Mater. Chem., 2007, 17(23), 2385-2393.

258 A. R. Hirst, B. Escuder, J. F. Miravet and D. K. Smith, HighTech Applications of Self-Assembling Supramolecular Nanostructured Gel-Phase Materials: From Regenerative Medicine to Electronic Devices, Angew. Chem., Int. Ed., 2008, 47(42), 8002-8018.

259 M. de Loos, J. H. van Esch, R. M. Kellogg and B. L. Feringa, C3-Symmetric, amino acid based organogelators and 
thickeners: a systematic study of structure-property relations, Tetrahedron, 2007, 63(31), 7285-7301.

260 L. A. Estroff and A. D. Hamilton, Water gelation by small organic molecules, Chem. Rev., 2004, 104(3), 1201-1217.

261 R. Zhang, A. Bowyer, R. Eisenthal and J. Hubble, A smart membrane based on an antigen-responsive hydrogel, Biotechnol. Bioeng., 2007, 97, 976-984.

262 Y. Huang, Y. Ma, Y. Chen, X. Wu, L. Fang and Z. Zhu, et al., Target-responsive DNAzyme cross-linked hydrogel for visual quantitative detection of lead, Anal. Chem., 2014, 86(22), 11434-11439.

263 R. Liu, Y. Huang, Y. Ma, S. Jia, M. Gao and J. Li, et al., Design and synthesis of target-responsive aptamer-cross-linked hydrogel for visual quantitative detection of ochratoxin A, ACS Appl. Mater. Interfaces, 2015, 7(12), 6982-6990.

264 B. Lin, Z. Guan, Y. Song, E. Song, Z. Lu and D. Liu, et al., Lateral flow assay with pressure meter readout for rapid point-of-care detection of disease-associated protein, $L a b$ Chip, 2018, 18(6), 965-970.

265 D. Liu, S. Jia, H. Zhang, Y. Ma, Z. Guan and J. Li, et al., Integrating Target-Responsive Hydrogel with Pressuremeter Readout Enables Simple, Sensitive, User-Friendly, Quantitative Point-of-Care Testing, ACS Appl. Mater. Interfaces, 2017, 9(27), 22252-22258, DOI: 10.1021/acsami.7b05531.

266 Q. Wang, S. Li, Z. Wang, H. Liu and C. Li, Preparation and characterization of a positive thermoresponsive hydrogel for drug loading and release, J. Appl. Polym. Sci., 2009, 111(3), 1417-1425.

267 K. Itoh, M. Yahaba and A. Takahashi, RT-I journal of, 2008 undefined, In situ gelling xyloglucan/pectin formulations for oral sustained drug delivery, Elsevier.

268 P. Alexandridis and T. Alan Hatton, Poly(ethylene oxide)poly(propylene oxide)poly(ethylene oxide) block copolymer surfactants in aqueous solutions and at interfaces: thermodynamics, structure, dynamics, and modeling, Colloids Surf., A, 1995, 96, 1-46.

269 Z. Li, X. Guo, S. Matsushita and J. Guan, Differentiation of cardiosphere-derived cells into a mature cardiac lineage using biodegradable poly(N-isopropylacrylamide) hydrogels, Biomaterials, 2011, 32(12), 3220-3232.

270 S. C. Cheng, W. Feng, I. I. Pashikin, L. H. Yuan, H. C. Deng and Y. Zhou, Radiation polymerization of thermo-sensitive poly (N-vinylcaprolactam), Radiat. Phys. Chem., 2002, 63(3-6), 517-519.

271 P. Jiang, X. Sheng, S. Yu, H. Li, J. Lu and J. Zhou, et al., Preparation and characterization of thermo-sensitive gel with phenolated alkali lignin, Sci. Rep., 2018, 8(1), 1-10, DOI: $10.1038 / \mathrm{s} 41598-018-32672-\mathrm{z}$.

272 H. Gai, J. Wu, C. Wu, X. Sun, F. Jia and Y. Yu, Synthesis and characterization of thermosensitive hydrogel with improved mechanical properties, J. Mater. Res., 2015, 30(16), 2400-2407, DOI: 10.1557/jmr.2015.233.

273 H. Jiang, L. Fan, S. Yan, F. Li, H. Li and J. Tang, Tough and electro-responsive hydrogel actuators with bidirectional bending behavior, Nanoscale, 2019, 11(5), 2231-2237.

274 L. Peng, Y. Liu, J. Huang, J. Li, J. Gong and J. Ma, Microfluidic fabrication of highly stretchable and fast electro-responsive graphene oxide/polyacrylamide/alginate hydrogel fibers, Eur. Polym. J., 2018, 103, 335-341, DOI: 10.1016/j.eurpolymj.2018.04.019.

275 Y. Li, Y. Sun, Y. Xiao, G. Gao, S. Liu and J. Zhang, et al., Electric Field Actuation of Tough Electroactive Hydrogels Cross-Linked by Functional Triblock Copolymer Micelles, ACS Appl. Mater. Interfaces, 2016, 8(39), 26326-26331.

276 C. M. Daikuzono, C. Delaney, H. Tesfay, L. Florea, O. N. Oliveira and A. Morrin, et al., Impedance spectroscopy for monosaccharides detection using responsive hydrogel modified paper-based electrodes, Anahyst, 2017, 142(7), 1133-1139.

277 S. Botelho da Silva, M. Krolicka, L. A. M. van den Broek, A. E. Frissen and C. G. Boeriu, Water-soluble chitosan derivatives and $\mathrm{pH}$-responsive hydrogels by selective C-6 oxidation mediated by TEMPO-laccase redox system, Carbohydr. Polym., 2018, 186, 299-309.

278 L. Xu, L. Qiu, Y. Sheng, Y. Sun, L. Deng and X. Li, et al., Biodegradable pH-responsive hydrogels for controlled dual-drug release, J. Mater. Chem. B, 2018, 6(3), 510-517.

279 N. Kanmaz, D. Saloglu and J. Hizal, Humic acid embedded chitosan/poly (vinyl alcohol) pH-sensitive hydrogel: Synthesis, characterization, swelling kinetic and diffusion coefficient, Chem. Eng. Commun., 2019, 206(9), 1168-1180, DOI: 10.1080/ 00986445.2018.1550396.

280 C. Jin, W. Song, T. Liu, J. Xin, W. C. Hiscox and J. Zhang, et al., Temperature and $\mathrm{pH}$ Responsive Hydrogels Using Methacrylated Lignosulfonate Cross-Linker: Synthesis, Characterization, and Properties, ACS Sustainable Chem. Eng., 2018, 6(2), 1763-1771.

281 Y. Liang, X. Zhao, P. X. Ma, B. Guo, Y. Du and X. Han, $\mathrm{pH}$-responsive injectable hydrogels with mucosal adhesiveness based on chitosan-grafted-dihydrocaffeic acid and oxidized pullulan for localized drug delivery, J. Colloid Interface Sci., 2019, 536, 224-234, DOI: 10.1016/j.jcis.2018.10.056.

282 Z. Wang, X. Han, Y. Wang, K. Men, L. Cui and J. Wu, et al., Facile preparation of low swelling, high strength, selfhealing and $\mathrm{pH}-$ responsive hydrogels based on the triplenetwork structure, Front. Mater. Sci., 2019, 13(1), 54-63.

283 T. Chen, P. J. Colver and S. A. F. Bon, Organic-Inorganic Hybrid Hollow Spheres Prepared from TiO2-Stabilized Pickering Emulsion Polymerization, Adv. Mater., 2007, 19, 2286-2289.

284 W. Zhao, K. Odelius, U. Edlund, C. Zhao and A. C. Albertsson, In Situ Synthesis of Magnetic Field-Responsive Hemicellulose Hydrogels for Drug Delivery, Biomacromolecules, 2015, 16(8), 2522-2528.

285 R. Messing, N. Frickel, L. Belkoura, R. Strey, H. Rahn and S. Odenbach, et al., Cobalt ferrite nanoparticles as multifunctional cross-linkers in PAAm ferrohydrogels, Macromolecules, 2011, 44(8), 2990-2999.

286 D. Huang, M. Sun, Y. Bu, F. Luo, C. Lin and Z. Lin, et al., Microcapsule-embedded hydrogel patches for ultrasound responsive and enhanced transdermal delivery of diclofenac sodium, J. Mater. Chem. B, 2019, 7(14), 2330-2337.

287 T. Emi, K. Michaud, E. Orton, G. Santilli, C. Linh and M. O'Connell, et al., Ultrasonic generation of pulsatile and 
sequential therapeutic delivery profiles from Calciumcrosslinked alginate hydrogels, Molecules, 2019, 24(6), 1048.

288 A. Alford, B. Tucker, V. Kozlovskaya, J. Chen, N. Gupta and R. Caviedes, et al., Encapsulation and ultrasound-triggered release of G-Quadruplex DNA in multilayer hydrogel microcapsules, Polymers, 2018, 10(12), 1342.

289 G. Li, Y. Wang, S. Wang and J. Jiang, A Tough Composite Hydrogel can Controllably Deliver Hydrophobic Drugs under Ultrasound, Macromol. Mater. Eng., 2018, 303(3), 1700483.

290 C. H. Wu, M. K. Sun, J. Shieh, C. S. Chen, C. W. Huang and C. A. Dai, et al., Ultrasound-responsive NIPAM-based hydrogels with tunable profile of controlled release of large molecules, Ultrasonics, 2018, 83, 157-163.

291 S. Yamaguchi, K. Higashi, T. Azuma and A. Okamoto, Supramolecular polymeric hydrogels for ultrasoundguided protein release, Biotechnol. J., 2019, 14(5), 1800530.

292 C. H. Wu, M. K. Sun, Y. Kung, Y. C. Wang, S. L. Chen and H. H. Shen, et al., One injection for one-week controlled release: In vitro and in vivo assessment of ultrasoundtriggered drug release from injectable thermoresponsive biocompatible hydrogels, Ultrason. Sonochem., 2020, 62, 104875.

293 Injectable Self-Healing Glucose-Responsive Hydrogels with pH-Regulated Mechanical Properties.pdf.

294 M. Peña Alvarez, P. Mayorga Burrezo, T. Iwamoto, L. Qiu, M. Kertesz and M. Taravillo, et al., Chameleon-like behaviour of cyclo[n]paraphenylenes in complexes with $\mathrm{C} \backslash \mathrm{n} 70 \backslash \mathrm{n}$ : on their impressive electronic and structural adaptability as probed by Raman spectroscopy, Faraday Discuss., 2014, 4(8), 1166-1169.

295 A. Matsumoto, M. Tanaka, H. Matsumoto, K. Ochi, Y. Moro-Oka and H. Kuwata, et al., Synthetic "smart gel" provides glucose-responsive insulin delivery in diabetic mice, Sci. Adv., 2017, 3(11), eaaq0723.

296 J. D. Ehrick, M. R. Luckett, S. Khatwani, Y. Wei, S. K. Deo and L. G. Bachas, et al., Glucose responsive hydrogel networks based on protein recognition, Macromol. Biosci., 2009, 9(9), 864-868.

297 H. Y. Liu, M. Korc and C. C. Lin, Biomimetic and enzymeresponsive dynamic hydrogels for studying cell-matrix interactions in pancreatic ductal adenocarcinoma, Biomaterials, 2018, 160, 24-36.

298 C. C. Lin, A. Raza and H. Shih, PEG hydrogels formed by thiol-ene photo-click chemistry and their effect on the formation and recovery of insulin-secreting cell spheroids, Biomaterials, 2011, 32(36), 9685-9695.

299 C. C. Lin, C. S. Ki and H. Shih, Thiol-norbornene photoclick hydrogels for tissue engineering applications, J. Appl. Polym. Sci., 2015, 132(8), 41563, DOI: 10.1002/app.41563.

300 Z. Mũnoz, H. Shih and C. C. Lin, Gelatin hydrogels formed by orthogonal thiol-norbornene photochemistry for cell encapsulation, Biomater. Sci., 2014, 2(8), 1063-1072.

301 H. Y. Liu, T. Greene, T. Y. Lin, C. S. Dawes, M. Korc and C. C. Lin, Enzyme-mediated stiffening hydrogels for probing activation of pancreatic stellate cells, Acta Biomater., 2017, 48, 258-269.

302 T. Su, Z. Tang, H. He, W. Li, X. Wang and C. Liao, et al., Glucose oxidase triggers gelation of $\mathrm{N}$-hydroxyimide-heparin conjugates to form enzyme-responsive hydrogels for cellspecific drug delivery, Chem. Sci., 2014, 5(11), 4204-4209.

303 X. Yao, L. Chen, J. Ju, C. Li, Y. Tian and L. Jiang, et al., Superhydrophobic Diffusion Barriers for Hydrogels via Confined Interfacial Modification, Adv. Mater., 2016, 28(34), 7383-7389.

304 L. Chen, Y. Yin, Y.-X. Liu, L. Lin and M. J. Liu, Design and fabrication of functional hydrogels through interfacial engineering, Chin. J. Polym. Sci., 2017, 35, 1181-1193.

305 L. Lin, H. Yi, X. Guo, P. Zhang, L. Chen and D. Hao, et al., Nonswellable hydrogels with robust micro/nano-structures and durable superoleophobic surfaces under seawater, Sci. China Chem., 2018, 61(1), 64-70, DOI: 10.1007/s11426-017-9149-x.

306 S. Rose, A. Prevoteau, P. Elzière, D. Hourdet, A. Marcellan and L. Leibler, Nanoparticle solutions as adhesives for gels and biological tissues, Nature, 2014, 505(7483), 382-385, DOI: $10.1038 /$ nature12806.

307 X. Huang, Y. Sun and S. Soh, Stimuli-Responsive Surfaces for Tunable and Reversible Control of Wettability, Adv. Mater., 2015, 27(27), 4062-4068, DOI: 10.1002/adma.201501578.

308 N. M. Oliveira, Y. S. Zhang, J. Ju, A.-Z. Chen, Y. Chen and S. R. Sonkusale, et al., Hydrophobic Hydrogels: Toward Construction of Floating (Bio)microdevices, Chem. Mater., 2016, 28(11), 3641-3648, DOI: 10.1021/acs.chemmater.5b04445.

309 L. Chen, X. Yao, Z. Gu, K. Zheng, C. Zhao and W. Lei, et al., Covalent tethering of photo-responsive superficial layers on hydrogel surfaces for photo-controlled release, Chem. Sci., 2017, 8(3), 2010-2016, DOI: 10.1039/C6SC04634G.

310 C. Xu, R. He, B. Xie, M. Ismail, C. Yao and J. Luan, et al., Silicone hydrogels grafted with natural amino acids for ophthalmological application, J. Biomater. Sci., Polym. Ed., 2016, 27(13), 1354-1368, DOI: 10.1080/09205063.2016. 1201916.

311 L. Xu, P. Ma, B. Yuan, Q. Chen, S. Lin and X. Chen, et al., Anti-biofouling contact lenses bearing surface-immobilized layers of zwitterionic polymer by one-step modification, $R S C$ $A d v .$, 2014, 4(29), 15030-15035, DOI: 10.1039/C3RA47119E.

312 X. Deng, M. Korogiannaki, B. Rastegari, J. Zhang, M. Chen and Q. Fu, et al., "click" Chemistry-Tethered Hyaluronic Acid-Based Contact Lens Coatings Improve Lens Wettability and Lower Protein Adsorption, ACS Appl. Mater. Interfaces, 2016, 8(34), 22064-22073.

313 X. Hu, H. Tan, X. Wang and P. Chen, Surface functionalization of hydrogel by thiol-yne click chemistry for drug delivery, Colloids Surf., A, 2016, 489, 297-304. Available from: http:// www.sciencedirect.com/science/article/pii/S0927775715303277.

314 Y. Guo, J. Bae, F. Zhao and G. Yu, Functional Hydrogels for Next-Generation Batteries and Supercapacitors, Trends Cogn. Sci., 2019, 1(3), 335-348.

315 Y. S. Zhang and A. Khademhosseini, Advances in engineering hydrogels, Science, 2017, 356(6337), 1-10, DOI: 10.1126/ science.aaf3627.

316 K. Tian, J. Bae, S. E. Bakarich, C. Yang, R. D. Gately and G. M. Spinks, et al., 3D Printing of Transparent and Conductive Heterogeneous Hydrogel-Elastomer Systems, Adv. Mater., 2017, 29(10), 1604827. 
317 H. P. Cong, X. C. Ren, P. Wang and S. H. Yu, Macroscopic multifunctional graphene-based hydrogels and aerogels by a metal ion induced self-assembly process, ACS Nano, 2012, 6(3), 2693-2703.

318 H. Qin, T. Zhang, H. N. Li, H. P. Cong, M. Antonietti and S. H. Yu, Dynamic Au-Thiolate Interaction Induced Rapid Self-Healing Nanocomposite Hydrogels with Remarkable Mechanical Behaviors, Chem, 2017, 3(4), 691-705.

319 S. Hong, D. Sycks, H. F. Chan, S. Lin, G. P. Lopez and F. Guilak, et al., 3D Printing of Highly Stretchable and Tough Hydrogels into Complex, Cellularized Structures, Adv. Mater., 2015, 27(27), 4035-4040.

320 S. Lin, H. Yuk, T. Zhang, G. A. Parada, H. Koo and C. Yu, et al., Stretchable Hydrogel Electronics and Devices, Adv. Mater., 2016, 28(22), 4497-4505.

321 X. Liu, T. C. Tang, E. Tham, H. Yuk, S. Lin and T. K. Lu, et al., Stretchable living materials and devices with hydrogel-elastomer hybrids hosting programmed cells, Proc. Natl. Acad. Sci. U. S. A., 2017, 114(9), 2200-2205.

322 M. Sun, R. Bai, X. Yang, J. Song, M. Qin and Z. Suo, et al., Hydrogel Interferometry for Ultrasensitive and Highly Selective Chemical Detection, Adv. Mater., 2018, 30(46), 1804916.

323 J. Sun, J. Du, J. Yang and J. Wang, Shear-horizontal waves in a rotated Y-cut quartz plate in contact with a viscous fluid, Ultrasonics, 2012, 52(1), 133-137.

324 Y. Yue, X. Wang, J. Han, L. Yu, J. Chen and Q. Wu, et al., Effects of nanocellulose on sodium alginate/polyacrylamide hydrogel: Mechanical properties and adsorption-desorption capacities, Carbohydr. Polym., 2019, 206, 289-301, DOI: 10.1016/j.carbpol.2018.10.105.

325 Y. Chen, K. Zheng, L. Niu, Y. Zhang, Y. Liu and C. Wang, et al., Highly mechanical properties nanocomposite hydrogels with biorenewable lignin nanoparticles, Int. J. Biol. Macromol., 2019, 128, 414-420, DOI: 10.1016/j.ijbiomac.2019.01.099.

326 C. Chen, D. Li, H. Yano and K. Abe, Insect Cuticle-Mimetic Hydrogels with High Mechanical Properties Achieved via the Combination of Chitin Nanofiber and Gelatin, J. Agric. Food Chem., 2019, 67(19), 5571-5578.

327 W. Liu, M. Song, B. Kong and Y. Cui, Flexible and Stretchable Energy Storage: Recent Advances and Future Perspectives, Adv. Mater., 2017, 29(1), 1603436, DOI: 10.1002/adma.201603436.

328 Y. Zhao, S. Chen, J. Hu, J. Yu, G. Feng and B. Yang, et al., Microgel-Enhanced Double Network Hydrogel Electrode with High Conductivity and Stability for Intrinsically Stretchable and Flexible All-Gel-State Supercapacitor, ACS Appl. Mater. Interfaces, 2018, 10(23), 19323-19330.

329 F. Wahid, X. H. Hu, L. Q. Chu, S. R. Jia, Y. Y. Xie and C. Zhong, Development of bacterial cellulose/chitosan based semi-interpenetrating hydrogels with improved mechanical and antibacterial properties, Int. J. Biol. Macromol., 2019, 122, 380-387, DOI: 10.1016/j.ijbiomac.2018.10.105.

330 H. Itagaki, T. Kurokawa, H. Furukawa, T. Nakajima, Y. Katsumoto and J. P. Gong, Water-Induced Brittle-Ductile Transition of Double Network Hydrogels, Macromolecules, 2010, 43(22), 9495-9500, DOI: 10.1021/ma101413j.
331 T. Nakajima, H. Furukawa, Y. Tanaka, T. Kurokawa, Y. Osada and J. P. Gong, True Chemical Structure of Double Network Hydrogels, Macromolecules, 2009, 42(6), 2184-2189, DOI: 10.1021/ma802148p.

332 X. Yan, J. Yang, F. Chen, L. Zhu, Z. Tang and G. Qin, et al., Mechanical properties of gelatin/polyacrylamide/graphene oxide nanocomposite double-network hydrogels, Compos. Sci. Technol., 2018, 163, 81-88, DOI: 10.1016/j.compscitech. 2018.05.011.

333 X. Li, H. Qin, X. Zhang and Z. Guo, Triple-network hydrogels with high strength, low friction and self-healing by chemical-physical crosslinking, J. Colloid Interface Sci., 2019, 556, 549-556, DOI: 10.1016/j.jcis.2019.08.100.

334 M. T. I. Mredha, S. K. Pathak, V. T. Tran, J. Cui and I. Jeon, Hydrogels with superior mechanical properties from the synergistic effect in hydrophobic-hydrophilic copolymers, Chem. Eng. J., 2019, 362, 325-338, DOI: 10.1016/j.cej. 2018.12.023.

335 F. Chen, S. Lu, L. Zhu, Z. Tang, Q. Wang and G. Qin, et al., Conductive regenerated silk-fibroin-based hydrogels with integrated high mechanical performances, J. Mater. Chem. $B, 2019,7(10)$, 1708-1715.

336 Q. Zhou, K. Yang, J. He, H. Yang and X. Zhang, A novel 3D-printable hydrogel with high mechanical strength and shape memory properties, J. Mater. Chem. C, 2019, 7(47), 14913-14922.

337 X. Luo, M. Y. Akram, Y. Yuan, J. Nie and X. Zhu, Silicon dioxide/poly(vinyl alcohol) composite hydrogels with high mechanical properties and low swellability, J. Appl. Polym. Sci., 2019, 136(1), 1-6.

338 Manuscript A. Materials Chemistry B, 2020.

339 X. Li, Y. Zhao, D. Li, G. Zhang, S. Long and H. Wang, Hybrid dual crosslinked polyacrylic acid hydrogels with ultrahigh mechanical strength, toughness and self-healing properties via soaking salt solution, Polymer, 2017, 121, 55-63.

340 P. Li, J. Zhao, Y. Chen, B. Cheng, Z. Yu and Y. Zhao, et al., Preparation and characterization of chitosan physical hydrogels with enhanced mechanical and antibacterial properties, Carbohydr. Polym., 2017, 157, 1383-1392.

341 C. B. Rodell, N. N. Dusaj, C. B. Highley and J. A. Burdick, Injectable and Cytocompatible Tough Double-Network Hydrogels through Tandem Supramolecular and Covalent Crosslinking, Adv. Mater., 2016, 28(38), 8419-8424.

342 Y. Zhou, P. F. Damasceno, B. S. Somashekar, M. Engel, F. Tian and J. Zhu, et al., Unusual multiscale mechanics of biomimetic nanoparticle hydrogels, Nat. Commun., 2018, 9(1), 181, DOI: 10.1038/s41467-017-02579-w.

343 T. Huang, H. Xu, K. Jiao, L. Zhu, H. R. Brown and H. Wang, A novel hydrogel with high mechanical strength: A macromolecular microsphere composite hydrogel, Adv. Mater., 2007, 19(12), 1622-1626.

344 T. L. Sun, T. Kurokawa, S. Kuroda, A. B. Ihsan, T. Akasaki and K. Sato, et al., Physical hydrogels composed of polyampholytes demonstrate high toughness and viscoelasticity, Nat. Mater., 2013, 12(10), 932-937. 
345 D. J. Sarkar and A. Singh, pH-triggered release of boron and thiamethoxam from boric acid crosslinked carboxymethyl cellulose hydrogel based formulations, Polym.-Plast. Technol. Eng., 2018, 58(1), 83-96.

346 H. Yuk, T. Zhang, G. A. Parada, X. Liu and X. Zhao, Skininspired hydrogel-elastomer hybrids with robust interfaces and functional microstructures, Nat. Commun., 2016, 7(1), 12028, DOI: 10.1038/ncomms12028.

347 A. A. Oun and J.-W. Rhim, Carrageenan-based hydrogels and films: Effect of $\mathrm{ZnO}$ and $\mathrm{CuO}$ nanoparticles on the physical, mechanical, and antimicrobial properties Biodegradable films with addition of antimicrobial and antioxidant activity View project Isolation of nanocellulose using, Elsevier, 2017.

348 T. Wu, J. Huang, Y. Jiang, Y. Hu, X. Ye and D. Liu, et al., Formation of hydrogels based on chitosan/alginate for the delivery of lysozyme and their antibacterial activity, Food Chem., 2018, 240, 361-369.

349 Chemistry MZ-TT in A, 2017 undefined, Application of nanocomposite polymer hydrogels for ultra-sensitive fluorescence detection of proteins in gel electrophoresis, Elsevier.

350 S. Azevedo, A. M. S. Costa, A. Andersen, I. S. Choi, H. Birkedal and J. F. Mano, Bioinspired Ultratough Hydrogel with Fast Recovery, Self-Healing, Injectability and Cytocompatibility, Adv. Mater., 2017, 29(28), 1700759, DOI: 10.1002/adma.201700759.

351 S. Li, S. Dong, W. Xu, S. Tu, L. Yan and C. Zhao, et al., Antibacterial Hydrogels, Adv. Sci., 2018, 5(5), 1700527, DOI: 10.1002/advs.201700527.

352 B. Chen and J. Wang, Antimicrobial hydrogels: promising materials for medical application, Int. J. Nanomed., 2018, 13, 2217-2263, DOI: 10.2147/IJN.S154748.

353 Y. Lu, Y. Mei, M. Drechsler and M. Ballauff, Thermosensitive core-shell particles as carriers for Ag nanoparticles: Modulating the catalytic activity by a phase transition in networks, Angew. Chem., Int. Ed., 2006, 45(5), 813-816.

354 H. Chi, Y. Qiao, B. Wang, Y. Hou, Q. Li and K. Li, et al., Swelling, thermal stability, antibacterial properties enhancement on composite hydrogel synthesized by chitosan-acrylic acid and ZnO nanowires, Polym. Technol. Mater., 2019, 58(15), 1649-1661.

355 E. M. Abdel Bary, A. N. Harmal, A. Saeed and M. A. Gouda, Design, Synthesis, Characterization, Swelling and in Vitro Drug Release Behavior of Composite Hydrogel Beads Based on Methotrexate and Chitosan Incorporating Antipyrine Moiety, Polym.-Plast. Technol. Eng., 2018, 57(18), 1906-1914.

356 Y. Wang, J. Wang, Z. Yuan, H. Han, T. Li and L. Li, et al., Chitosan cross-linked poly(acrylic acid) hydrogels: Drug release control and mechanism, Colloids Surf., B, 2017, 152, 252-259.

357 S. Mondal, Review on Nanocellulose Polymer Nanocomposites, Polym.-Plast. Technol. Eng., 2018, 57, 1377-1391.

358 H. S. Samanta and S. K. Ray, Controlled release of tinidazole and theophylline from chitosan based composite hydrogels, Carbohydr. Polym., 2014, 106(1), 109-120.

359 H.-W. Chang, Y.-S. Lin, Y.-D. Tsai and M.-L. Tsai, Effects of chitosan characteristics on the physicochemical properties, antibacterial activity, and cytotoxicity of chitosan/2-glycerophosphate/nanosilver hydrogels, J. Appl. Polym. Sci., 2013, 127(1), 169-176, DOI: 10.1002/app.37855.

360 H. Tang, A. Lu, L. Li, W. Zhou, Z. Xie and L. Zhang, Highly antibacterial materials constructed from silver molybdate nanoparticles immobilized in chitin matrix, Chem. Eng. J., 2013, 234, 124-131. Available from: http://www.sciencedir ect.com/science/article/pii/S1385894713011492.

361 T. Jayaramudu, G. M. Raghavendra, K. Varaprasad, R. Sadiku, K. Ramam and K. M. Raju, Iota-Carrageenan-based biodegradable AgO nanocomposite hydrogels for the inactivation of bacteria, Carbohydr. Polym., 2013, 95(1), 188-194.

362 K. A. Juby, C. Dwivedi, M. Kumar, S. Kota, H. S. Misra and P. N. Bajaj, Silver nanoparticle-loaded PVA/gum acacia hydrogel: Synthesis, characterization and antibacterial study, Carbohydr. Polym., 2012, 89(3), 906-913. Available from: http://www. sciencedirect.com/science/article/pii/S0144861712003736.

363 J. Stojkovska, D. Kostić, Ž. Jovanović, M. VukašinovićSekulić, V. Mišković-Stanković and B. Obradović, A comprehensive approach to in vitro functional evaluation of Ag/alginate nanocomposite hydrogels, Carbohydr. Polym., 2014, 111, 305-314. Available from: http://www.sciencedir ect.com/science/article/pii/S0144861714004202.

$364 \mathrm{H}$. Ghasemzadeh and F. Ghanaat, Antimicrobial alginate/ PVA silver nanocomposite hydrogel, synthesis and characterization, J. Polym. Res., 2014, 21(3), 355, DOI: 10.1007/ s10965-014-0355-1.

365 M. Zafar, T. Shah, A. Rawal and E. Siores, Preparation and characterisation of thermoresponsive nanogels for smart antibacterial fabrics, Mater. Sci. Eng., C, 2014, 40, 135-141. Available from: http://www.sciencedirect.com/science/arti cle/pii/S0928493114001593.

366 K. Madhusudana Rao, K. S. V. Krishna Rao, G. Ramanjaneyulu, K. Chowdoji Rao, M. C. S. Subha and C.-S. Ha, Biodegradable sodium alginate-based semi-interpenetrating polymer network hydrogels for antibacterial application, J. Biomed. Mater. Res., Part A, 2014, 102(9), 3196-3206, DOI: 10.1002/jbm.a.34991.

367 K. Sivudu and K. Y. Rhee, Preparation and characterization of pH-responsive hydrogel magnetite nanocomposite, Colloids Surf., A, 2009, 349, 29-34.

368 M. Yadollahi, S. Farhoudian and H. Namazi, One-pot synthesis of antibacterial chitosan/silver bio-nanocomposite hydrogel beads as drug delivery systems, Int. J. Biol. Macromol., 2015, 79, 37-43. Available from: http://www.sciencedirect.com/ science/article/pii/S0141813015002706.

369 E. Bozaci, E. Akar, E. Ozdogan, A. Demir, A. Altinisik and Y. Seki, Application of carboxymethylcellulose hydrogel based silver nanocomposites on cotton fabrics for antibacterial property, Carbohydr. Polym., 2015, 134, 128-135Available from.

370 T. Jiao, H. Guo, Q. Zhang, Q. Peng, Y. Tang and X. Yan, et al., Reduced Graphene Oxide-Based Silver NanoparticleContaining Composite Hydrogel as Highly Efficient Dye Catalysts for Wastewater Treatment, Sci. Rep., 2015, 5, 11873. Available from: https://pubmed.ncbi.nlm.nih. gov/26183266. 
371 S. Bhowmick, S. Mohanty and V. Koul, Fabrication of transparent quaternized PVA/silver nanocomposite hydrogel and its evaluation as an antimicrobial patch for wound care systems, J. Mater. Sci.: Mater. Med., 2016, 27(11), 160, DOI: $10.1007 / \mathrm{s} 10856-016-5772-8$.

372 M. Ribeiro, M. P. Ferraz, F. J. Monteiro, M. H. Fernandes, M. M. Beppu and D. Mantione, et al., Antibacterial silk fibroin/nanohydroxyapatite hydrogels with silver and gold nanoparticles for bone regeneration. Nanomedicine Nanotechnology, Biol. Med., 2017, 13(1), 231-239. Available from: http://www.sciencedirect.com/science/article/ pii/S1549963416301423.

373 A. L. Daniel-da-Silva, A. M. Salgueiro and T. Trindade, Effects of Au nanoparticles on thermoresponsive genipincrosslinked gelatin hydrogels, Gold Bull., 2013, 46(1), 25-33, DOI: 10.1007/s13404-012-0078-1.

374 W. Gao, D. Vecchio, J. Li, J. Zhu, Q. Zhang and V. Fu, et al., Hydrogel Containing Nanoparticle-Stabilized Liposomes for Topical Antimicrobial Delivery, ACS Nano, 2014, 8(3), 2900-2907, DOI: 10.1021/nn500110a.

375 A. Mohandas, P. T. S. Kumar, B. Raja, V.-K. Lakshmanan and R. Jayakumar, Exploration of alginate hydrogel/nano zinc oxide composite bandages for infected wounds, Int. J. Nanomed., 2015, 10(Suppl. 1), 53-66. Available from: https://pubmed.ncbi.nlm.nih.gov/26491307.

376 J. Wang, H. Hu, Z. Yang, J. Wei and J. Li, IPN hydrogel nanocomposites based on agarose and $\mathrm{ZnO}$ with antifouling and bactericidal properties, Mater. Sci. Eng., C, 2016, 61, 376-386. Available from: http:/www.sciencedirect.com/ science/article/pii/S0928493115306354.

377 F. Wahid, J.-J. Yin, D.-D. Xue, H. Xue, Y.-S. Lu and C. Zhong, et al., Synthesis and characterization of antibacterial carboxymethyl Chitosan/ZnO nanocomposite hydrogels, Int. J. Biol. Macromol., 2016, 88, 273-279. Available from: http://www.sciencedirect.com/science/article/ pii/S0141813016302689.

378 N. A. Kumar, N. S. Rejinold, P. Anjali, A. Balakrishnan, R. Biswas and R. Jayakumar, Preparation of chitin nanogels containing nickel nanoparticles, Carbohydr. Polym., 2013, 97(2), 469-474. Available from: http://www.science direct.com/science/article/pii/S0144861713004840.

379 H. Hezaveh and I. I. Muhamad, Impact of metal oxide nanoparticles on oral release properties of $\mathrm{pH}$-sensitive hydrogel nanocomposites, Int. J. Biol. Macromol., 2012, 50(5), 1334-1340. Available from: http://www.sciencedir ect.com/science/article/pii/S0141813012001146.

380 M. R. Alison, Stem cells in pathobiology and regenerative medicine, J. Pathol., 2009, 217(2), 141-143, DOI: 10.1002/ path. 2497.

381 S. J. Morrison and A. C. Spradling, Stem cells and niches: mechanisms that promote stem cell maintenance throughout life, Cell, 2008, 132(4), 598-611. Available from: https:// pubmed.ncbi.nlm.nih.gov/18295578.

382 K. Hu, N. Zhou, Y. Li, S. Ma, Z. Guo and M. Cao, et al., Sliced Magnetic Polyacrylamide Hydrogel with Cell-Adhesive Microarray Interface: A Novel Multicellular Spheroid
Culturing Platform, ACS Appl. Mater. Interfaces, 2016, 8(24), 15113-15119.

383 D. Loessner, K. S. Stok, M. P. Lutolf, D. W. Hutmacher, J. A. Clements and S. C. Rizzi, Bioengineered 3D platform to explore cell-ECM interactions and drug resistance of epithelial ovarian cancer cells, Biomaterials, 2010, 31(32), 8494-8506.

384 M. J. Powers, R. E. Rodriguez and L. G. Griffith, Cell-substratum adhesion strength as a determinant of hepatocyte aggregate morphology, Biotechnol. Bioeng., 1997, 53(4), 415-426.

385 T. Dvir, B. P. Timko, M. D. Brigham, S. R. Naik, S. S. Karajanagi and O. Levy, et al., Nanowired three-dimensional cardiac patches, Nat. Nanotechnol., 2011, 6(11), 720-725.

386 E. B. Peters, N. Christoforou, K. W. Leong, G. A. Truskey and J. L. West, Poly(Ethylene Glycol) Hydrogel Scaffolds Containing Cell-Adhesive and Protease-Sensitive Peptides Support Microvessel Formation by Endothelial Progenitor Cells, Cell. Mol. Bioeng., 2016, 9(1), 38-54.

387 M. S. Hahn, L. J. Taite, J. J. Moon, M. C. Rowland, K. A. Ruffino and J. L. West, Photolithographic patterning of polyethylene glycol hydrogels, Biomaterials, 2006, 27(12), 2519-2524.

388 L. Han, L. Yan, K. Wang, L. Fang, H. Zhang and Y. Tang, et al., Tough, self-healable and tissue-adhesive hydrogel with tunable multifunctionality, NPG Asia Mater., 2017, 9(4), e372, DOI: 10.1038/am.2017.33.

389 M. M. Hasani-Sadrabadi, P. Sarrion, S. Pouraghaei, Y. Chau, S. Ansari and S. Li, et al., An engineered cell-laden adhesive hydrogel promotes craniofacial bone tissue regeneration in rats, Sci. Transl. Med., 2020, 12(534), 1-13, DOI: 10.1126/ scitranslmed.aay6853.

390 S. A. Bencherif, R. W. Sands, D. Bhatta, P. Arany, C. S. Verbeke and D. A. Edwards, et al., Injectable preformed scaffolds with shape-memory properties, Proc. Natl. Acad. Sci. U. S. A., 2012, 109(48), 19590-19595.

391 J. H. Waite, N. H. Andersen, S. Jewhurst and C. Sun, Mussel adhesion: Finding the tricks worth mimicking, J. Adhes., 2005, 81(3-4), 297-317.

392 J. Yu, W. Wei, E. Danner, R. K. Ashley, J. N. Israelachvili and J. H. Waite, Mussel protein adhesion depends on interprotein thiol-mediated redox modulation, Nat. Chem. Biol., 2011, 7(9), 588-590.

393 A. Song, A. A. Rane and K. L. Christman, Antibacterial and cell-adhesive polypeptide and poly(ethylene glycol) hydrogel as a potential scaffold for wound healing, Acta Biomater., 2012, 8(1), 41-50.

394 K. P. Sai and M. Babu, Collagen based dressings - A review, Burns, 2000, 26(1), 54-62.

395 S. P. Zhong, Y. Z. Zhang and C. T. Lim, Tissue scaffolds for skin wound healing and dermal reconstruction, Wiley Interdiscip. Rev.: Nanomed. Nanobiotechnol., 2010, 2(5), 510-525.

396 L. G. Ovington, Advances in wound dressings, Clin. Dermatol., 2007, 25(1), 33-38.

397 S. Cosson, E. A. Otte, H. Hezaveh and J. J. Cooper-White, Concise review: tailoring bioengineered scaffolds for stem 
cell applications in tissue engineering and regenerative medicine, Stem Cells Transl. Med., 2015, 4(2), 156-164 Available from: https://pubmed.ncbi.nlm.nih.gov/25575526.

398 J.-Y. Lee, J.-E. Choo, H.-J. Park, J.-B. Park, S.-C. Lee and I. Jo, et al., Injectable gel with synthetic collagen-binding peptide for enhanced osteogenesis in vitro and in vivo, Biochem. Biophys. Res. Commun., 2007, 357(1), 68-74. Available from: http://www.sciencedirect.com/science/article/ pii/S0006291X07005505.

399 Y. Liu and S. Hsu, Synthesis and Biomedical Applications of Self-healing Hydrogels, Front. Chem., 2018, 6, 449. Available from: https://www.frontiersin.org/article/10.3389/fchem.2018. 00449.

400 S. Islam and G. S. Bhat, Progress and challenges in self-healing composite materials, Mater. Adv., 2021, 2(6), 1896-1926, DOI: 10.1039/D0MA00873G.

401 S. Talebian, M. Mehrali, N. Taebnia, C. P. Pennisi, F. B. Kadumudi and J. Foroughi, et al., Self-Healing Hydrogels: The Next Paradigm Shift in Tissue Engineering?, Adv. Sci., 2019, 6(16), 1801664. Available from: https://pubmed.ncbi. nlm.nih.gov/31453048.

402 Designed Research; A. SVP, Performed Research; A SVP, Pnas G. Rapid self-healing hydrogel, 2012;109(12):4383-4388.

403 X. F. Cui, W. J. Zheng, W. Zou, X. Y. Liu, H. Yang and J. Yan, et al., Water-retaining, tough and self-healing hydrogels and their uses as fire-resistant materials, Polym. Chem., 2019, 10(37), 5151-5158.

404 A. J. R. Amaral, V. M. Gaspar and J. F. Mano, Responsive laminarin-boronic acid self-healing hydrogels for biomedical applications, Polym. J., 2020, 52(8), 997-1006, DOI: $10.1038 / \mathrm{s} 41428-020-0348-3$.

405 S. U. Kadam, B. K. Tiwari and C. P. O’Donnell, Extraction, structure and biofunctional activities of laminarin from brown algae, Int. J. Food Sci. Technol., 2015, 50(1), 24-31.

406 B. Wang, L. Liu and L. Liao, Light and ferric ion responsive fluorochromic hydrogels with high strength and selfhealing ability, Polym. Chem., 2019, 10(47), 6481-6488.

407 R. Xu, S. Ma, P. Lin, B. Yu, F. Zhou and W. Liu, High Strength Astringent Hydrogels Using Protein as the Building Block for Physically Cross-linked Multi-Network, ACS Appl. Mater. Interfaces, 2018, 10(9), 7593-7601.

408 L. Zhou, L. Fan, X. Yi, Z. Zhou, C. Liu and R. Fu, et al., Soft Conducting Polymer Hydrogels Cross-Linked and Doped by Tannic Acid for Spinal Cord Injury Repair, ACS Nano, 2018, 12(11), 10957-10967.

409 C. Yu, D. Alkekhia and A. Shukla, $\beta$-Lactamase Responsive Supramolecular Hydrogels with Host-Guest Self-Healing Capability, ACS Appl. Polym. Mater., 2020, 2, 55-65.
410 J. Tang, M. U. Javaid, C. Pan, G. Yu, R. M. Berry and K. C. Tam, Self-healing stimuli-responsive cellulose nanocrystal hydrogels, Carbohydr. Polym., 2020, 229, 115486.

411 S. Palantöken, K. Bethke, V. Zivanovic, G. Kalinka, J. Kneipp and K. Rademann, Cellulose hydrogels physically crosslinked by glycine: Synthesis, characterization, thermal and mechanical properties, J. Appl. Polym. Sci., 2020, 137(7), 23-25.

412 K. Ravishankar, M. Venkatesan, R. P. Desingh, A. Mahalingam, B. Sadhasivam and R. Subramaniyam, et al., Biocompatible hydrogels of chitosan-alkali lignin for potential wound healing applications, Mater. Sci. Eng., C, 2019, 102, 447-457.

413 W. Dai, H. Guo, B. Gao, M. Ruan, L. Xu and J. Wu, et al., Double network shape memory hydrogels activated by near-infrared with high mechanical toughness, nontoxicity, and 3D printability, Chem. Eng. J., 2019, 356, 934-949.

414 B. Gao, L. Chen, Y. Zhao, X. Yan, X. Wang and C. Zhou, et al., Methods to prepare dopamine/polydopamine modified alginate hydrogels and their special improved properties for drug delivery, Eur. Polym. J., 2019, 110, 192-201.

415 Y. Ren and J. Feng, Skin-Inspired Multifunctional Luminescent Hydrogel Containing Layered Rare-Earth Hydroxide with 3D Printability for Human Motion Sensing, ACS Appl. Mater. Interfaces, 2020, 12(6), 6797-6805, DOI: 10.1021/acsami.9b17371.

416 X. F. Sun, Y. Hao, Y. Cao and Q. Zeng, Superadsorbent hydrogel based on lignin and montmorillonite for $\mathrm{Cu}$ (II) ions removal from aqueous solution, Int. J. Biol. Macromol., 2019, 127, 511-519.

417 A. Taki, B. John, S. Arakawa and M. Okamoto, Structure and rheology of nanocomposite hydrogels composed of DNA and clay, Eur. Polym. J., 2013, 49(4), 923-931.

418 Reena, A. Kumar, V. Mahto and A. K. Choubey, Synthesis and characterization of cross-linked hydrogels using polyvinyl alcohol and polyvinyl pyrrolidone and their blend for water shut-off treatments, J. Mol. Liq., 2020, 301, 112472, DOI: 10.1016/j.molliq.2020.112472.

419 Khushbu, S. G. Warkar and A. Kumar, Synthesis and assessment of carboxymethyl tamarind kernel gum based novel superabsorbent hydrogels for agricultural applications, Polymer, 2019, 182, 121823, DOI: 10.1016/j.polymer.2019. 121823.

420 L. Wu, G. Chen and Z. Li, Layered Rare-Earth Hydroxide/ Polyacrylamide Nanocomposite Hydrogels with Highly Tunable Photoluminescence, Small, 2017, 13(23), 1604070.

421 M. Yadollahi, H. Namazi and M. Aghazadeh, Antibacterial carboxymethyl cellulose/Ag nanocomposite hydrogels cross-linked with layered double hydroxides, Int. J. Biol. Macromol., 2015, 79, 269-277. 